\title{
Children's Engagement with their Learning using E-portfolios
}

\author{
By \\ Nicola Goodman
}

\begin{abstract}
A thesis
submitted to the Victoria University of Wellington in fulfilment of the requirements for the degree of

Master of Education
\end{abstract}

Victoria University of Wellington

2015 


\begin{abstract}
Narrative approaches to documentation and assessment in early childhood education (ECE) encourages children to be active contributors in their own learning journey. With the growing emphasis of technology in society it is natural that this shift has transformed assessment practices with the introduction of e-portfolios. Eportfolios are seen in tertiary, secondary and primary settings nationwide and most recently have been introduced into ECE as a way to extend traditional documentation methods. As a result, documentation and the role children have in their own learning has shifted. Despite their growing popularity in early childhood settings there is very little research into the effect that e-portfolios have on teachers, parents, and most importantly, children and their learning. Given this limited research this study sought to understand the ways in which children are engaging with their learning through e-portfolios. This mixed methodology study used a national online survey as well as case studies to develop an understanding of this topic. Participants included early childhood centre educators, parents and children from settings across New Zealand. Findings revealed a distinct variation in the ways that centres are using $e$ portfolios to engage children with their learning. A large number of centres are maintaining both hard-copy and online versions of a child's portfolio to ensure that children are not removed from contributing to and revisiting their learning. Whilst results showed examples of children's in-depth engagement with e-portfolios, they also highlighted that many centres are not yet harnessing their full potential. These findings suggest implications for teacher practice, including the need for greater support and training for teachers. As e-portfolios are still a new phenomenon in ECE this study suggests areas of future research to investigate this topic further to improve learning outcomes for children.
\end{abstract}




\section{Acknowledgments}

"Commit to the LORD whatever you do, and he will establish your plans."

Proverbs 16:3

This thesis was not accomplished alone, but through the support of many incredible loving people:

To Victoria University and CORE Education, thank you for the generous scholarships that enabled me to pursue my academic dreams. Thank you also to Victoria University for the grant that enabled my case study work to be undertaken.

Sue Cherrington, the word 'supervisor' does not do you justice! Thank you for being an amazing support and mentor. A mere acknowledgement does not cover the gratitude I feel but I am so grateful. To Mary Jane Shuker, you have been such a pivotal influence on me; thank you for your support and time in helping me develop this thesis topic.

To the teachers, families and, most importantly, children from Dibley and Grendale. Thank you for generously opening your doors to me and my audio recorder - your willingness to share your experiences was humbling! To the centres that completed the national survey; thank you for giving up your time and perspective so willingly.

To Mum and Dad; a girl couldn't ask for a more supportive family. Thank you for everything you have done for me - you have never once left my side! You always said I loved words - well, here are 45,000... I promise I'll go get a real job now! To Dan - the greatest brother and friend. Thank you for your encouragement, love and constant support of "you've got this" - you were right!

To my friends, both old and new, thank you so much for your constant love, support and patience with both my study and health - and for always listening and appearing interested! Whilst I cannot promise that this is the end I go forward knowing you will always have my back. I am so blessed! To Rosie, Tamsin and Anna - thank you for over-analysing my pilot survey questions and continually supporting me! You are my ECE heroes and I am so blessed to learn from and alongside you! Anna - thank 
you for your wacky title creations, never-ending patience and continued support and enthusiasm.

To the under 5's of NZ, your wonder, energy and love is what inspires me to do what I do. This is for each and every one of you - I hope it helps to keep you at the centre of your learning!

\section{Dedicated to my Grandfather - Big G.}

Who always encouraged me to pursue academia and to do so with excellence (and big words) 


\section{Table of Contents}

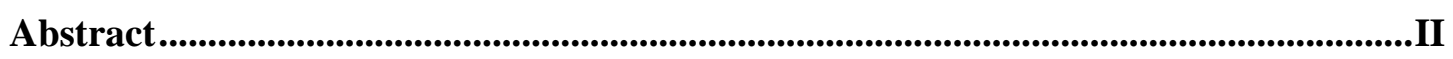

Acknowledgements................................................................................................... III

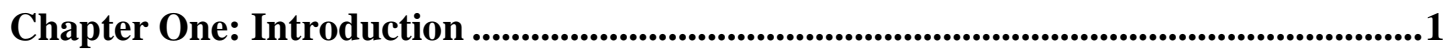

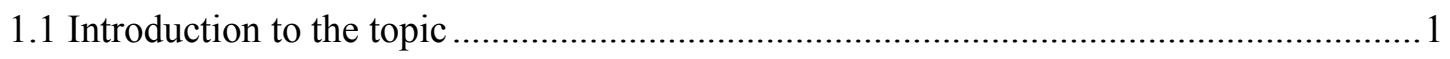

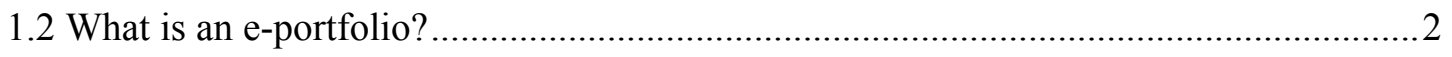

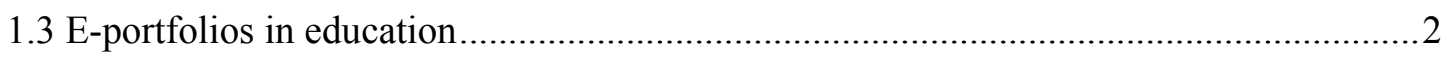

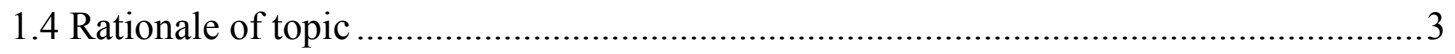

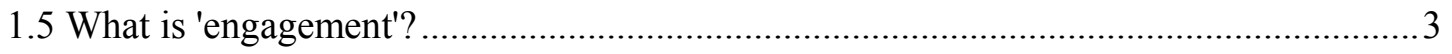

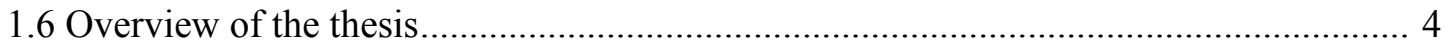

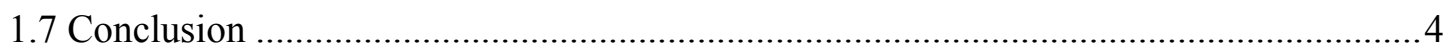

Chapter Two: Literature Review ...............................................................................5

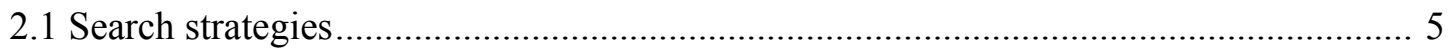

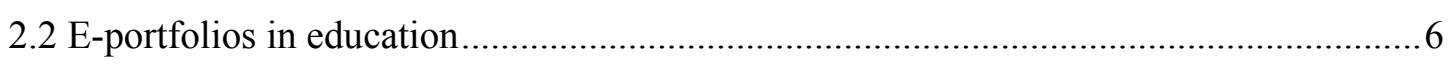

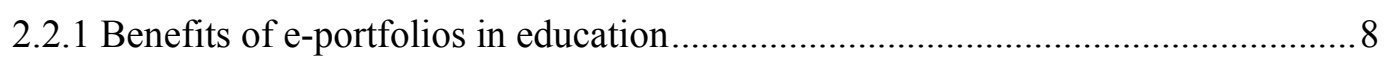

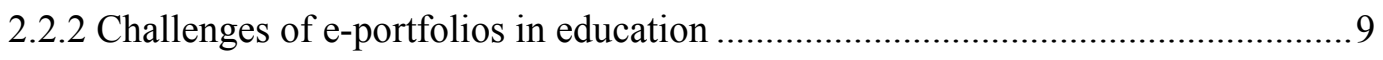

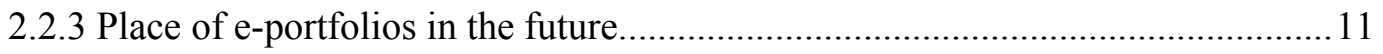

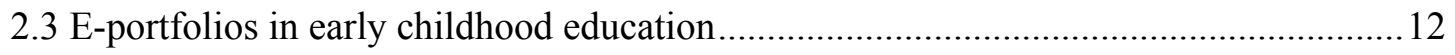

2.3.1 Benefits of e-portfolios in an early childhood setting ........................................ 13

2.3.2 Challenges of e-portfolios in an early childhood setting ................................... 13

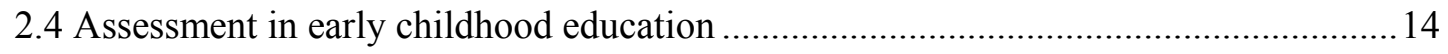

2.4.1 Te Whäriki early childhood curriculum ............................................................ 14

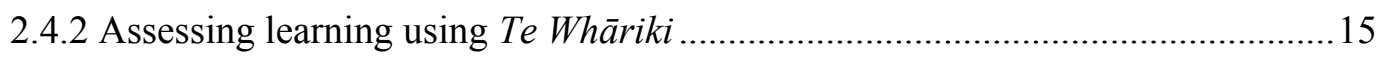

2.5 Children's engagement with their learning using hard-copy portfolios ......................... 17

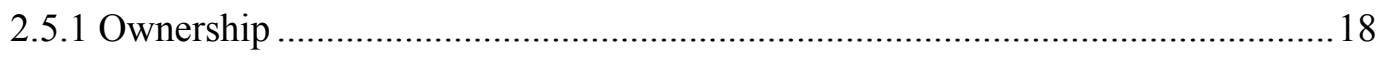

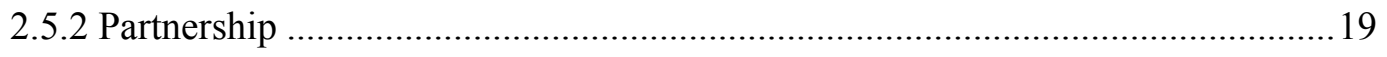

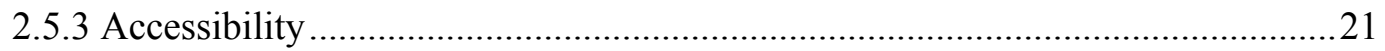

2.6 Children's engagement with their learning using e-portfolios .....................................22

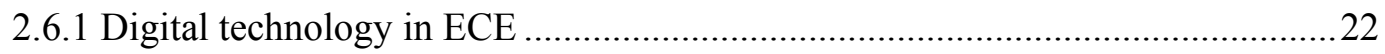

2.6.2 E-portfolios and young children's engagement .............................................2 23 


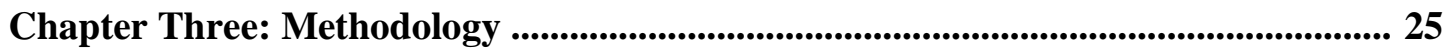

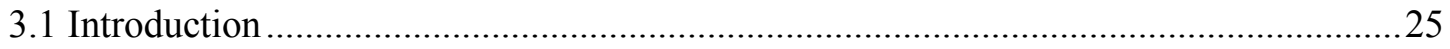

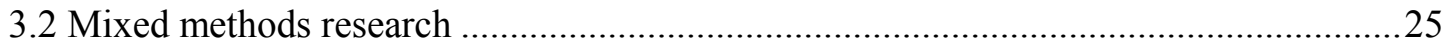

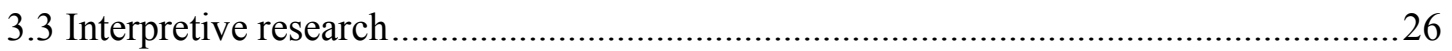

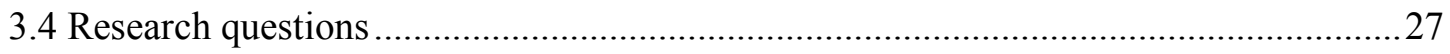

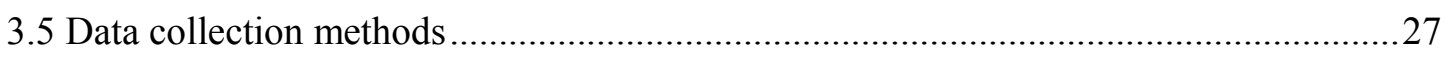

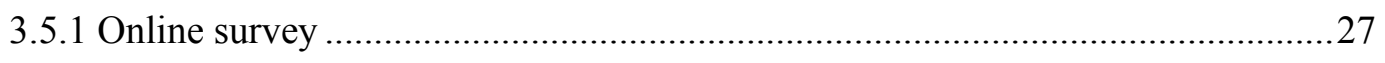

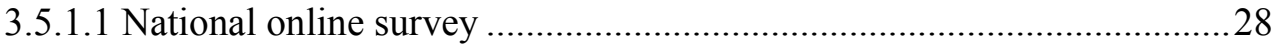

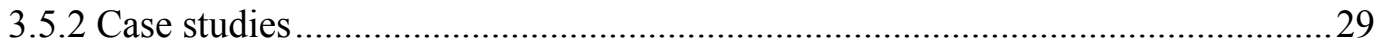

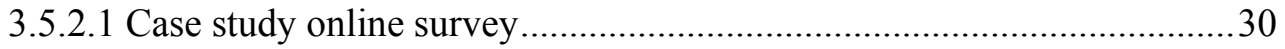

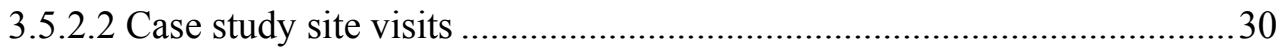

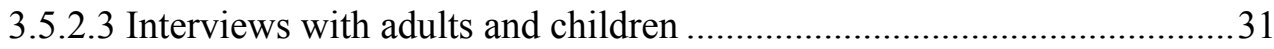

3.5.2.4 Observation and document analysis................................................ 32

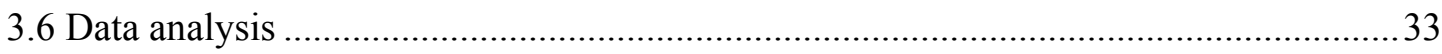

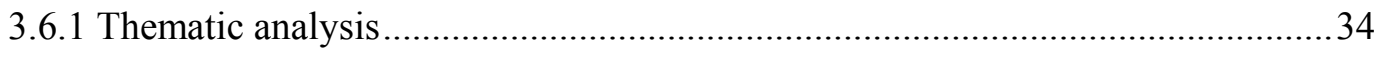

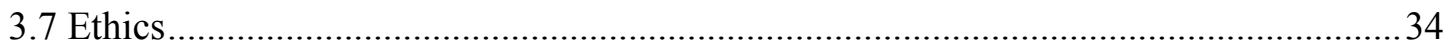

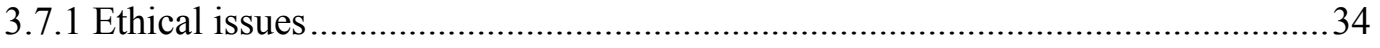

3.7.1.1 Engaging in research that involves children ........................................36

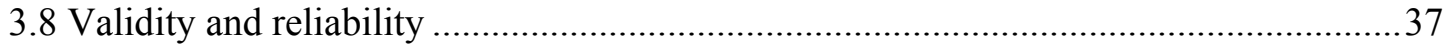

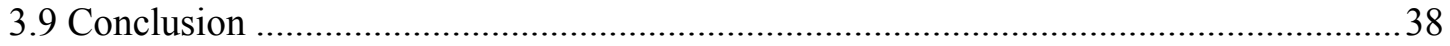

Chapter Four: National Online Survey Results ...................................................................39

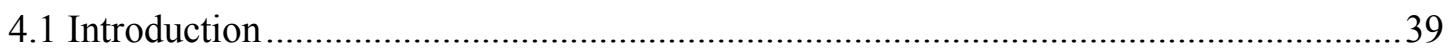

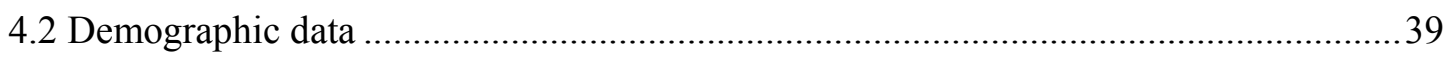

4.3 Children's engagement with their e-portfolios ....................................................... 41

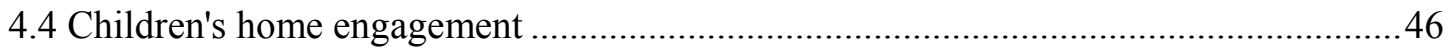

4.5 Differences in children's engagement between online and hard copy ..........................49

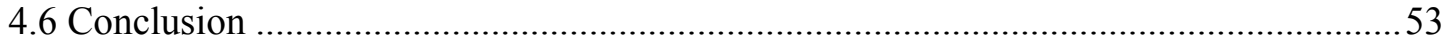

Chapter Five: Case Study Results ................................................................................................54

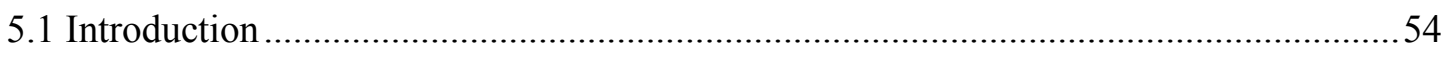

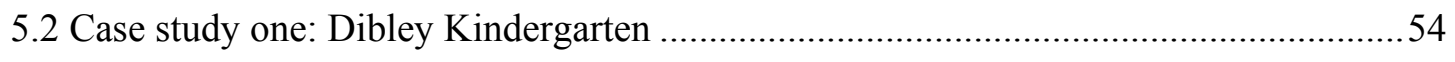

5.2.1 Initial introduction of e-portfolios to children and families................................54

5.2.2 Children's engagement with their e-portfolio.....................................................54 
5.2.3 Teacher practice around children's engagement .57

5.2.4 Connections between home and the centre ........................................................59

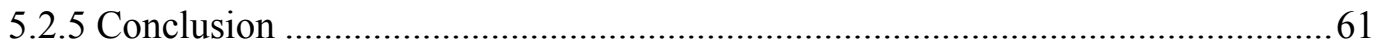

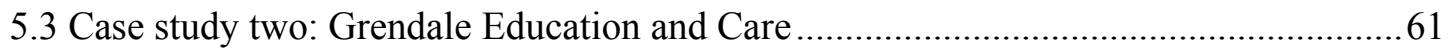

5.3.1 Initial introduction of e-portfolios to children and families..................................62

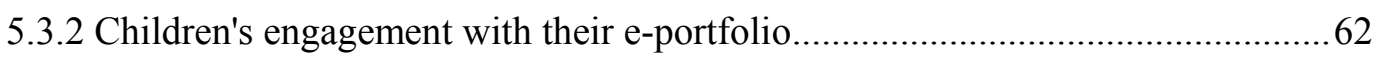

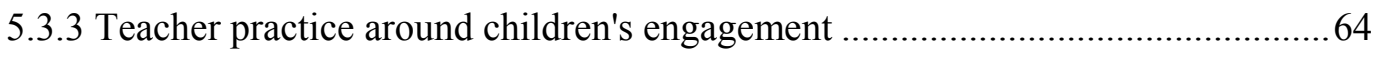

5.3.4 Connections between home and the centre …..................................................6 66

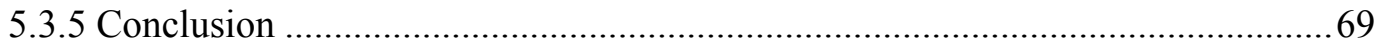

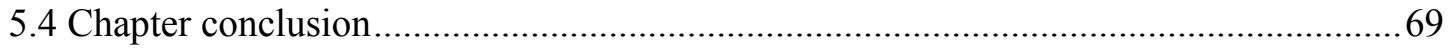

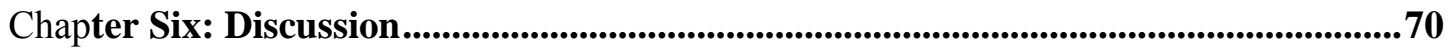

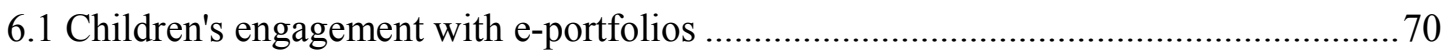

6.1.1 Children's home engagement with e-portfolios ............................................. 71

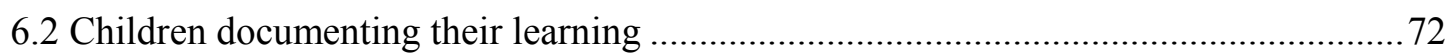

6.3 Children's engagement with their learning through e-portfolios ................................. 73

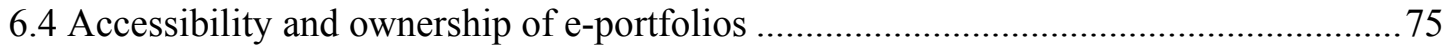

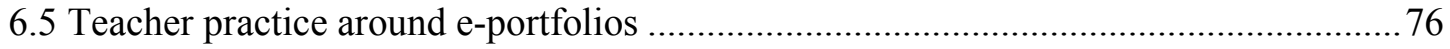

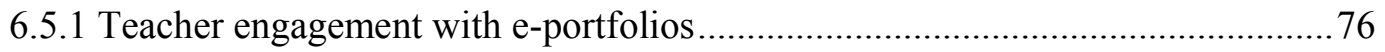

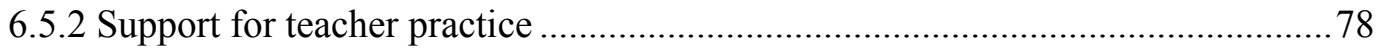

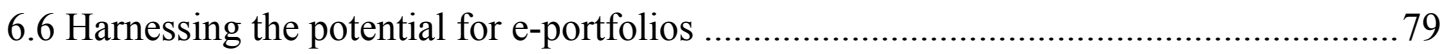

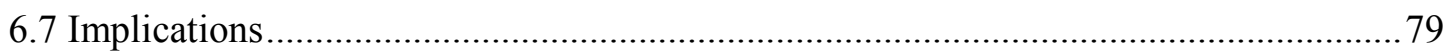

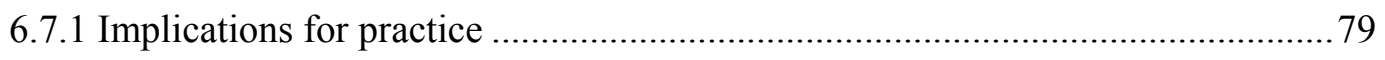

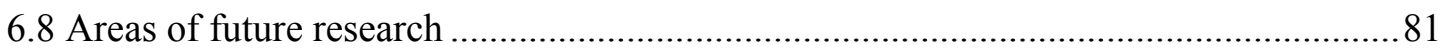

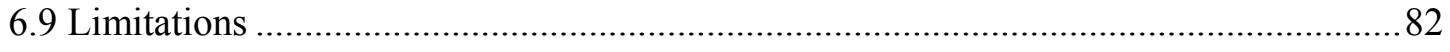

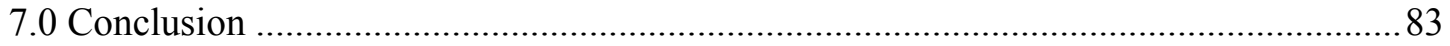

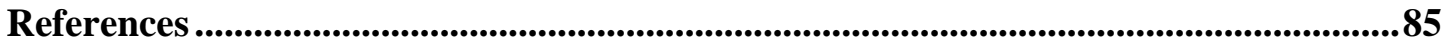

Appendices ...............................................................................................................................992

Appendix A: Participant Information Sheet for National Online Survey ............................92

Appendix B: National Online Survey Consent Page (On Qualtrics survey) ........................96

Appendix C: Participant Information Sheet for Case Study Centre Online Survey

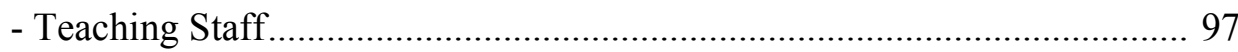


Appendix D: Information Sheet for Case Study Centre Online Survey - Families

Appendix E: Case Study Centre Online Survey Consent Page (On Qualtrics Survey

- Teachers/Families 106

Appendix F: Information sheet for Case Study Involvement - Teaching Staff

(Stage Two/Three)

Appendix G: Consent Form for Case Study Involvement - Teachers

Appendix H: Participant Information Sheet for Case Study Involvement - Family

Members and Children (Stage Two/Three)

Appendix I: Consent Form for Case Study Involvement - Children and Parents

Appendix J: Child Consent Form

Appendix K: Case Study Data Collection Protocol

Appendix L: National Online Survey questions 128

Appendix M: Case Study Online Survey questions (Teaching Staff) 132

Appendix N: Case Study Online Survey questions (Families)

\section{List of tables}

Table 4.1: Geographic location of early childhood services 39

Table 4.2: Frequency that new stories were added to children's e-portfolios 41

Table 4.3: Opportunities provided for children to access their e-portfolios within the centre

Table 4.4: Frequency children visit their e-portfolio 42

Table 4.5: Children's preference for revisiting their e-portfolios .43

Table 4.6: Role children have in documentation practices in the centre .44

Table 4.7: Ways children encouraged to contribute to their e-portfolio 45

Table 4.8: Children's connections between e-portfolio engagement and their play 46

Table 4.9: Connections made between home and centre by parents, teachers and children .47

Table 4.10: Ways parents revisit e-portfolios at home with children 49

Table 4.11: Extent that e-portfolios influenced children's engagement with their learning compared with hard-copy portfolios. 


\section{Chapter One: Introduction}

\subsection{Introduction to the topic}

The way we communicate and share information has shifted dramatically over the last few decades; we now text, message, email, photo share, blog and video chat. Children and adults alike are exposed to a technological-driven world, and individuals are rapidly developing the skills to engage in this manner. For young children today technology is the accepted norm and they are competent in using a variety of electronic devices (Ministry of Education, 2011). It is natural then for this technological influence to become evident in different facets of society, namely assessment and documentation, through the introduction of e-portfolios. E-portfolios have been popular in the workplace sector for many years (Lorenzo \& Ittelson, 2005; Wade, Abrami \& Sclater, 2005) but more recently have become part of educational practice as a way to collaborate and communicate with students, families and teachers (Barrett \& Garrett, 2009). Their popularity has grown over the years due to increased availability of wireless internet, their similarities to social networking sites and their convenience for busy individuals (Becta, 2007; Barrett \& Garrett, 2009).

Narrative approaches to assessment and documentation in early childhood education (ECE) empower children to be active contributors to their own learning and developmental journey. With the growing popularity of e-portfolios into ECE settings the role of the child, in contributing to and reflecting upon their learning, has shifted. E-portfolios enable teachers and parents to collaborate and share children's learning experiences as well as communicate and support greater learning connections (Goodman, 2013). Whilst there has been research which shows the benefit for teachers and parents in engaging with children's learning using e- portfolios (Goodman, 2013), there is little evidence that explores their influence on children's engagement with their learning. The purpose of this study was to gain insight into the ways young children may be engaging with their learning through e- portfolios.

\subsection{What is an e-portfolio?}

The term e-portfolios, the shortened form of electronic portfolios or online portfolios, refers to online spaces personalised to individuals through the 
presentation and collaboration of digital artefacts of achievement and learning to a selected audience (Becta, 2007; Goldsmith, 2007; Ministry of Education, 2011). The term, e-portfolio has multiple interpretations as each individual can use e-portfolios differently. Generally, however, this form of documentation used in both workplace and education settings is likened to a resume in that it celebrates both the learning process and the achievement of each individual through sharing images, text, video and commentary to a selected audience, such as teachers, employers or wider family members (Woodward \& Nanlohy, 2004). The success of an e-portfolio is evident through the wider engagement, enabling its relevance and purpose for each individual in their own learning situation (Ministry of Education, 2011; Meyer \& Latham, 2008). As noted by Meyer and Latham (2008, p.40), "e-portfolios are just a tool;" it is the engagement with them by wider groups of individuals that ensures they are of relevance and benefit to individuals.

\subsection{E-portfolios in education}

The introduction of e-portfolios into the education sector in the early 1990's (Lorenzo \& Ittelson, 2005) has changed the face of documentation and assessment dramatically; initially seen as an alternative to traditional assessment practices eportfolios are now used to enhance existing pedagogical practices within tertiary and secondary settings (Barrett \& Garrett, 2009; Reardon \& Hartley, 2007). More recently e-portfolios have been introduced into the ECE sector with the intention of supporting teachers and enhancing learning outcomes for young children through their simple, collaborative nature (Goodman, 2013). Within an ECE context, e- portfolios are being used to document and share the learning of children in meaningful ways with wider family members thus encouraging collaboration and connection to support further learning outcomes (Bolstad, New Zealand Council for Educational Research \& Ministry of Education, 2004).

Whilst the use of e-portfolios is becoming commonplace in many ECE settings around New Zealand, the empirical evidence surrounding their use and benefit is minimal, relying instead upon research from other sectors, which is at times irrelevant (Woodward \& Nanlohy, 2004). 


\subsection{Rationale of topic}

The impetus for this study stemmed from research I conducted as a Summer Scholar in November 2012 - March 2013. This project looked at the engagement of parents and families in ECE with one e-portfolio programme and the elements that supported this engagement (Goodman, 2013). Results showed an increased interest and involvement by parents in young children's learning as a result of e-portfolios (Goodman, 2013). Whilst the results showed deeper involvement and developed relationships between teachers and families it did not directly address the engagement of young children with their own e-portfolio. The results from this study motivated me to undertake further research, focusing particularly on children, as I was concerned that if traditional methods of documentation were replaced within ECE, how were children able to revisit their learning and achievements? My own experience as a teacher showed the value children placed on their hard-copy portfolios and the ability to read these easily and I began to question whether adding a technological facet to documentation would assist or challenge children's engagement with their learning. I realised that if e-portfolios were to become commonplace in ECE more research was needed to see how they influence and affect children and their learning. This research is significant in that it provides insight into an under-researched area, which may help support teachers and families empower children in their role as reflectors and documenters on their own journey.

\subsection{What is 'engagement'?}

Engagement is a term that is complex in meaning and interpretation as it can occur on multiple levels (Abbott, 2014). The most basic form of engagement is an individual behaving in a way that indicates great interest or attention (Engaging,

2015). However, in an educational sense the term engagement goes one step further to refer "to the degree of attention, curiosity, interest, optimism, and passion that students show when they are learning or being taught" (Abbott, 2014) which in turn influences the motivation and interest they show in progressing that learning (Abbott, 2014). In this study children's engagement was not measured or predetermined, however it was observed at two levels. Firstly, children viewing their eportfolio independently or alongside teachers or peers; and secondly, deeper engagement which showed children making connections with the content and reflection or action as a result. 


\subsection{Overview of the thesis}

This first chapter has introduced the focus area for the research as well as set the scene for the study. Chapter two examines current literature around assessment practice; children's engagement with their learning; online documentation and technology. Chapter three presents the research design and methodological strategies followed to gather data on children's engagement, and discusses the ethical issues associated with this research. The following two chapters present the results from the data collection, chapter four focuses on the national online survey data and chapter five on the two case studies. Chapter six discusses the results in relation to the research questions for this study, linking these findings to the literature. This discussion chapter concludes with limitations of the study, implications for future research, and implications for practicing educators about ways to support the implementation of online portfolios in their environment.

\subsection{Conclusion}

As technology infiltrates into different aspects of our daily lives, the landscape of documentation and assessment has altered to keep up with the introduction of eportfolios into education. Considering the dearth of literature on e-portfolios in ECE the experiences and perspectives of children, teachers and families with children's eportfolios are valuable in investigating children's engagement with their learning through this medium. The findings for this study can help to shape understanding on this topic and provide information to both teachers and families to help strengthen how e-portfolios are used to increase their benefit for young children. 


\section{Chapter Two: Literature Review}

This chapter will outline empirical research and literature in the field of e-portfolios and young children. Due to the dearth of literature concerning e-portfolios in ECE, a wider scope was taken for this review focusing on four main areas: e-portfolios in education, e-portfolios in ECE, assessment in ECE, and children's engagement with their learning using e-portfolios. The literature reviewed in this chapter has informed the research design for this project.

\subsection{Search strategies}

The literature search for this study began with articles and empirical research from my previous research study (Goodman, 2013). Whilst not all articles were pertinent to this study they assisted in developing a baseline foundation. Using the Victoria University of Wellington database I accessed two databases in particular, ERIC (via ProQuest) and $A+$ Education. The combination of these two databases enabled me to undertake advanced searches and link back to articles within the Library records. A number of keywords were used in all search strategies to find relevant literature. These terms were as follows:

- e-portfolios, electronic portfolios, online assessment portfolios, digital portfolios.

To ensure greater clarity with these different terms I used the words 'AND', 'OR' and 'NOT' to allow a more advanced and specific search.

These searches revealed a number of articles relevant to the topic of e-portfolios, however reading the abstracts indicated that very few articles were related to eportfolios in ECE, or with young children. Due to my previous research I anticipated difficulties in finding literature on this topic and so expanded the search terminology to gather a wider collection of articles. These terms included:

- engagement with e-portfolios, e-portfolios and children, e-portfolios in ECE, young children's engagement with their learning, engagement with assessment, children's contribution to learning.

Each of these phrases revealed fewer than 10 results; with only one article in one search being relevant to ECE. 
Further articles and position pieces were discovered using the Library catalogue or wider Internet search, revealing articles not found in the databases. Articles which focused on the current status and development of e-portfolios assisted my understanding of their role within an early years setting. My search in conference proceedings and Handbooks elicited no relevant results, aside from the study which I had undertaken the previous year (Goodman, 2013).

Due to the popularity and interest of e-portfolios in education I widened my search to include online and print media to see what was being addressed in the wider sector. Newspaper articles revealed many different opinions, concerns and benefits with technology and young children but again provided little evidence to support eportfolios.

In order to ensure reliability (Johnson \& Christensen, 2012) of literature found on the Internet or in wider search locations I searched for details on the author and publishing source. This ensured that any relevant articles were scholarly work from reputable sources (Johnson \& Christensen, 2012).

\subsection{E-Portfolios in education}

Within educational institutions, technology plays a significant part in the collection and sharing of artefacts, learning and information (Barrett, 2008; Goldsmith, 2007); therefore transitioning to an online method of documentation has built on this technological influence to support students in their learning and assessment (Barrett, 2008; Bolstad et al., 2004). The multi-faceted nature of e-portfolios supersedes that of hard-copy portfolios, allowing individuals the flexibility to create and update their own personalised portfolio (Buzzetto-More \& Alade, 2006; Ministry of Education, 2011). The popularity of e-portfolios in education has been linked to the notion that assessment and learning are more enjoyable through technology and as a result students are developing authentic learning which is of relevance and benefit to them (BuzzettoMore \& Alade, 2006; Goldsmith, 2007). However other literature emphasises that the reflective and collaborative elements of e-portfolios must be valued more than the technology itself in order for e-portfolios to be effective for students' learning (Barrett, 2008; Buzzetto-More \& Alade, 2006). 
A number of empirical studies have looked at different elements of e-portfolio use in secondary, tertiary and primary settings; seven were selected as relevant to this review (Barrett, 2008; Barrett \& Garrett, 2009; Becta, 2007; Emmett, 2011; Garthwait \& Verrill, 2003; Hollingworth, Allen, Abol Kuyok, Mansaray \& Rose, 2009; Joyes, Gray \& Hartnell-Young, 2010). These studies were all conducted overseas; three in the United States (Barrett, 2008; Barrett \& Garrett, 2009; Garthwait \& Verrill, 2003), three in the United Kingdom (Becta, 2007; Hollingworth et al., 2009; Joyes et al., 2010) and one in Australia (Emmett, 2011). The studies identified the tangible benefits of using e-portfolios, such as accessibility, efficiency and greater feedback (Becta, 2007; Barrett \& Garrett, 2009; Joyes et al., 2010) and came to similar conclusions in that e-portfolios empowered students to engage with their learning on a deeper level (Barrett, 2008; Barrett \& Garrett; 2009; Becta, 2007; Emmett, 2011; Garthwait \& Verrill, 2003; Joyes et al., 2010), fostering positive selfreflection and promoting increased self-esteem (Becta, 2007; Garthwait \& Verrill, 2003). However, one study by Emmett (2011) conducted over a period of 18 months discovered that some second and third year University students engaged with their eportfolios purely for the required assessment tasks but otherwise remained disengaged. Emmett's point addresses a relevant concern regarding e-portfolio engagement and is supported by Hollingworth et al., (2009) who found that adults were more engaged with e-portfolios when they understood the value of their role in contributing. This indicates the need for more training and education to occur with students and teachers using this medium so that the value of e-portfolios is evident.

Two of the seven empirical studies introduced above were undertaken with primary to intermediate aged children (Becta, 2007; Garthwait \& Verrill, 2003) with another study targeting parents of intermediate aged children regarding their engagement with their children's learning using technology (Hollingworth et al., 2009). Two examined secondary and tertiary engagement with e-portfolios (Barrett, 2008; Emmett, 2011) and two studies explored e-portfolio use beyond educational institutions (Barrett \& Garrett, 2009; Joyes et al., 2010). Joyes et al., (2010) analysed

21 funded-projects and focused on e-portfolio engagement in the UK, whilst Barrett and Garrett (2009) developed their study around an online archive of e-portfolio engagement artefacts. Garthwait and Verrill's study (2003) drew on experiences within a third grade classroom and found that teacher and student understandings of 
e-portfolio use changed over the period of the study. At first e-portfolios were seen purely as an assessment tool, but by the end of the project they were valued as a multidisciplinary part of their classroom (Garthwait \& Verrill, 2003). Overall these studies emphasised the critical role of teachers, family members and peers in the success of e-portfolios (Barrett, 2008; Becta, 2007; Garthwait \& Verrill, 2003; Hollingworth et al., 2009; Joyes et al., 2010). However, as these studies were conducted over a period of one to two years (Barrett, 2008; Garthwait \& Verrill, 2003; Joyes et al., 2010) there is still little evidence of engagement with e-portfolios over a more extended period of time. This research on younger children's engagement with e-portfolios will add to the developing body of research in this area contributing to knowledge about e-portfolio use in ECE.

\subsubsection{Benefits of e-portfolios in education.}

The benefits of e-portfolios are evident in many empirical studies and position pieces with researchers interested in their role in education. With teachers becoming increasingly dependent on technology in both their personal and professional lives, studies have shown that they have found e-portfolios easily complement their current teaching practices (Buzzetto-More \& Alade, 2006; Meyer and Latham, 2008). The most commonly identified benefit in many studies was the instantaneous nature of eportfolios which allows them to be accessed from any location at any time (Becta, 2007; Buzzetto-More \& Alade, 2006; Goldsmith, 2007; Goodman, 2013; Joyes et al., 2010; Kankaanranta, 2001; Mason, Pegler \& Weller, 2004; Ministry of Education, 2011; Strudler \& Wetzel, 2008; Woodward \& Nahlohy, 2004). This accessibility enables students and their wider family network to be more engaged in learning thus extending the classroom and developing meaningful connections (Becta, 2007; Buzzetto-More \& Alade, 2006; Hewett, 2004; Kankaanranta, 2001; Ministry of Education, 2011; Papp, 2014; Strudler \& Wetzel, 2008; Wade et al., 2005).

Further benefits identified in these studies include the minimisation of costs, reliability of programmes and being able to store large quantities of data for extended periods of time (Becta, 2007; Buzzetto-More \& Alade, 2006; Goldsmith,

2007; Joyes et al., 2010; Meyer \& Latham, 2008; Ministry of Education, 2011; Wade et al., 2005). Becta (2007) and Woodward and Nanlohy (2004) found that students using e-portfolios were not only more motivated and engaged with their learning, but 
they also developed ownership of their work by relating their learning to personal skills and learning outcomes (Wade et al., 2005). This means e-portfolios allow students to tailor their individual e-portfolios as well as showcase their achievements, with parents and teachers able to give feedback to assist and support learning (Becta, 2007; Hewett, 2004). Several studies have found students to have increased confidence in their learning, stronger decision-making and self-assessment skills as well as greater self-regulation in tasks as a result of moving to e-portfolios (Becta, 2007; Buzzetto-More \& Alade, 2006; Woodward \& Nanlohy, 2004; Wade et al., 2005). Becta (2007) and Buzzetto-More and Alade (2006) identified that these improvements are a result of technology removing some of the barriers of standard rote learning, encouraging mastery in different tasks and allowing stronger ownership of one's work.

Teachers were also found to have benefited from the introduction of e-portfolios; indicating a greater involvement in planning, reflection and communication with parents (Becta, 2007; Goodman, 2013; Lorenzo \& Ittelson, 2005). Teachers in New Zealand are supported in their practices as e-portfolios align well with the New Zealand Curriculum, which places emphasis on exploring technology as a way to support and extend teaching (Ministry of Education, 2011). Teachers in two New Zealand studies reported experiencing deeper relationships with students, parents and wider family members as a result of using e-portfolios due to more frequent and instant communication (Goodman, 2013; Ministry of Education, 2011), which in turn supported greater connections between the home and educational settings (Barrett, 2008; Becta, 2007; Goodman, 2013; Strudler \& Wetzel, 2008). Barrett (2008) found that the teacher's role is critical to the success of e-portfolios, as their connections with the students' learning helps to empower and encourage greater involvement. Eportfolios emphasise the learning process by enabling teachers to holistically assess and support students through a more reciprocal teacher/learner model, thus being more responsive to each individual (Barrett, 2008; Becta 2007; Meyer \& Latham, 2008; Strudler \& Wetzel, 2008).

\subsubsection{Challenges of e-portfolios in education.}

As with the introduction of any new programme there are identified challenges and areas of development. The most common challenges identified in the literature acknowledge the difficulty of moving from traditional hard-copy documentation to 
online (Buzzetto-More \& Alade, 2006; Goldsmith, 2007; Lorenzo \& Ittelson, 2005; Strudler \& Wetzel, 2008; Wade et al., 2005). This meant a baseline understanding of technology was required for effective implementation and maintenance of online programmes in a new setting (Lorenzo \& Ittelson, 2005; Wade et al., 2005). Without this general understanding the demands of maintaining and updating e-portfolios becomes cumbersome thus lessening their effectiveness compared with hard-copy documentation (Strudler \& Wetzel, 2008; Wade et al., 2005). This challenge is coupled with initial concerns, raised in many studies, from parents and students regarding security of their information and availability of technological support where needed (Barrett \& Garrett, 2009; Buzzetto-More \& Alade, 2006; Goodman, 2013; Lorenzo \& Ittelson, 2005; Ministry of Education, 2011; Papp, 2014; Strudler \& Wetzel, 2008). Individuals may be hesitant to rely so heavily on an online programme for fear of losing work or having personal details revealed (Becta, 2007; Lorenzo \& Ittelson, 2005). This latter issue is exacerbated in settings with younger children where parents and teachers are the main users of e-portfolios, leaving young children at risk of being manipulated and having little say about what information is shared (Becta, 2007; Lorenzo \& Ittelson, 2005). An element of trust and respect is required by teachers and parents when engaging in online documentation (Becta, 2007), so that information is not misused.

Within a teaching or learning context the challenges of time and quality emerged regularly in the literature (Becta, 2007; Strudler \& Wetzel, 2008; Reardon \& Hartley, 2007; Wade et al., 2005). Whilst research has shown that teachers find e-portfolios effective for creating and sharing information, there is still a significant amount of time required to maintain and communicate within individual profiles (Goldsmith, 2007; Goodman, 2013). Mason, Pegler and Weller's study (2004), using e-portfolios to evaluate a course, found that at times regularly engaging pupils and their wider networks through e-portfolios resulted in decreased achievement and more generalised entries which lacked quality. Their study identified the need for genuine connections to be made between students, teachers and families online to support individual achievements and encourage students to take pride in their work (Mason et al., 2004). These issues are accentuated with the number of students and families who do not have access, regularly or otherwise, to computers or electronic devices to engage with students' work outside of the classroom (Barrett, 2008; Goodman, 2013; 
Strudler \& Wetzel, 2008) or for those who have difficulty engaging due to culture, language and literacy differences (Hollingworth et al., 2009). Studies identified the need for appropriate provisions to be made to support students and their families if they are going to begin using e-portfolios (Barrett, 2008; Hollingworth et al., 2009; Strudler \& Wetzel, 2008).

\subsubsection{Place of e-portfolios in the future.}

One of the most controversial aspects in e-portfolio literature relates to their future in an educational or workplace setting. Some writers and researchers advocate for the introduction of a life-time, self-directed web space for individuals, which is continually added to as they progress through education and work (Lorenzo \& Ittelson, 2005; Papp, 2014). Woodward and Nanlohy (2004) challenge this future perspective and question whether the technological appeal of e-portfolios is increasing their desirability. They ask whether this technological appeal will overshadow their purpose over time - is it about developing better learning or a better product (Woodward \& Nanlohy, 2004)? The New Zealand Ministry of Education report on e-portfolios in the primary and secondary sector queries whether it is necessary for documentation and assessment to become digital just to keep up with the technological world (Ministry of Education, 2011). This concern embodies the question around whether e-portfolios will be of benefit in all environments.

Several writers outline some critical factors that need to be addressed before implementing portfolios: gaining agreement as a wider community regarding their introduction; addressing the cultural and socio-economic considerations of the community (Ministry of Education, 2011; Kankaanranta, 2001; Nichols \& McLachlan, 2006; Meade, 2012); and, adapting educational philosophies to encompass the change (Ministry of Education, 2011). The difficulty with research in this field is that eportfolios have not yet been implemented long enough for longitudinal studies to have found conclusive evidence on their effect on students. As a result, Reardon and Hartley (2007) question whether their introduction into education is actually beneficial to students' learning outcomes without strong evidence to back it up. This is where the call comes for more research to be undertaken to better understand the place of eportfolios in the educational sector. 


\subsection{E-Portfolios in early childhood education}

E-portfolios are becoming increasingly evident in ECE. Within a New Zealand context, e-portfolios have been introduced as an enhancement to traditional hard- copy portfolios, with the intention of supporting teachers in teaching and planning as well as enhancing learning outcomes for young children through their collaborative nature (Bolstad et al., 2004; Goodman, 2013). The socio-cultural philosophy valued within New Zealand ECE centres is well supported by the online facets of e- portfolios, allowing teachers to create learning stories, upload daily snapshots and communicate easily with parents (Goodman, 2013). Due to the instantaneous nature of e-portfolios, sharing and communicating between parents and family members can be more frequent and meaningful, and as a result this communication has resulted in improved learning outcomes for children (Goodman, 2013).

One of the first pieces of empirical research on e-portfolios in ECE in New Zealand was conducted in 2013, with a survey of $80 \mathrm{ECE}$ centres and case studies of two centres (Goodman, 2013). This study looked at parents' and teachers' engagement with eportfolios and the elements that supported this engagement using one e- portfolio provider, Educa (Goodman, 2013). Data showed increased involvement from parents and family members in their children's learning thus increasing learning outcomes and support for their child's development (Goodman, 2013). Teachers reported enjoying documentation more, confident in the fact that their online contributions were being read and valued, which in turn boosted the number of stories and photos they contributed (Goodman, 2013). Whilst most participants found e-portfolios useful and engaging, some users identified potential difficulties; particularly for those without computer access, those with concerns around security, and those who preferred hardcopy portfolios (Goodman, 2013). Whilst this study gathered interesting data its scope was narrow as its purpose was to look at engagement using one e-portfolio system over a short period of time. This study did also not explicitly consider the role of children's engagement with their e-portfolio; whilst observations were taken where children were engaged, this was not the focus of the study. My concern after reflecting upon this study was if documentation becomes wholly electronic there are many environments where children may not have the same access or skills to review their learning that they currently have with hard-copy portfolios. This concern paved the way for this current study as I sought to 
find out how children are engaging with their learning and how it might be affecting their reflective and self-assessment skills.

\subsubsection{Benefits of e-portfolios in an ECE setting.}

To date, understandings about the use and benefit of e-portfolios within ECE settings have relied upon empirical research from other educational settings which is, at times, irrelevant (Woodward \& Nanlohy, 2004). In saying this, many of the benefits revealed in other studies also apply to ECE, such as the accessibility and ease of communicating with parents (Goodman, 2013; Hewett, 2004; Kankaanranta, 2001; Ministry of Education, 2011) and the instantaneous nature of viewing new stories and images (Becta, 2007; Buzzetto-More \& Alade, 2006; Goldsmith, 2007). Within an ECE setting the immediacy of stories and notices means that parents can be informed throughout the day and be reassured of how their child is doing during transitions or difficult situations (Goodman, 2013). Evidence of these benefits were found in Goodman's study (2013) where parents revealed that they liked being able to find out what had happened that day before collecting their child as this led to greater conversations at home. Meade (2012) has argued that communication and participation by parents is critical to enhancing learning outcomes for children, reflecting a principle of the New Zealand ECE curriculum, Te Whāriki, (Ministry of Education, 1996) focusing on promoting relationships between parents and the centre to support and extend children's learning outcomes. Frequent involvement from parents has resulted in improved quality learning stories for children and more enjoyment for parents in connecting with their child's learning (Goodman, 2013).

\subsubsection{Challenges of e-portfolios in an ECE setting.}

Cost is one of the primary challenges facing implementation of e-portfolios in ECE settings (Goodman, 2013). Limited Government funding requires ECE centres to prioritise their spending and decide whether introducing e-portfolios would be viable. In addition some centres prioritise having both online and hard-copy versions of children's portfolios; these are at times difficult to maintain, with cost and time being the major attributing factors (Goodman, 2013). Woodward and Nanlohy (2004) identified difficulties in gaining the support of the EC community before the introduction of e-portfolios, particularly given the lack of evidence to inform parents on how to engage confidently with this new medium. In Goodman's (2013) study, teachers shared their personal challenge in including children in online 
documentation as they felt the technology element removed children from the process. Meyer and Latham (2008) note e-portfolios are simply a programme, highlighting the changes in practice that need to be made by teachers to maximise e- portfolios for both teacher documentation and children's contribution (Barrett, 2008; Meyer \& Latham, 2008; Strudler \& Wetzel, 2008). The purpose of e-portfolios has been overlooked if children are suddenly removed from the collaborative and responsive learning story process; rather e-portfolios should better support current practices with young children rather than diminish them. This current study aims to investigate the wider use of this pedagogical tool in supporting children's engagement in their learning.

\subsection{Assessment in early childhood education}

Assessment within education contexts has taken on different forms over the years and varies significantly based on the curriculum and teaching values within each setting. Within a New Zealand ECE context, the introduction of the ECE curriculum, Te Whäriki, (Ministry of Education, 1996) dramatically altered the practices of ECE assessment turning the emphasis to pedagogical documentation (Rameka, 2007; Te One, 2002). Whilst reflections, records and observations of children were always valued as important in developing an understanding of a child (Kankaanranta, 2001; Ministry of Education, 2009; Te One, 2002), the introduction of pedagogical documentation dramatically altered the ways that teachers and parents view and value learning for young children (Carr, 2011).

\subsubsection{Te Whäriki ECE curriculum.}

The ECE curriculum of New Zealand, Te Whāriki, (Ministry of Education, 1996) underpins the way in which early childhood education settings assess, teach and plan. Whilst drawing on the theories of Piaget and Erikson, Te Whäriki is heavily influenced by Vygotsky's socio-cultural theory and Bronfenbrenner's ecological theory, both of which place significant influence on the important role of relationships in contributing to a child's learning and development (Meade, 2012; Ministry of Education, 2009; Ritchie \& Buzzelli, 2012). As well, the influence of the Reggio Emilia philosophy on New Zealand teaching practices has resulted in significant pedagogical and philosophical changes to teaching practices and values (Goodman, 2013; Rameka, 2007). The chosen name for the curriculum, Te Whäriki, encompasses the socio-cultural values espoused within the document; placing 
emphasis on the weaving of each child's own learning 'pattern' or 'mat' through the support and collaboration from the centre and those in their wider environments (Ritchie \& Buzzelli, 2012). This can be achieved by teachers and children, as Te Whäriki was created as a non-prescriptive document, allowing each child to develop their own learning relevant to their needs, philosophy and values (Ritchie \& Buzzelli, 2012). One of the foundational principles of Te Whāriki is that children learn through "responsive, reciprocal relationships" (Ministry of Education, 1996, p.

9) with the world around them, therefore taking ownership of their learning in a meaningful way (Carr, 2011).

Te Whäriki is unique to the culture and context of New Zealand ECE, including being based on strong respect for Māori, the indigenous people of Aotearoa New Zealand, and the aligning of its values to the obligations laid out in Te Tiriti O Waitangi (The Treaty of Waitangi) (Ritchie \& Buzzelli, 2012). In this way, the curriculum places children within their own socio-cultural context; this in turn helps teachers and families to support learning that is relevant and reflective of each child's individual strengths and interests (Ritchie \& Buzzelli, 2012). The metaphor of a mat or whāriki allows the different cultural and ethnic diversities of each child to be celebrated and supported in their learning (Ritchie \& Buzzelli, 2012). Te Whāriki has faced criticism however and challenged as to whether its open-ended nature posed difficulty for practitioners in meaningfully applying the curriculum to their daily context (Ritchie \& Buzzelli, 2012), particularly when articulating what children are learning. According to Ritchie and Buzzelli (2012), this challenge is amplified in ECE settings with low staffing numbers, unqualified teachers or minimal funding (Meade, 2012) - aspects which can be present in ECE centres around New Zealand at present.

\subsubsection{Assessing learning using Te Whāriki.}

Out of the socio-cultural approach came the introduction of pedagogical documentation as a way to assess and share young children's learning (Te One, 2002). Pedagogical documentation is recognised as one of the most valuable forms of authentic teacher practice to extend children's individual learning and development (Goodman, 2013; Harris Helm, Beneke \& Steinheimer, 1998; Loveridge, 2004; Te One, 2002). From this pedagogical shift emerged the Learning Story Framework - a formative and holistic way to assess and document young 
children's learning using a variety of forms such as narrative, images and reflection to further extend and support learning (Te One, 2002). Learning stories are designed to make learning visible by acknowledging the achievements of children, linking these to the principles and goals of the curriculum, and for planning to extend learning (Carr, 2001; Goodman, 2013). Carr (2011) describes learning stories as learning that is documented by teachers but with a strong influence from children in dictating or sharing their views. An action research study by Kankaanranta (2001), investigating portfolios with young children in 14 different educational settings, identified that portfolios and learning stories are one of the more promising forms of authentic assessment as they represent the individual skills and interests of children whilst being engaging and enjoyable for parents and teachers to read.

Learning stories also reflect traditional Māori methods of assessment where learning and assessment is embedded within the supportive daily interactions with one's peers and family, in order to celebrate and nurture an individual's mana and wellbeing (Rameka, 2007; 2011). In this way learning stories invite the collaboration of children, other teachers and wider family members to support and reflect upon children's learning, thus ensuring that learning is meaningful and relevant (Buzzetto- More \& Alade, 2006; Rameka, 2007). Children develop a deeper understanding and value for their learning through reflection on these narratives alongside teachers, peers and family (Carr, 2011); thus participation is valued as critical to developing strong learnercentred models of assessment (Meade, 2012). Studies have shown that parents have a greater understanding of and involvement with their child's learning through engaging with these descriptive narratives and explanations (Goodman, 2013; Loveridge, 2004; Meade, 2012). Meade's (2012) study also found that in centres with $100 \%$ qualified teachers the narratives were of greater quality, resulting in a higher level of communication between parents and teachers regarding children's learning.

The literature on learning stories consistently suggests that teachers have a greater understanding of children, their families and their wider support network due to this holistic method of assessment and documentation (Goodman, 2013; Harris Helm et al., 1998; Jones, 2006; Rameka, 2007; Rameka, 2011; Te One, 2002). Learning stories show continuity, development and change in both thinking and learning 
(Carr, 2001), and this in turn supports teachers to relate to each child. However Fendler (2001) conversely states that whilst holistic approaches to documentation encourage teachers to celebrate children individually, there can, at times, be limited support for teachers to effectively document through this new medium.

A search of empirical literature revealed 14 studies on assessment in early childhood education, both nationally and overseas, with three particularly relevant to this study as they looked at engagement with narrative assessment. Two studies were small case studies of single ECE centres in New Zealand (Davis, 2006; Te One, 2002). Te One (2002) investigated narrative portfolios to see whether they promoted learning, informed the curriculum and kept families updated. Te One (2002) discovered that teachers felt they understood children better through this more holistic method of documentation and observed greater self-esteem and reflections by children regarding their learning. Davis (2006) visited one ECE setting to see how teachers used narrative assessment to inform their programme planning and decision-making. Davis (2006) discovered that making assessment meaningful was difficult when it was not connected to strong communication and relationships within a teaching team. The third study was conducted overseas in the Pen Green Centre investigating teacher practice as they embraced narrative assessment (Whalley \& Dennison, 2008). Similar results in these studies emerged in that they initially found that teachers responded negatively to the notion of narrative stories, viewing them as a formal obligation without particular benefit to the children (Davis, 2006; Te One, 2002; Whalley \& Dennison, 2008). However through use and specific support teachers began to see improved communication with families and deeper relationships with children and their individual learning journey (Davis, 2006; Te One, 2002). Teachers experienced a shift in perspective from seeing portfolios as just a product to viewing them as pedagogy where they could share and celebrate children's learning authentically (Te One, 2002).

\subsection{Children's engagement with their learning using hard-copy portfolios}

New Zealand research into children's portfolios suggests variations in how children engage with their portfolios. In some ECE settings hard-copy portfolios may go unread by parents or children (Goodman, 2013). Teachers may find the task of writing and collaborating learning stories to be arduous when they know that stories are not being read or contributed to by children or their families (Goodman, 2013). 
In other settings, however, children engage frequently with their hard-copy portfolios, taking them home and showing their families as well as adding stories themselves to contribute to their learning (Steele, 2007). The topic of children's engagement with their learning is evident in a number of research studies as ECE settings attempt to discover the successes and challenges of narrative assessment with children. Carr (2011) identified three factors that appear imperative in assisting children to engage with their own learning - ownership, partnership and accessibility. This study consisted of a two year action-research project with teachers in nine ECE centres and was designed to explore and understand young children's reflection with their own learning (Carr, 2011). Data was collected through each centre's observations of a child over a one-year period, noting any changes in their engagement as teacher practice was adapted (Carr, 2011). Results from this study showed that joint attention and involvement by teachers, children and their peers resulted in better quality learning stories and greater ownership by children of their learning (Carr, 2011).

\subsubsection{Ownership.}

The primary aspect evident in research investigating children's reflection on their learning was that of ownership (Te One, 2000). When children are aware of the documentation process and of the different roles they can enact to contribute to their learning this empowers them to own their learning and be proud of what they have achieved (Garthwait \& Verrill, 2003; Te One, 2000). Ownership is developed when children have an active role and greater understanding of their learning and have control of what is shared with their family (Carr, 2011). In secondary or primary school settings ownership is clearer cut, with students having a greater role in documentation (Barrett, 2008; Becta, 2007; Emmett, 2011; Ministry of Education,

2011). Conversely in an ECE setting this sense of ownership is harder to support and develop as teachers can have significant power over children in learning, documentation and decision-making. In order for young children to develop ownership of their learning Carr $(2001 ; 2011)$ and Te One (2000) state it is important for ECE teachers to listen to children, ask open-ended questions in order to understand what is important learning for them, and to then co-author with children in the documentation process. Carr (2011) argues for a shift from teachers' power over children to a co-constructivist approach where children are given equal 
opportunity to steer learning for themselves, as once this was done Carr noted in her study that children revisited conversations and learning experiences in daily activities.

Ownership is heavily influenced by the acknowledgment of the child's voice. Lewis (2010) writes that since the introduction of The United Nations Convention of the Rights of the Child (UNCROC) in 1989, educational settings and Government policies have placed more emphasis on advocating for the child's voice. In particular, Article 12 in UNCROC states that "the child who is capable of forming his or her own views [has] the right to express those views freely in all matters affecting the child" and that the views of the child are "given due weight" (Child Rights Information Network, 2014). This outlines the critical role that children must have in affairs that concern them especially as it benefits their learning and development. Lewis (2010) suggests it is important to consult with children to ensure they contribute actively to their learning and have greater choice in what is being shared about them.

\subsubsection{Partnership.}

Parents pass on their values, beliefs and expectations to children (Carr, 2011) and in this way it is important for centres and families to partner with each other and the child's learning in order to establish more learner-centred outcomes for children (Meade, 2012). Te Whäriki promotes relationships at the core of the curriculum and parents, families and communities are viewed as valuable contributors to children's learning and development (Jones, 2006; Meade, 2012; Ministry of Education, 1996). Strong relationships are developed by teachers enabling reciprocal relationships with families, discouraging the view of parents as novice (Jones, 2006; Porter, 2008) and developing relationships built on trust, respect, communication and responsiveness to diversity (Jones, 2006; Meade, 2012; Mitchell, 2003; Whalley, 2000). When parents and teachers genuinely partnered together both parties were seen to better understand each other's values - this in turn transformed the learning with children and the quality of assessment (Jones, 2006; Meade, 2012; Whalley, 2000; Whalley \& Chandler, 2007).

Carr's study (2011) acknowledged that conversations between parents and their children at the end of the day contributed to children's meaning making of their own 
learning. However, parents are increasingly working longer hours and this role of communication falls to both parents and teachers (Carr, 2011; Harris Helm et al., 1998). Meade identified that communication, through conversation, email, text, or the child's portfolio, is pivotal to developing strong, trustworthy partnerships between parents and teachers that place the child at the centre (2012). Whilst this is a challenge for teachers, strong communication channels equips parents to speak with and extend their child's learning at home and contribute more to centre planning (Goodman, 2013).

Meade's (2012) research looked at parent participation in 10 ECE centres in New Zealand: five centres had 100\% qualified teachers and five had 50-79\% qualified teachers. Meade found that in the centres with $100 \%$ qualified teachers the children's portfolios were filled with rich narratives which made connections to both home and centre interests as well as planned for future extension. This was contrary to the centres with fewer qualified teachers whose portfolio books showed more imagery and brief anecdotes with minimal analysis or celebration of learning (Meade, 2012). Meade noticed a difference between the involvement of parents in the different centres and found stronger participation in centres where emphasis was placed on quality documentation; this resulted in stronger reciprocal communication and greater connections for children (Meade, 2012). Four other empirical studies echo this sentiment: parents had a greater understanding of their child's learning and stronger relationships with teachers as a result of persistent engagement with their child's learning and portfolio (Jones, 2006; Mitchell, 2003; Whalley, 2000; Whalley

$\&$ Chandler, 2007). Two of these studies were conducted overseas (Whalley, 2000; Whalley \& Chandler, 2007), one qualitative study was undertaken in New Zealand over a period of three years with 27 children from five ECE centres (Jones, 2006), and the final study was a comparative action-research project between Australian and New Zealand ECE settings (Mitchell, 2003). The unequivocal view, from all four studies, highlighted the benefits to children's learning and development as a result of genuine relationships between teachers and families, which in turn helped to support improved learning outcomes (Goodman, 2013; Jones, 2006; Mitchell, 2003; Whalley, 2000; Whalley \& Chandler, 2007). 


\subsubsection{Accessibility.}

Regardless of the quality of partnerships between parents and teachers, children's portfolios are less relevant to children if they do not have access. Ownership of learning comes not only from involvement but also in having easy access - this is particularly pertinent with young children. Carr's study (2011) found that children were more likely to engage with their learning in a hard-copy portfolio when these were accessible. This meant being well-labelled for easy identification, placed in easy reach and near a couch or cushioned area to encourage children and parents to take time reading (Carr, 2011). As well as this parents were more likely to take home their child's portfolio if it was accessible and in a place in the centre that prompted them to sit with their child and read (Goodman, 2013). This is a challenge for teachers because as parents become increasingly busy the ways of connecting and engaging with them needs to evolve to ensure ease and accessibility, such as displaying portfolios in a place that suits parent's needs (Porter, 2008).

The accessibility of portfolios has significant influence on the contribution of young children to their learning (Steele, 2007). A New Zealand action-research study by Steele (2007) in her ECE centre investigated the availability of hard-copy portfolios for children and parents over the period of a year and initially discovered that children were not contributing to their portfolio because they were not aware they could. Steele (2007) also identified early on that teachers were not revisiting portfolios with children; this gave teachers complete ownership over the portfolios and did not model respect for children's learning. After adapting teacher practices and making portfolios accessible a noticeable change was observed - children revisited their portfolios daily, developed more critical self-reflection and also respected their books through careful reading and storing of them. Steele (2007) also noticed over the year that children had an increased desire to take photos and write learning stories and share these with their family.

Accessibility is not just about having physical access to ones work it is also about intellectual accessibility (Te One, 2000). This means that additions to a young child's portfolio are not only comprehensible to both adults and children but balance photos and words to encourage reflection. Learning stories are traditionally either written to the child or about the child and share the particular activities or interest they explored (Te One, 2002); making them interesting and appropriate for children to 
revisit with their peers and family. Te Whäriki espouses that children are active constructors of their own learning (Ministry of Education, 1996) and that children develop their identity through engagement with and contribution to their learning. Therefore assessment narratives must reflect the different stages of the child and be relatable for them to revisit (Te One, 2000).

\subsection{Children's engagement with their learning using e-portfolios}

Despite the popularity of e-portfolios in the educational sector, including its recent emergence into ECE, there is little empirical research as to how students are engaging with this online medium (Emmett, 2011). Therefore, this study aims to help inform the field on how young children are engaging with their learning using e-portfolios, and investigate new ways for teachers to support parents and children to access children's learning.

\subsubsection{Digital technology in ECE.}

The introduction of digital technology into society has influenced communication, image sharing and assessment and this has impacted the lives of young children (Plowman, McPake \& Stephen, 2010), particularly with use of computers and mobile electronic devices in ECE and home settings. A study conducted in the United Kingdom in 2010 looked at 24 children's use of technology in their home, as well as surveying 346 families (Plowman et al., 2010). This study found that children were competent in using different forms of technology before the age of five and that this use was not damaging to their learning or development if parents enforced boundaries (Plowman et al., 2010). Research shows that allowing children a greater role in technology and documentation ensures they are not overlooked by enabling them to actively see and approve images and information of themselves before they are uploaded (Becta, 2007; Lorenzo \& Ittelson, 2005). Meade (2012) discovered that the use of electronic communication with parents in ECE was transforming the way in which they participated in the centre; parents contributed to learning more frequently and made connections to home. Parents were also able to share photos and stories with extended family by emailing around the world (Goodman, 2013).

Technology is transforming childhood - cognitively, emotionally and socially - with the predominance of screen-based media (Plowman et al., 2010) and this 
transformation is being addressed in popular media. In particular, one article in the New Zealand Herald in 2014, commented that more parents are allowing their young children access to iPads, iPhones and the home computer (Jones, 2014). The article indicated that many adults praise the interactive nature of iPads and iPhones in that they help children problem solve, share and master fine motor tasks and then transfer these skills into their daily life (Jones, 2014). This is supported by research from Dr Kaufman who studied young children and babies' use of technology, discovering that spatial problem solving undertaken on an iPad can easily be transposed into other tasks (Killman, 2013). His Australian study asked children to complete tasks, initially with real objects, and then on the iPad and found no difference in their ability with either medium (Killman, 2013). This emphasis on technology is not without contention with many adults advocating for less as they believe children are missing out on real activities, such as physical exertion and social stimulation (Jones, 2014; Plowman et al., 2010). Kaufman believes that research into the negative impact of television watching has been grouped with iPad use, when in fact the activities are completely different (Killman, 2013).

Two small scale empirical studies were identified in the literature that addressed this contentious technology argument. Both undertaken in New Zealand, one study was a pilot investigation in one kindergarten and one education and care ECE setting (Fagan \& Coutts, 2012), whilst the other was a study in one ECE setting in Hamilton looking at the effect of technology on learning (Khoo, Merry, Nguyen, Bennett \& MacMillan, 2013). Both studies found that children collaborated together when using devices such as a centre computer or iPad (Fagan \& Coutts, 2012; Khoo et al., 2013) and were able to add their own voice easily through the many recording and video functions (Fagan \& Coutts, 2012). Khoo et al., (2013) discovered that children are extremely capable with these tools and teachers took advantage of this, using iPads to revisit and contribute to learning stories alongside children.

\subsubsection{E-portfolios and young children's engagement.}

Whilst studies within tertiary and secondary settings have shown benefits to student engagement and learning as a result of using e-portfolios (Barrett, 2008; BuzzettoMore \& Alade, 2006; Joyes et al., 2010) a search of the literature revealed no empirical studies investigating young children's engagement with e-portfolios. Goodman's (2013) research investigating parent and teacher engagement with e- 
portfolios found that children were viewing their e-portfolios with their parents at home as well as sharing these with wider family but it did not focus on children's engagement. Research undertaken in higher education found that e-portfolios are spaces where older students can take responsibility for presenting and storing their work (Barrett \& Garrett, 2009); however in an ECE environment young children do not have the skills to manage their e-portfolio but do deserve to be part of the process

- how can this be acknowledged authentically? Reardon and Hartley (2007) call for more research to be undertaken into this digital phenomenon in order to challenge their current status in education and provide evidence of children's engagement. This research study aims to explore this topic and develop a greater understanding of young children's e-portfolio use, placing particular emphasis on the aspects identified as critical for children's engagement - ownership, partnership and accessibility. 


\section{Chapter Three: Methodology}

\subsection{Introduction}

This chapter outlines the methodological approach used in this research. The chapter begins with an introduction to both mixed methods research and the interpretive paradigm selected for this study. Data collection methods are described in detail, together with information on the participants involved and the approach used for data analysis. This chapter also includes a discussion on the ethical issues involved in this project, focusing particularly on undertaking research with young children.

\subsection{Mixed Methods Research}

A mixed methods research design is a procedure for collecting, analysing, and "mixing" both quantitative and qualitative research and methods in a single study to understand a research problem. The basic assumption is that the use of both quantitative and qualitative methods, in combination, provides a better understanding of the research problem.

(Creswell, 2008, p. 552)

Mixed methods is an approach chosen for its ability to draw on the strengths of both quantitative and qualitative research, enabling different levels of enquiry to be addressed to answer the research question (Creswell, 2008; Newby, 2010). Mixed methods is commonly used in educational research as qualitative data gathered from discussions, interviews and observation build upon quantitative data, such as surveys or questionnaires (Creswell, 2008). The use of multiple perspectives, ideas and research methods strengthens educational research as it enables a deeper understanding of participants' perspectives (Creswell, 2008; Wiersma \& Jurs, 2009), an aspect which single method strategies lack (Johnson \& Christensen, 2012). It also allows complementary data to be gathered through multiple strategies that assist in developing reliable conclusions (Johnson \& Christensen, 2012; Newby, 2010).

The nature of mixed methods is advantageous as it reduces possible bias since researchers can draw on the strengths of both qualitative and quantitative methods in data collection (Wiersma \& Jurs, 2009). With multiple data sources discovering similar findings, data triangulation is strengthened thus increasing the credibility of conclusions and enabling reliable data analysis (Johnson \& Christensen, 2012).This in turn allows the collected findings to be relevant to the various audiences for which the study has been designed (Wiersma \& Jurs, 2009). Both qualitative and quantitative methods serve different purposes in the use of their data and therefore 
each method's results will be more appropriate to different people for application (Wiersma \& Jurs, 2009).

In this study both quantitative and qualitative survey data were collected from a nationwide survey and a case study survey and these were aligned with observations, interviews and document analysis from two case studies. The case study data included the perspectives of parents, teachers and most importantly, children. Data from each method complemented and critiqued one another enabling triangulation of the data and allowed a wealth of information to be gathered (Johnson \& Christensen, 2012). The case study data enhanced the survey responses and brought to life the different experiences of children with e-portfolios, enabling a greater understanding on this topic.

\subsection{Interpretive Paradigm}

In a general sense a paradigm is a "perspective about research held by a community of researchers that is based on a set of shared assumptions, concepts, values and practices" (Johnson \& Christensen, 2012, p. 31); put simply, it is a way of thinking about and viewing the world (Walsham, 2006). Walsham (2006) argues that interpretive research is carried out with the researcher's involvement moving back and forth along a continuum, shifting from being wholly involved to an outside perspective to a more neutral view. Walsham also comments that neutral does not mean unbiased, as all researchers have their own experiences, prejudices and values. Rather, Walsham identifies a neutral researcher as one that participants do not perceive to be affiliated with a particular organisation, individual or opinion; enabling them to feel reassured and comfortable in sharing their experiences with the researcher (2006). Neutrality allows researchers to be wholly immersed in the data collection, thus gathering genuine experiences of participants rather than presuming or interpreting opinions (Walsham, 2006). This paradigm allows meaning to be continually constructed through the different contributions of participants, thus bringing light to the empirical data and assisting in developing credible conclusions (Sundin \& Fahy, 2008).

This study used an interpretive paradigm which is a socially constructed approach that seeks to record particular phenomena from perspectives of the participants involved (Joniak, 2002). The data collection drew on the genuine experiences of 
teachers, family members and children, in understanding children's engagement with their learning through e-portfolios. Due to the dearth of research in this area an interpretive paradigm allowed a combination of participants' perspectives to develop a greater understanding on this topic.

\subsection{Research Questions}

The key research question for this study was:

\section{In what ways are children engaging with their learning through their e-portfolio?}

Sub-questions arising from this were as follows:

- What access is provided for children to view their online portfolio?

- In what ways are children involved in the documentation process?

- $\quad$ How are children encouraged to contribute to their e-portfolio?

- What connections are being made by children between the home and their centre through using their e-portfolio?

- In what ways are parents revisiting the child's portfolio with their child at home?

\subsection{Data Collection Methods}

This study comprised of a three phase data collection process in order to gather a wide range of perspectives from teachers, parents and children. Phase one of data collection was a national online survey which was sent to all education and care and kindergarten settings in New Zealand, and was followed by phases two and three which were case studies undertaken in two New Zealand ECE centres. The case studies included an initial online survey for teachers and family members, followed by interviews, observations and document analysis in the centres. These chosen methods are detailed further below.

\subsubsection{Online survey}

A survey is a data collection instrument allowing information and views to be gathered over a large population (Johnson \& Christensen, 2012). Surveys enable researchers to gather both qualitative and quantitative data through specific and 
open-ended questioning (Johnson \& Christensen, 2012). Surveys assist in determining trends, identifying issues and learning about beliefs and experiences, which is why they are one of the most commonly used methods of data collection (Creswell, 2008). An online survey has the ability to easily reach a large population, and for this study the online method enabled me to contact a larger number of potential respondents, since I had no information on which settings used e-portfolios, in order to gather as much data as possible.

\subsubsection{National online survey}

For this study, phase one consisted of an online survey sent to all education and care and kindergarten services around New Zealand registered on the Ministry of Education ECE database. The survey was aimed at centres that use e-portfolios in New Zealand and asked for one response per centre. As there was no information available about which ECE settings use e-portfolios the survey was emailed to all of these services, a total of 2,315 around New Zealand. The email invited their participation in the survey which was open from the 11th September until the middle of October 2014 and contained both an information sheet as well as a link to the survey. Recipients were invited to take part in the survey if they were using e- portfolios in their centre and those who were ineligible were thanked for their time and asked to click a link which removed them from receiving further survey reminders. Two reminders were sent to those remaining on the email database throughout the period the survey was open. A total of 876 centres opened the email with the survey invitation; 146 opened the link to the survey, 115 began the survey questions and 77 completed the survey.

This survey consisted of two qualitative and 15 quantitative questions. The survey opened with six quantitative questions seeking demographic data such as location, centre license size, e-portfolio provider used, and general usage of the programme. These were followed by nine further quantitative and the two qualitative questions gathering information on their perspective and experiences of children's engagement with their learning using e-portfolios. Eight out of the 15 quantitative questions asked for a text response to explain the fixed response answers (see Appendix L for the survey instrument). The final question asked for interested centres to provide their email address if they were willing to be considered for a case study visit as part 
of phases two and three of the study. National survey results were used to refine the data collection protocol and instruments for the two case studies.

\subsubsection{Case Studies.}

Case studies are a valuable form of data collection as they allow "in-depth exploration" (Creswell, 2008) when investigating more descriptive and qualitative research questions (Johnson \& Christensen, 2012). Case studies allow researchers to develop a greater understanding of individuals' perspectives and experiences by being immersed in the environment (Wiersma \& Jurs, 2009; Yin, 2009.) It is through building a rapport with participants that researchers are able to ask specific questions in order to ascertain relevant data (Cohen, Manion \& Morrison, 2000). For this research, the case study approach was selected as relevant as whilst the survey enabled a wide range of perspectives to be gathered (Wiersma \& Jurs, 2009; Yin, 2009), the case studies collected more nuanced data thus enabling a greater understanding of the experiences of participants' (Cohen, Manion \& Morrison, 2000; Goodman, 2013; Yin, 2009). Spending time in the two ECE settings allowed me (as the researcher) to develop a rapport with the teaching staff, parents and children of the centre prior to interviewing or observing them. This assisted in a greater understanding of the context and the children's engagement.

Case studies for this research were undertaken in two ECE centres around New Zealand. These two centres were randomly chosen from the list of centres that showed their interest in the final question of the online national survey. Centres were eligible to indicate their interest if they fitted the following criteria: they were using an e-portfolio programme and had been doing so for at least one year; they had a number of children aged three-four years of age who could talk about their e- portfolio involvement; and they had not been involved in another research study in the last two years. From this list two centres were randomly selected using a random number generator and contacted about being a case study centre. One of the case study centres was located in a main city, had 77 children on the roll and 11 teaching staff whilst the other was in a smaller town, had 43 children and five teaching staff. Both services had been using e-portfolios for at least a year and all children had their own e-portfolio. 


\subsubsection{Case study online survey.}

Before the site visits began two different online surveys were sent to the two centres to be distributed; one to parents and family members and the other to teaching staff. The teachers' survey built on the original national survey, however asked more specific questions about teachers' own practices regarding children's engagement with eportfolios. The survey was designed to be completed easily, in order to gather the most responses, and had nine quantitative questions and one qualitative question to enable a basic understanding of their practices with e-portfolios before commencing interviews. Two of the quantitative questions asked for a reason for respondents' choices thus allowing further depth to their responses. (See Appendix $M$ for the survey instrument).

The parents' and family members' survey differed in that it sought to discover more about children's engagement with their e-portfolio within their home and community context. The survey consisted of two initial quantitative questions to establish whether respondents were parents or wider family members. Wider family members, such as grandparents, aunties, uncles, or siblings, are included in this study as many have their own login to view a child's portfolio. Those who identified as anything other than a parent were directed to three further quantitative questions to understand their involvement with the child's e-portfolio. Those who identified as parents were asked a further eight quantitative and one qualitative question to develop an understanding of how children were engaging at home alongside their family. As with the teaching survey the parents' survey asked for a reason for their choice in three of the quantitative questions. (See Appendix $\mathrm{N}$ for the survey instrument).

\subsubsection{Case study site visits.}

After the distribution of the online survey to centres the case study site visits commenced. Each visit involved four days in the centre gathering data through interviews with parents, teachers and children, as well as observation and document analysis from the centre environment. There was an option of a fifth day of data collection, Saturday, for those families or teachers who were unable to be part of the data collection during the week. On this fifth day data would be collected in participants' homes, offering the opportunity to see how children engage with their eportfolios in their home setting. In both site visits the fifth day of data collection was not used as whilst parents supported the study, all preferred to be interviewed within 
the centre environment due to other external commitments. (See Appendix K for the case study protocol).

All centre families were invited to take part in the data collection in two ways. Parents could request general permission for themselves and/or their child to be observed in daily interactions regarding their child's engagement with their e- portfolio. Parents were also invited to be involved further through interviews with themselves and/or their child, as well as general observation of themselves/their child and analysis of their child's portfolio throughout the data collection week. Parents were given information and permission letters prior to commencing site visits and I then approached families upon arrival in the centre to further explain the project to ensure each family felt fully informed. (See Appendix $\mathrm{F}$ and $\mathrm{H}$ for information letter). The consent form asked parents to tick the aspects of the study which they gave consent for their child or themselves to be involved in. This allowed families to be involved to the degree that they felt comfortable. Any family or child who had not given permission to be part of the project was not excluded from interactions but were not recorded as part of the data collection. All teaching staff were invited to give consent for their involvement in an interview as well as consent to be observed. All full-time teaching staff in both settings gave their consent to be involved in the study however not all teachers participated in an interview. (See Appendix G and I for consent forms).

\subsubsection{Interviews with adults and children.}

Interviews are interpersonal encounters where researchers have the chance to develop a rapport with participants and learn more about their perspective (Johnson $\&$ Christensen, 2012). This is why they are one of the most valuable methods of data collection as they allow a fluidity of conversation, stemming from, but not restricted to, specific pre-set questions (Yin, 2009). Interviews also allow participants to share openly about their perspective, arguably more so than they would in a written medium (Cohen et al., 2000). Interviews for this study occurred in the case study settings during the site visits with teachers, parents and children. The interviews followed an open-ended questioning approach. This approach gave depth to the data and helped guide the conversation to gain the most relevant information (Yin, 2009). 
Each interviewee was asked if they were comfortable with our conversation being audio-recorded to ensure an accurate recording of responses and to enable me to be wholly involved in the discussion. All parents and teachers were comfortable with being audio-recorded, and it assisted in a flexibility and accuracy of conversation, particularly in interviews with three or more parents. Interviews with parents were casual in nature, using open-ended questions to lead the discussion and were conducted in a space where they were most comfortable - either in the staffroom or a space in the centre. In order to ensure data reliability, any comments I was uncertain of were clarified with the interviewee to ensure a correct understanding. Due to the number of interviews undertaken full transcripts were not made available to participants. However upon request they could receive a summary of their interview if they desired, and these summaries were sent out within a few weeks of the site visit having been completed.

One of the most valuable forms of data collection for this study was the informal conversations with children. These enabled me to speak one-on-one with children to understand their views and experiences with this online form of documentation. Only children who I had received parent consent to talk to were approached regarding an informal conversation and children were then asked for their consent to speak with me. If a child declined I then stepped away and allowed them to continue what they were doing. However if they gave their consent they were asked to confirm this on a child consent form (Phelan \& Kinsella, 2013). This form had their name and three simple emoticon faces which portrayed sad, neutral and happy. (See Appendix J for the child consent form). Children were read the statement across the top regarding their consent and then were asked to colour which face they felt - smiley faces were an indication that I could undertake an informal conversation. Due to the nature of these informal conversations notes were taken instead of an audio-recording whilst children showed me their e-portfolio. This allowed our conversations to be more natural and relaxed. Parents were given the opportunity to receive a summary of their child's conversation if they wished and these were emailed to parents a few weeks after the completion of the site visits.

\subsubsection{Observation and document analysis.}

Observation and document analysis are both methods of data collection that allow 'live' data to be observed that may have been missed through alternative methods 
(Cohen et al., 2000). Observations are spontaneous in nature and allow researchers to gather relevant and, at times, unexpected data that assists in the researcher understanding the investigated phenomenon (Cohen et al., 2000; Yin, 2009). In observational vignettes the "product and the process are both embedded" (Podmore, 2006 , p. 14) which assists in developing a fuller understanding of the situation. Observations allow for data to be collected from participants, their interactions and connections as well as through the physical environment, programme and resources (Cohen et al., 2000).

Observations in this research were gathered across the centre's daily programme and routines, as well as from observing interactions, discussions and viewing wall displays. The data was written up as observational vignettes, similar to a narrative style of observation, and which included details about the location, environment, context and interactions to ensure the moment was accurately captured (Podmore, 2006). In order to lessen observer bias I observed as objectively as possible and then noted down any reflective thoughts following the vignette that related to the observation.

Within this study my role as an observer moved between being a "complete observer" to "observer-as-participant" (Cohen et al., 2000, p.305), depending upon each situation and its relevance to the research (Goodman, 2013). Within this research an "observer as participant" (Cohen et al., 2000, p.305) was exemplified in situations where I viewed a child's online portfolio alongside them - therefore contributing to document analysis, or in situations where I partook in discussions and interactions related to e-portfolio engagement. Consent was given prior to looking at any e-portfolio and I also asked for permission from children before viewing their portfolio, preferring to invite them to show it to me instead of just viewing it myself. No photos were taken from the portfolios, only observational notes and descriptions.

\subsection{Data Analysis}

Whilst the national survey data assisted in informing the case study protocol, full data analysis commenced after the completion of case study data collection. The online surveys were created using Qualtrics Survey software, which managed the data during the collection period and then enabled descriptive statistics to be presented in tables. I transcribed the qualitative data from the surveys and case 
studies, coded the data into themes and then used thematic analysis to examine the findings.

\subsubsection{Thematic Analysis.}

Thematic analysis is one of the most common forms of qualitative data analysis due to its accessibility to researchers in different fields and its lack of complexity in implementation (Howitt \& Cramer, 2007). Thematic analysis requires the researcher to be wholly involved in the process (Guest, MacQueen \& Namey, 2012) drawing more on the emerging ideas and themes from the data rather than focusing on explicit details (Guest et al., 2012). In this way researchers need to be very familiar with their findings, preferably conducting the research themselves, in order to assist in developing accurate conclusions that represent the elements collected (Howitt \& Cramer, 2007). Thematic analysis is conducted through the process of coding in which data is grouped together according to different emerging themes; there is no definitive process for how to do this and it alters depending on the different fields of research (Howitt \& Cramer, 2007). This form of analysis relies upon researchers to code the collected data without allowing their personal interpretations to impinge on the decisions made (Guest et al., 2012). For this study the qualitative responses from the national survey and case study data were coded allowing themes to emerge related to how children engaged with their learning through e-portfolios. These themes assisted in developing overall conclusions that shed light on this topic.

\subsection{Ethics}

Gaining ethical approval is vital when undertaking any form of empirical research, particularly in studies involving humans, as it helps to prevent harm to participants and protects their point of view (Johnson \& Christensen, 2012). Ethical approval was received for this research project from the Victoria University of Wellington Human Ethics Committee before the commencement of data collection (Application \#21198, 26/08/2014).

\subsubsection{Ethical issues.}

The protection and treatment of participants is one of the primary ethical concerns in research with human subjects (Johnson \& Christensen, 2012). These aspects require extensive consideration and must be treated seriously by researchers (Phelan \& Kinsella, 2013). In this way it is important as a researcher to anticipate and explain any risks, where necessary, to participants and endeavour to expunge any potential 
areas of harm for them or oneself (Phelan \& Kinsella, 2013). In this study all participants were provided detailed information explaining the project, were given the opportunity to ask questions and were not pressured to be involved if they were not comfortable. All involved participants were protected with pseudonyms and no identifying factors were included about individuals or centres to ensure that no participant could be identified. Consent from participants meant that data could be collected from them and/or their children and used in the thesis, subsequent conference presentations and publications using pseudonyms to protect all identities.

Ethical aspects were addressed in both the national and case study surveys through their design. The national survey was distributed by email which included an overview of the purpose of the research and a statement regarding informed consent to participate, as well as a link to the survey. By clicking on the link participants were deemed to have given consent. The information indicated that at any stage participants could withdraw from the survey although all previous responses would be recorded. In order to ensure the greatest participation each question was designed as a forced response so that participants could not continue without answering the question. Forced response encouraged participants to either complete all questions or withdraw part way through rather than only completing some questions throughout the survey. These design decisions were made based on feedback from the Ethics Committee.

The survey responses were confidential and a statement made in the information letter ensured that centres would not be identified based on their responses and there would be no links between their responses and their email addresses. Those responding centres interested in being part of the case studies were the only centres that identified themselves with their email address; however they were not linked to their responses, except to confirm the e-portfolio programme provider they used. The same ethical procedures were adhered to for the case study surveys.

As noted earlier, the case study centres were randomly selected from the list of interested centres in the national survey. All information sheets and consent forms were posted to the centres prior to the commencement of the visit, with the opportunity for further explanation by email or when I arrived. Parents were invited to give consent for their child to be involved in different aspects of the case study: 
for general involvement in the case study; for their e-portfolio to be viewed; and for their involvement in informal conversations and more in-depth observations. They were also asked to give permission for their own involvement in the case study, both as part of general observations and for more in-depth interviews. Those who did not give permission were not included in data collection but were not excluded from any experiences where they were involved. Upon completion of the data collection, those who had participated in an interview could request a summary of the transcript; they were then given two weeks to decide whether they wanted any changes to be made to their summary or if they wanted to withdraw from the data collection. No participant withdrew from the study after reading these summaries.

Parents and children were given the option to be interviewed and observed at home. This was an aspect to be treated with great ethical consideration particularly in regards to the way researchers dresses and behaves whilst in a participants' home (Phelan \& Kinsella, 2013) to ensure participants feel relaxed and comfortable. Whilst this was an option provided to families in both site visits no data was collected outside of the centre.

\subsubsection{Engaging in research that involves children.}

My ethics application focused specifically on conducting research with children and including their voice as they will provide critical data on this topic. Since the introduction of the United Nations Convention on the Rights of the Child (UNCROC) in 1989 there has been a significant shift from viewing children as passive to seeing them as active participants who make a valuable contribution to their own learning and future (Lewis, 2010; Loveridge, 2010). This shift altered the way in which research with children is conducted and brought to light the considerations required when researching with children - particularly with regards to consent. Regardless of these shifts it is still necessary to be primarily gaining consent from the children's parents regarding their children's involvement before speaking with children; then gaining assent from the child at the time of the interaction (Loveridge, 2010).

When conducting research involving children it is important to develop a study that is safe for the children, allows them dignity and most importantly encourages their voice (Phelan \& Kinsella, 2013). These three aspects are crucial to research with 
children and require strong researcher reflexivity when constructing and enacting this research (Phelan \& Kinsella, 2013). Building a strong rapport with children before undertaking data collection helps to diminish any power imbalances, as children begin to trust and feel comfortable with the researcher which assists in genuine data collection (Phelan \& Kinsella, 2013). This also includes the power of body language, recognising non-verbal cues and using sensitivity to ensure children feel comfortable in the environment (Phelan \& Kinsella, 2013). An important part of research with children is ensuring that children who are not willing or allowed to be part of the research are not excluded from interactions (Phelan \& Kinsella, 2013). This is important as children should not feel excluded or undermined as a result of their choices and instead should be included with respect for their decision. Having both their verbal and written consent gave me confidence in the data I was collecting as well as showed children that I valued their contribution to the study.

By drawing on the opinions and experiences of children, as well as viewing their eportfolios alongside them, I was able to gather a greater understanding of what children were learning and I was able to add these understandings to the data collected with the parents and teaching staff.

\subsection{Validity and Reliability}

Within any empirical study validity and reliability are critical aspects to be addressed in order to ensure that the collected data and associated inferences are a sound and accurate reflection of the phenomena being studied (Johnson \& Christensen, 2012). Whilst it is impossible to assure complete validity and reliability in research the use of both qualitative and quantitative data methods ensures a triangulation of results, as the different strengths of each approach assist in strengthening the inferences made (Johnson \& Christensen, 2012). By ensuring validity in studies, results are not only considered to be accurate but can also help to establish conclusions across populations - thus enabling research to be of use across wider sectors to develop inferences and to implement change (Wiersma, 2000). Within this study, the data collected through the online surveys, interviews, observations and document analysis assisted in drawing consistent overall themes and reliable conclusions regarding children's engagement with their learning using e-portfolios. 
In order to strengthen validity considerable efforts were made to ensure that data collection processes were consistent and fair through the different strategies and within the different case study settings (Johnson \& Christensen, 2008). Trustworthiness of the qualitative data was ensured through focusing on researcher reflexivity. This helped manage researcher bias through noting any additional reflections from interviews or observations thus keeping any subjective views out of the data collection (Johnson \& Christensen, 2012). Interviews and informal conversations were audio-recorded, where possible, which allowed accurate transcriptions to be made. Any confusion about comments made by interviewees was clarified and corrected (member checking) to ensure reliable data collection (Johnson

$\&$ Christensen, 2012). The conclusions made from the data collection assist in drawing overall themes as the findings are representative of participating centres at the time of data collection. These themes can be used to gather an understanding of a topic based on the centres involved however cannot be generalised to a greater population.

\subsection{Conclusion}

This chapter outlined and explained the chosen approaches to data collection and analysis employed in this research. Through using a mixed method research design, both qualitative and quantitative forms of data were collected through surveys, interviews, observations and document analysis in order to investigate children's engagement with their learning using e-portfolios. The mixed method approach allowed for stronger validity and reliability of findings and helped to ensure valid inferences could be developed. Ethical considerations were addressed to ensure that the findings were accurate and confidential; paying particular emphasis to the implications of undertaking research with children to ensure they were respectfully included. The next two chapters present the results from the online survey and case study visits. 


\section{Chapter Four: National Online Survey Results}

\subsection{Introduction}

This chapter reports the quantitative and qualitative data from the national online survey component of the study. Each question in the survey is reported, with themes and responses grouped to examine trends within the data. The chapter begins with demographic information about the online survey participants.

\subsection{Demographic Data}

The survey invitation was emailed to a total of 2,315 education and care and kindergarten services around New Zealand. A total of 876 (37\%) recipients opened the email, which contained background information about the study and online survey including ethical considerations and informed consent. Only services that used eportfolios were eligible to take the survey and $146(16 \%)$ started the survey by opening the email link which displayed the informed consent page. From this 115 commenced the survey by clicking to the first question; this indicated their consent to partake in the survey.

Table 4.1: Geographic location of early childhood services

\begin{tabular}{lcr}
\hline Region & Number & \% \\
\hline Northland & 6 & $5 \%$ \\
Auckland & 35 & $30 \%$ \\
Waikato & 16 & $14 \%$ \\
Taranaki & 0 & $0 \%$ \\
Bay of Plenty & 9 & $8 \%$ \\
Hawkes Bay & 5 & $4 \%$ \\
Manawatu/Whanganui & 7 & $6 \%$ \\
Wairarapa & 1 & $1 \%$ \\
Wellington & 18 & $16 \%$ \\
Marlborough/Nelson Tasman & 3 & $3 \%$ \\
Canterbury & 10 & $9 \%$ \\
West Coast & 0 & $0 \%$ \\
Otago & 5 & $4 \%$ \\
\hline Total & $\mathbf{1 1 5}$ & $\mathbf{1 0 0 \%}$ \\
\hline
\end{tabular}


Responses represented a good nationwide spread with the largest number of responses coming from Auckland $(\mathrm{N}=35 ; 30 \%)$, Wellington $(\mathrm{N}=18 ; 16 \%)$ and Waikato $(\mathrm{N}=16 ; 14 \%)$ (see Table 4.1).

Respondents were then asked about the number of children their setting was licensed for. Eighty settings were licensed for between 30-60 children (70\%) with 10 services licensed for under 30 children (9\%) and 25 services licensed for over 60 children $(22 \%)$.

In order to understand the e-portfolio programmes used, ECE services were asked which provider they used and for how long. The two main e-portfolio providers used by respondents were Educa $(\mathrm{N}=57 ; 57 \%)$ and StoryPark $(\mathrm{N}=27 ; 27 \%)$. The option 'none' was provided and three respondents $(3 \%)$ indicated this.

Thirteen settings (13\%) indicated that they used another e-portfolio platform and were asked to specify which. Their responses are listed below:

- Webmail

- Infocare $(\mathrm{N}=2)$

- Blogger $(\mathrm{N}=2)$

- We were using Infocare, now using StoryPark

- Both Educa and StoryPark at present

- Roots and shoots

- Growing Kiwis $(\mathrm{N}=2)$

- Our own website

- Kinderloop

- None right now.

Almost half of the respondents indicated they had used e-portfolios for less than one year $(\mathrm{N}=49 ; 49 \%)$. However $36 \%$ had been using e-portfolios between one to two years $(\mathrm{N}=36)$, with $15 \%$ longer than two years $(\mathrm{N}=15)$.

The survey asked the number of children within each setting who had an e-portfolio and how often teachers were adding stories to these. Over half of the 100 settings that responded to this question indicated that all children had their own e-portfolio $(\mathrm{N}=56 ; 56 \%)$ with a further $30 \%$ indicating that $75 \%$ to $100 \%$ of their children had 
one. Fourteen percent of respondents shared that less than $50 \%$ of children in their setting had their own portfolio. Overall, most children in the settings surveyed do have their own e-portfolio.

Respondents were asked about the frequency with which new stories were added to children's e-portfolios (see Table 4.2).

Table 4.2: Frequency that new stories were added to children's e-portfolios

\begin{tabular}{lcc}
\hline Frequency & Number & \multicolumn{1}{l}{$\%$} \\
\hline At least once a week & 25 & $25 \%$ \\
Once a week & 10 & $10 \%$ \\
Once a fortnight & 27 & $27 \%$ \\
Once a month & 32 & $32 \%$ \\
Less than once a month & 6 & $6 \%$ \\
\hline Total & $\mathbf{1 0 0}$ & $\mathbf{1 0 0 \%}$ \\
\hline
\end{tabular}

Thirty-five percent $(\mathrm{N}=35)$ of settings surveyed said that stories were uploaded to children's portfolios once a week or more, with $59 \%(\mathrm{~N}=59)$ indicating additions at least once a fortnight to once a month. This shows there is significant input of stories by teachers to children's portfolios from the settings involved in the survey.

\subsection{Children's Engagement with their E-portfolio}

Several survey questions examined the engagement children have with their eportfolio. Centres were asked about the opportunities provided within the setting for children to access their e-portfolio (see Table 4.3). Eighty-nine centres responded to this question with seventy-three settings indicating that they provided either a computer or electronic device, such as iPad, tablet or mobile phone, for children to access their e-portfolio. Fifty-seven centres (64\%) had both online and hard-copy portfolios for children's access. Conversely, nine centres $(10 \%)$ had no access for children within the centre. 
Table 4.3: Opportunities provided for children to access their e-portfolio within the centre

\begin{tabular}{lcc}
\hline Engagement & Number & $\mathbf{\%}$ \\
\hline Use of centre computer & 24 & $27 \%$ \\
Use of centre iPad or other electronic device & 40 & $45 \%$ \\
Use of iPhone or Android phone & 9 & $10 \%$ \\
Keep a hard-copy as well as an online copy & 57 & $64 \%$ \\
Children can access with a staff member on the staff computer & 45 & $52 \%$ \\
No access available & 9 & $10 \%$ \\
Other (please specify) & 8 & $9 \%$ \\
\hline
\end{tabular}

Those who selected Other were asked to specify what opportunities they provided for children's access. Their responses were as follows:

- Hard copies of stories available in centre for infants and toddlers

- They still have a paper copy to access

- Data projector

- Plan to have iPads

- Via projector

- This is a new process for us and children's stories are still available to them in hard-copy portfolios which they can revisit at any time as they are in the playroom.

- Children access hard-copy all the time. Hardly ever online.

- Learning screen via Apple TV and iPad.

Table 4.4: Frequency children revisit their e-portfolio

\begin{tabular}{lcr}
\hline Frequency & Number & \multicolumn{1}{l}{$\%$} \\
\hline Every day & 4 & $5 \%$ \\
3 - 4 times a week & 9 & $10 \%$ \\
1 - 2 times a week & 17 & $19 \%$ \\
Once a fortnight & 8 & $9 \%$ \\
Less than once a fortnight & 32 & $36 \%$ \\
Never & 19 & $21 \%$ \\
\hline Total & $\mathbf{8 9}$ & $\mathbf{1 0 0 \%}$ \\
\hline
\end{tabular}


A further question asked how frequently children were revisiting their e-portfolios whilst in the centre. Table 4.4 above shows the varied responses provided for this question.

Thirty-four percent of centres $(\mathrm{N}=30)$ specified that children in their centre were revisiting their e-portfolio at least once or twice a week. Less engagement was indicated by $45 \%$ of centres $(\mathrm{N}=40)$ who said that children engaged once a fortnight or less. Nineteen centres (21\%) shared that children never revisited their portfolio; which could be due to not having access, or children not being interested in their e- portfolio.

Survey participants were then asked about how children preferred to revisit their eportfolio and were invited to select all applicable choices from a range of options (see Table 4.5).

Table 4.5: Children's preference for revisiting their e-portfolio

\begin{tabular}{lcc}
\hline Preference & Number & \% \\
\hline Independently & 19 & $21 \%$ \\
Alongside their peers & 25 & $28 \%$ \\
Alongside a teacher & 49 & $55 \%$ \\
Alongside a teacher and their peers & 41 & $46 \%$ \\
Not applicable & 21 & $24 \%$ \\
\hline
\end{tabular}

Eighty-nine centres answered this question with the majority of responses indicating that children preferred to revisit their e-portfolio either alongside a teacher or a teacher and their peers. Nineteen respondents $(21 \%)$ shared that children viewed their eportfolio alone; and 25 (28\%) said children preferred to do so alongside their peers. Respondents were asked to select not applicable if children did not engage with their e-portfolio: twenty-one settings (24\%) selected this option.

Engagement goes further than children simply revisiting their e-portfolio to also include contribution to documentation practices; both for their own portfolios and to wider centre planning. Table 4.6 presents the responses indicating children's 
contribution to centre documentation practices. Respondents were encouraged to select all relevant responses.

Table 4.6: Role children have in documentation practices in the centre

\begin{tabular}{lcc}
\hline Role of child & Number & $\mathbf{\%}$ \\
\hline Taking photos to contribute to stories & 59 & $6 \%$ \\
Dictating stories or adding their voice & 62 & $79 \%$ \\
Assisting in writing up their story on the computer/iPad & 28 & $36 \%$ \\
Reading and/or reflecting on their stories with peers or teachers & 59 & $76 \%$ \\
Sharing the stories with their peers or putting up stories on the walls & 61 & $78 \%$ \\
Other (please explain) & 6 & $8 \%$ \\
\hline
\end{tabular}

Seventy-eight settings answered this question, with a mixed spread across all options. Sixty two responses (79\%) indicated that children had an active role in dictating stories or adding their voice and 61 (78\%) reported that children shared stories: either with their peers, or by adding documentation to the walls. Fifty nine (76\%) centres indicated children's engagement through taking photos to contribute to stories and reading/reflecting on their stories with peers or teachers. Only 28 centres $(36 \%)$ reported that children assisted with writing up stories online.

Four of the six respondents who selected Other gave the following examples: children chose the artwork for their profiles, children contributed to centre-wide planning, and children contributed if they asked a teacher. Two wrote that children did not have a role in documentation within their centre.

The next question differed slightly in that it asked centres the ways children were encouraged to contribute to documentation and learning with their own e-portfolio. This question sought to understand how teachers were encouraging children in revisiting, extending and supporting their own learning through their e-portfolio. Many of the fixed choices were the same as the previous question as the role of a child would be similar in both their own and centre-wide documentation practices. (see Table 4.7). 
Table 4.7: Ways children encouraged to contribute to their e-portfolio

\begin{tabular}{lcc}
\hline Role of child & Number & $\mathbf{\%}$ \\
\hline Taking photos to add to stories & 52 & $67 \%$ \\
Dictating stories or adding their voice & 49 & $63 \%$ \\
Assisting in writing up their story on the computer/iPad & 23 & $29 \%$ \\
Contributing comments or responses to those provided on their e-portfolio & 45 & $58 \%$ \\
Other (please explain) & 13 & $17 \%$ \\
\hline
\end{tabular}

Seventy-eight settings responded to this question and the responses indicated that children were less likely to contribute to documentation with their own e-portfolio. The most common form of contribution by children was taking photos to add to their online stories $(\mathrm{N}=52)$. Forty-nine responses showed that children dictated or added their voice to stories and forty-five shared that children contributed comments or responses to those provided on their e-portfolio, either by family members or teachers. Twentythree responses indicated children assisted in writing up stories online. This was the lowest form of contribution in the centre-wide documentation as well, possibly indicating an area where more support is needed.

Those who selected Other were asked to explain the alternative ways children contributed to their e-portfolio and their responses were categorised into the following themes: children adding photographs of their artwork to their e-portfolio; adding stories from home; or teachers predominately do the stories unless children requested to help. Five of the thirteen (17\%) who selected Other indicated that children did not contribute to their e-portfolio.

Survey respondents were asked to provide an example of the connections they had observed children making in their conversations and play that related to their eportfolio engagement and learning (Table 4.8). 
Table 4.8: Children's connections between online engagement and their play

\begin{tabular}{lcc}
\hline Connections being made by children & Number & $\mathbf{\%}$ \\
\hline Yes, frequently & 11 & $14 \%$ \\
Yes, occasionally & 33 & $42 \%$ \\
We have not noticed this & 34 & $44 \%$ \\
\hline Total & $\mathbf{7 8}$ & $\mathbf{1 0 0 \%}$ \\
\hline
\end{tabular}

Of the eleven respondents who selected that they had noticed frequent connections made by children, five gave an example. These examples identified that children made connections between their e-portfolio and future planning, revisited learning, interests and ideas and retold stories. One response indicated that children asked their teachers for their activities to be uploaded to their e-portfolio as well as conversed with their peers about which pictures to upload.

Thirty-three respondents indicated that they had noticed occasional connections being made and sixteen gave one or more examples to support their choice: two identified that children used their e-portfolio to plan for and try new activities or interests; ten suggested children reflected upon and revisited activities with teachers or peers as a result of their e-portfolio; and nine examples related to communication and discussions between children, teachers and peers that related to e-portfolio content.

Thirty-four respondents selected 'we have not noticed this' and eight of these thirtyfour provided an example to support their choice. Three respondents commented on how children preferred to engage with their hard-copy portfolio; three indicated that eportfolios are new to their centre and so they had not yet observed any connections by children with one indicating it was not applicable. One respondent said "we leave it up to parents to show their child their online portfolio" and another said they will "look for evidence of [connections] in future".

\subsection{Children's Home Engagement}

Children's engagement with their learning does not occur purely within the centre setting and the next section shares the data collected from questions which examined parent involvement and children's engagement at home. The first question explored 
connections made between the child's home and their centre setting by teachers, by parents and by children, with respondents asked to provide supporting examples for their choice.

Table 4.9: Connections made between home and centre by parents, teachers and children

\begin{tabular}{lcccc}
\hline Connections made & Yes & No & $\begin{array}{c}\text { Not } \\
\text { Applicable }\end{array}$ & $\begin{array}{c}\text { Total } \\
\text { Responses }\end{array}$ \\
\hline By children & 35 & 19 & 10 & 6 \\
By parents & 71 & 2 & 1 & 74 \\
By teachers & 58 & 5 & 2 & 65 \\
\hline
\end{tabular}

Of the 64 respondents who provided an answer for the connections made by children 35 indicated that they had observed children making connections, 19 indicated that they had not, and 10 chose not applicable to their setting. Of those 64 responses 31 examples were provided to support their choice. Only one of these comments related to a no response, saying children did not share their voice on their e-portfolio. The other 30 comments related to a yes response and were categorised into 9 themes. Comments sometimes touched on more than one theme, and both have been included.

- Children talking about their stories and linking to home $(\mathrm{N}=8)$

- Sharing whānau stories from home $(\mathrm{N}=8)$

- Adding their own voice $(\mathrm{N}=4)$

- Adding photos $(\mathrm{N}=3)$

- Making connections to their learning from hearing parent comments $(\mathrm{N}=2)$

- Revisiting home experiences in the centre $(\mathrm{N}=1)$

- Children asking to see their e-portfolio $(\mathrm{N}=1)$

- Parent contribution $(\mathrm{N}=1)$

- Not applicable/unsure $(\mathrm{N}=2)$

Seventy-four responses were collected regarding connections being made by parents; 71 said that yes they had noticed connections whilst two said no and one selected not 
applicable. Of those 74 responses, 62 gave a comment to support their yes selection and were coded into seven themes. Comments again included more than one theme and both were included.

- Parent comments on stories $(\mathrm{N}=31)$

- Writing home stories $(\mathrm{N}=23)$

- Conversing with teachers in centre and providing feedback $(\mathrm{N}=11)$

- Reinforce learning within the home $(\mathrm{N}=3)$

- Read stories during day to contribute to end of day conversation $(\mathrm{N}=3)$

- Adding wider family to e-portfolio $(\mathrm{N}=2)$

- Contribution from only some families $(\mathrm{N}=1)$

Sixty-five provided a choice for connections being made by teachers between the home and the centre; with 58 saying that yes they had observed connections, five saying no and two indicating not applicable. Of those 65 responses, 56 gave an example and all but one of these comments related to noticed connections from those who chose yes. One comment was made in regards to a 'not applicable' selection about parent contribution. The other 56 comments were coded into eleven themes; again comments could include more than one theme:

- Teacher comments $(\mathrm{N}=17)$

- Share children's learning/images with children and families $(\mathrm{N}=10)$

- Extend children's learning based on comments and family stories $(\mathrm{N}=4)$

- Develop strong teacher/parent relationships around children's learning $(\mathrm{N}=8)$

- Making stronger links between home and the centre $(\mathrm{N}=6)$

- Ask questions of parents $(\mathrm{N}=2)$

- Writing stories about connections made by children $(\mathrm{N}=2)$

- Reflecting on their own practice $(\mathrm{N}=2)$

- Parent contribution $(\mathrm{N}=2)$

- Managing centre-wide/community activities $(\mathrm{N}=1)$

- Using Skype to connect families $(\mathrm{N}=1)$

- Discussing learning with children $(\mathrm{N}=1)$

Participants were then asked to provide examples on their understanding of how parents were revisiting learning with their children at home and could select more than one choice (see Table 4.10). 
Table 4.10: Ways parents revisit e-portfolios at home with children

\begin{tabular}{lcc}
\hline Ways parents revisiting & Number & \% \\
\hline Reading the stories aloud with their child at home & 44 & $57 \%$ \\
Letting the child review their portfolio independently at home & 22 & $29 \%$ \\
Using the stories online to make connections to learning interests at home & 50 & $65 \%$ \\
Contributing new stories from home with their child & 54 & $70 \%$ \\
Sharing the e-portfolios with their child and wider family members & 56 & $73 \%$ \\
Not sure how parents revisit the portfolio with their children & 22 & $29 \%$ \\
Other (please explain) & 4 & $5 \%$ \\
\hline
\end{tabular}

Seventy-seven responses were given for this question indicating the most common way parents revisited their child's e-portfolio was sharing learning stories with their child or with extended family and reading stories aloud with their child $(\mathrm{N}=100)$ as well as writing stories in collaboration with their child $(\mathrm{N}=54)$. Other responses indicated parents made connections to their child's interests $(\mathrm{N}=50)$ whilst only 22 responses showed that parents let children revisit their e-portfolio independently. Twenty-two respondents also commented that they were not sure how parents were revisiting with their child at home.

Of the four respondents who selected Other three gave further evidence to explain their choice: two said they were not sure; however they do see examples of engagement with some parents; and one who said video content was mainly used with their eportfolios.

\subsection{Differences in Children's Engagement between Online and Hard-copy}

In order to gather a greater understanding of any potential difference between children's engagement with their learning using e-portfolios or their traditional hard- copy portfolio, the survey asked centres who have used both to share the ways which children engage differently with their learning between e-portfolios and hard-copy portfolio. Centres that did not have both mediums of documentation were asked to respond with not applicable. The responses to the question were analysed into categories and are expanded upon with direct quotes from the survey. 
Forty-seven (52.8\%) respondents indicated that children preferred their hard-copy portfolio or only had access to their hard-copy to revisit their learning:

- The children have very easy access to their hard-copy portfolios with them being down at their level. We generally don't show them their e-portfolios.

- Our children prefer their hardcopy profile books; they enjoy reading them independently, but also sharing them with friends. Often more than one will sit together to read their books at the same time - something that isn't possible with the e-portfolios. We look at the e-portfolio only if we are sharing the video that was uploaded. The hard-copy is actually more accessible to the children in the ECE environment.

- Children have taken more ownership with the hard-copy as it is easy for them to access on their own and they can quickly add their own work using basic tools.

Twenty-eight $(31.5 \%)$ respondents indicated that children had either no access or were not able to engage with their e-portfolio whilst in the centre:

- As there are at present no computers in the room they don't have access to the e-portfolio at the centre

- We do have iPads here which the children use, but have not thought to use them to look at their portfolios, might be a good idea we can try.

Twenty (22.3\%) responses noted how children only accessed their e-portfolio with a teacher or on a large screen as a group:

- We do access [e-portfolio] on the iPad but a teacher has to be present when using the iPad (one of our centre rules for using the iPad).

- Accessing online is too hard for them and in practice they don't ask to see it online unless a teacher brings up another child's first.

- When they are online they prefer to look for games rather than look or listen to their stories. There is a lot more teacher direction with online rather than hard-copy.

Twelve (13.5\%) comments mentioned how much children enjoyed and became excited by engagement with their e-portfolio:

- With the e-portfolio the students are far more engaged and it tends to be much more communal in nature...when a computer is involved there seems to be a lot more interest.

- Online is in colour, pictures are bigger than the black and white in profile books so children enjoy looking at online profiles better.

- Children are more motivated to engage with the technology and most love to watch and share videos of them that are uploaded onto [e-portfolio]. The learning becomes much more exciting and visible to them in this way. 
Ten $(11.2 \%)$ comments showed that centres had observed children being shown their e-portfolio at home but not within the centre:

- I do know they view them at home with parents and this is instant rather than waiting for their portfolio to have a story and come home with it.

- We have had feedback from parents that some of our children look at their portfolios at home on the computer/iPad/iPhone etc with their parents.

Conversely, nine $(10.1 \%)$ comments acknowledged that they felt e-portfolios are purely for parent and whānau engagement and hard-copy portfolios were for the children:

- E-portfolios are used with the audience of parents and whanau in mind...Hard copies are slightly different with the audience being for children and their peers so there are bigger photos and shorter stories.

- Children are not really aware of the presence of the e-portfolios as currently they are utilised by parents.

- It is our impressions from parental comments that whānau do not share the tamariki's [eportfolio] stories with them at home.

Two respondents commented on how both mediums of documentation had their individual uses and purposes.

Twenty-three $(25.8 \%)$ of the 89 respondents indicated that this question was not applicable to them.

The next question asked participants the extent to which they felt using an eportfolio had influenced children's engagement with their learning compared with their hard-copy version. Respondents were asked to provide a reason for their choice.

Table 4.11: Extent that e-portfolios influence children's engagement with their learning compared with hard-copy portfolios

\begin{tabular}{lcc}
\hline Extent of engagement & Number & \% \\
\hline A great deal & 12 & $16 \%$ \\
Quite a lot & 19 & $25 \%$ \\
A little & 27 & $35 \%$ \\
Not at all & 19 & $24 \%$ \\
\hline Total & $\mathbf{7 7}$ & $\mathbf{1 0 0 \%}$ \\
\hline
\end{tabular}


Of the 77 respondents to this question, 37 (48\%) gave examples to support their response. The responses are grouped into four categories and expanded upon below.

Twelve respondents (16\%) felt that children's engagement with their learning had been influenced a great deal as a result of e-portfolios and eight of these gave examples of support. Five of the eight wrote about children having a greater involvement and contribution in the documentation process; two of these five also wrote of children's enjoyment in engaging with their e-portfolio. Three of the comments identified that e-portfolios encouraged greater discussion between teachers and children and amongst children themselves, particularly with group stories and videos:

Children are becoming so familiar and skilled at using the centre iPads; they then share what is happening to peers and teachers. The use of the large screen means larger groups can talk about what is happening, asking questions, talking to their learning, even "what am I going to do next?"

One further comment acknowledged that e-portfolios are up-to-date and so there are greater connections made with parents which are reflected into discussions with children at the end of the day.

Of the 19 respondents that felt that there was quite a lot of influence on children's learning nine gave examples of further support. These comments showed greater engagement of children in the documentation process: shared learning with family and friends, contribution of their perspective and own stories, engagement with videos and greater group discussion. One respondent commented "teachers are doing stories straight away with children rather than waiting for non-contact and the child is there and engaged at the time." Other comments showed indicated improved communication between parents and teachers; one commenting that not all parents engaged but overall interactions were increased and more comfortable.

Eleven of the 27 respondents who felt there was a little influence on children's engagement gave examples to support their selection. Four of these comments showed little change as teachers were either unsure or still developing their confidence in using the programme. Five of the comments noted the greater interest children have in viewing photos and being part of the documentation process; with 
two comments sharing greater engagement by families in children's learning. Two further comments make note of the fact that children have little access or understanding of their e-portfolio: "some children have been surprised that we know what they do at home and this has opened up some interesting conversations."

Of the 19 respondents who selected not at all nine gave a comment to support their selection. Two commented that they had not noticed a difference; two noted that children engaged more with their hard-copy portfolio; two commented it was too early in the process to know; and, three commented that children did not have access or were not part of their documentation:

The e-portfolio system was specifically set up so that parents can have access anywhere and anytime as long as they have a computer or mobile phone to download the app. Unfortunately the children do not have access to their e-portfolio.

\subsection{Conclusion}

This chapter presented the results from the national online survey which was undertaken as phase one of data collection. The next chapter presents the findings from the two selected case study centres: Dibley Kindergarten and Grendale Education and Care. The results in this next chapter were collected through smaller case study online surveys, interviews with teachers, parents and children, and observations whilst in the centre setting. 


\section{Chapter Five: Case Study Results}

\subsection{Introduction}

This chapter will present the findings from the case study settings: Dibley Kindergarten and Grendale Education and Care, as part of phases two and three of this study. The findings from the case studies include results of the online survey, as well as observations and interviews gathered within the case study settings. Each case study is presented separately below with the information gathered under themes.

\subsection{Case study one: Dibley Kindergarten}

Dibley Kindergarten is located in a small town, close to a large New Zealand city. The kindergarten has up to 40 families on the roll with four full time teachers as well as one administrator who also works part-time in the Kindergarten. The children are between three and five years of age, attend up to five days a week, excluding holidays, and kindergarten sessions are from $8.30 \mathrm{am}$ until $2.30 \mathrm{pm}$. The open-plan centre environment has different areas providing numerous activities for the children, as well as a large outdoor space. Dibley Kindergarten has been using e- portfolios for just over a year, with two different e-portfolio programmes. Before the commencement of data collection an online survey was emailed to all teaching staff and families in the kindergarten. The teacher survey was completed by all five of the staff and the family survey was completed by nine families. In addition to the online survey, observations and interviews with teachers, parents and children revealed more in-depth data about the engagement of children with their learning through e- portfolios at Dibley Kindergarten.

\subsubsection{Initial introduction of e-portfolios to children and families}

E-portfolios were introduced to Dibley Kindergarten by one of the teachers who had used them in her own family and wanted to bring them to the Kindergarten. As a teaching team an e-portfolio model was implemented into their centre environment through a management database system. However whilst they valued the programme's efficiency, it was not designed for e-portfolios and was clunky and difficult to use. They approached the Kindergarten Association about being part of an e-portfolio trial that was being implemented within the wider Association and were successful in being selected. As it was a new trial, Dibley Kindergarten had little support in implementation but their interest in e-portfolios meant that online documentation immediately became a big part of the teaching practice. The teachers' 
enthusiasm, as well as word of mouth from interested parents, meant that families quickly became connected to the programme and within a few weeks most parents had made some form of contribution to their child's e-portfolio. The teachers introduced eportfolios to the children by including them in their daily activities and providing tablets to give children access; parents supported this by viewing e- portfolios at home with their children and writing comments and stories alongside them.

\subsubsection{Children's engagement with their e-portfolios}

The children of Dibley Kindergarten were confident about and proud of their eportfolio and would say "I want to show you my [e-portfolio]" or would sit and view their portfolio with their peers, or family whilst in the centre. Access was provided through two tablets available in the reading corner, and children were aware of the expectations around appropriate iPad use. Children were respectful of electronic devices and most children I spoke with were confident in finding their profile and manoeuvring around the programme. Teachers reported, in both interviews and the online survey, that children's engagement with their e-portfolio on the tablets varied, and data from the online survey showed children did so both independently and with teachers or peers. If the tablets were charging or not available children would ask a teacher for access.

The children of Dibley Kindergarten were aware of the e-portfolio documentation process and teachers and parents commented that children often asked teachers if a photo could be taken to be uploaded onto their e-portfolio. Some parents said that if children saw the teachers take photos or use the iPad during the day they would ask their parents' if they could see if a new story had been written for them at home that evening. The children also were aware of new stories: for example during data collection a local puppeteer visited the kindergarten. A video of the performance was uploaded that day and each child who revisited their e-portfolio afterwards noticed this video, "Look, it's a new story!", and spent time with their peers singing the songs together. New stories from home are shared with the children and their peers, sometimes on the mat or in small groups, and children had the opportunity to expand upon these as well as write a comment to their family. Observations showed the importance teachers placed on including children in the documentation process. One 
child said to me, "I'm always happy about looking at my [e-portfolio]. Did you know that [e-portfolio] closes at night time? That is because everyone goes to bed."

Twenty children were spoken to over the duration of the case study site visit and over half of these children revisited the learning or activity straight after reading their stories with me. Other children were observed returning to activities after reading their e-portfolio alone or with their peers. Teacher's online survey data supported these findings with three out of four teachers noting that they observed children frequently revisiting favourite stories or events through their play. One teacher noted occasional connections and commented that children watched e- portfolio videos and then reenacted the experiences. The online survey asked parents the same question and four out of seven said that they had noticed connections occasionally: such as making learning connections, revisiting stories and wanting to contribute images to their e-portfolio. One parent noticed frequent connections and two indicated they had not noticed any. Some examples of connections were children who went back to play on swings to see how high they could now swing, or those who sang a song from a video, or mastered tasks they could not do before. Most of the children commented in the interviews on their improvement in a task since the story had been written, such as; "Look at my riding - I can do it without training wheels now. I got better at riding," or "I like it coz I like the patterns. I did it all myself without [teacher]. She did help me but not this time. I can do it now." Other children reflected with their friends on particular interactions in a story, for example; "That's me helping you with my strong muscles," or "Yay. Look at me, I member this song. Do you? You were there!" Children were observed reflecting confidently on activities, events or interactions with their teachers and peers throughout the day and used these conversations to build upon their ideas and extend themselves by returning to past activities.

The children's favourite stories were those that included their friends or ones that depicted activities or events they were particularly interested in, especially stories from home. During the case study site visit a child revisited their e-portfolio with me and selected a story and video about the persistence she showed in completing a hard puzzle. She watched the video and we read the story and she turned to me and said "Nicola, we still have that puzzle, I'll go do it again I think. Can you watch me?" We 
went to the table and she began to put the puzzle back together however again found it difficult to complete. She instantly thought of the video she had just seen and brought the iPad over, re-watched the video and slowly pieced the puzzle back together as she saw on the screen. Afterwards she did the puzzle again exclaiming "that was much faster than the video one wasn't it Nicola? But it's not fast enough." Teacher feedback in the online survey supported these examples as teachers felt that e-portfolios had had quite a lot of influence on children's engagement with their learning and noted the ability for children to revisit their learning easily and contribute through extending or adding to their learning portfolios.

\subsubsection{Teacher practice around children's engagement}

The teaching team were all competent in using e-portfolios regularly; three teachers had used them for more than 18 months - having used them prior to their kindergarten trial, and two others had used them for less than a year. The teachers all spoke highly of e-portfolios, and each afternoon wrote up new stories for the children. Learning stories were written individually, however they collaborated as a team and celebrated learning and achievements as well as discussed next steps to extend children. The teachers acknowledged that the accessibility of e-portfolios assisted them in writing learning stories, especially with identifying learning links. They said that their focus with e-portfolios was primarily on the learning that occurred, and the photos and videos must support that rather than letting the technology dominate. As teachers, they were pushing for teachers to be intentional in using eportfolios in a professional manner so that stories were not about a child being 'cute' and that comments instead supported and extended learning. Teachers had found that parents would sometimes comment "cute" on a child's learning story; similar to if they were commenting on a social media update. Teachers found these superficial comments difficult to connect with as they did not address, support or extend the children's learning and possible next steps. One of the teachers said "Why are we here? What is the emphasis on a child's learning if it's going to be so cute? Why have we gone and studied if the parents only want cute?" Teachers indicated that they were working with parents to encourage comments that made learning visible and made connections between home and the centre in meaningful ways. Teachers believed connecting with parents in this way would not only improve learning outcomes for children, but would also send inherent messages and place 
genuine value on what children had been achieving, particularly when comments and stories were read aloud to children, or as they got older and read independently.

The teaching team shared that they were developing their practices around encouraging children to contribute to their e-portfolio, through writing stories alongside children, or including the child's voice. The online survey data showed that half of the teachers revisited e-portfolios and had conversations with children about their learning and how they could contribute. One teacher noted they wrote as many stories as they could in collaboration with children, and encouraged them to take photos for their stories. However encouraging greater contribution by children was their area of focus as they moved forward with this method of documentation. For example one observation was of a new child to the kindergarten who on his second day was sitting in the book corner revisiting his e-portfolio. As the teacher approached the couches the boy moved over to her and wanted to show her stories from his previous kindergarten and so they sat and reviewed them together. The teacher came across some photos the boy had taken of himself on his first day on the iPad and asked whether he would like to add them as a story to his e-portfolio for his Mum. He was keen to do so and they sat together and selected the pictures and then he said "I want to write some words to Mum now." When this boy returned the next day, Mum had commented on the story and together he and I read the story and the comment and he excitedly took the iPad to show some of his new friends.

The teaching team identified a concern they had with e-portfolios in that they noticed how commonly children talked about "me, me me" when revisiting their e-portfolio, rather than speaking about the learning or activity. They found that whilst children were interested in viewing their e-portfolio, they were less interested in undertaking a Google search, or looking at a website to discover more information on a topic. The teachers questioned whether it was actually the prevalence of images and videos of themselves and their peers that made e-portfolios appealing to children rather than the actual learning activities and interests portrayed. In a discussion, one teacher shared "kindergarten never used to be about 'me'. I worry about the learning and is it all 'me, me, me'? Are we going to lose traditional learning?" They commented that to an extent this did happen with hard-copy portfolios, because they too shared photos of the children, however they felt that the influence of social media in society may 
have impacted on how children engage online. Whilst they did not believe children recognising and enjoying images of themselves was a negative aspect, they wanted to ensure that the focus stayed on the learning and development and therefore were looking at alternative ways to present children's learning in a story.

\subsubsection{Connections between home and the centre}

Parents and family members spoke positively about the benefits of moving to an eportfolio system to increase communication with both the teachers and their children. They also felt they had better relationships with teachers as a result of using eportfolios and they enjoyed engaging with their child's learning through this medium. Teaching staff felt that parents were engaging with e-portfolios at home $a$ little to quite a lot. Eight parents completed the family survey, along with one respondent who selected Other but who did not expand on their relationship. Six of the nine families said they engaged with e-portfolios at least once a week and the remaining three engaged at least once a month. Five respondents engaged with eportfolios on their home computer, three engaged using their mobile device and three others engaged with their child on the home computer. Of the 14 parents interviewed, nine said that they let their child know when there was a new story and they looked either themselves or with their child, and added their own comments. Eight of the parents felt more connected to what was happening in kindergarten during the day, as their child shared more with them through viewing the photos and videos online. Three parents commented that they felt e-portfolios were for them rather than their child, and therefore viewed the portfolio after their child went to bed, but ensured they talked about the stories together the next day.

Four of the fourteen parents interviewed commented that they missed hard-copy portfolios and being able to sit down and flick through, but all agreed that they preferred e-portfolios as it increased accessibility for them, particularly with their capacity to easily share stories at family events. These comments were supported by the online survey findings as parents indicated a preference for online portfolios, however noted that the value of hard-copies for young children to access and share. A couple of parents did print the stories and either added them to their home hard-copy portfolio or displayed them around the house. However they noted that their child preferred to revisit their online version instead. Five parents indicated they had added their own stories to their child's e-portfolio, with two who said that their wider 
family added relevant stories, which the children enjoyed viewing. Most the children at Dibley Kindergarten had extended whānau from around New Zealand and the world connected to the e-portfolios and parents commented that being able to share their child's learning with their family was extremely valuable.

Ten of the 20 children spoken to indicated that they viewed their e-portfolio at home, either independently or with their family. Five children shared that they helped their parents write home stories or provided comments to stories uploaded by teachers. Children were confident in showing which stories were written at home, and teachers said that when new stories were written children wanted to share them. The online survey asked parents whether they felt e-portfolios had assisted greater engagement of children to their learning: half of the parents felt that e-portfolios had helped children engage a little. They commented that this was because they felt e-portfolios were primarily for parent use, or because children did not have access. Conversely two of the eight respondents indicated that e-portfolios had assisted quite a lot and three said a great deal. They commented that children were more regularly connected with their learning and they are "something tangible and exciting that children can be involved in".

The online survey asked parents about whether e-portfolios had assisted them in supporting their child's learning through greater connections and communication with the teaching staff. Five out of seven responded that e-portfolios had helped them a great deal as they felt more connected and confident to share learning from home. The teaching staff used e-portfolios to connect families, teachers and special intervention teachers or support workers to ensure greater collaboration in regards to planning for and celebrating children's development. Two of the seven said they felt eportfolios had helped quite a lot with one who indicated that they loved seeing what happened in the centre. In the observations one three-year-old paid particular attention to noting any comments made by his parents within his portfolio. He recognised the picture of his parents in the comment box and said to me "what did Mum say?" A further example shared showed how children were confidently making connections between their home environment and the centre with a four-year-old girl who had recently attended a show. A story was written online by both the girl and her parents and was read with her peers within the centre. A lot of discussion ensued 
between the children and teachers about the music from the show and the girl's mother was asked about what the show's soundtrack was. In reply the girl's mother attached a link to clips of the music and this was shared with the children and they danced together. The girl and her friends would often look through this story on the iPad and dance to the music as they revisited the moves from the show. During the case study visit the girls were still seen dancing to the soundtrack of the show and showing me the correct moves: their enthusiasm had not waned despite the show being months earlier.

\subsubsection{Conclusion}

Dibley Kindergarten have been using e-portfolios for over a year and have found ways to incorporate this technology into their daily practices with the introduction of tablets for children in the centre. The children have strong ownership over their e- portfolios and regularly engage alongside teachers or their peers, as well as at home with their families. Findings from the case study showed children competently engaging with and revisiting their learning, making connections to prior experiences and extending their own learning and interests. The teaching team are working on practices to ensure that children are involved more in contributing to their learning stories and are also encouraging parents to actively contribute to the learning through comments and uploading home stories.

\subsection{Case study two: Grendale Education and Care}

Grendale Education and Care is a full-day EC centre situated in a major New Zealand city. The setting caters for children from three months to school age and is open from 7.30am until 5.30pm, with children attending at least six hours a day. There was a centre manager, three team leaders and seven additional full-time staff at the time of data collection, with 77 children on the roll. The Centre was split into three different rooms, each of which catered to different age groups; however the centre can be opened up into two larger rooms to enable all children to intermingle. The outdoor environment was divided into two large areas for older and younger children, with a low fence encouraging engagement with peers or siblings. Grendale has been using e-portfolios for almost 18 months, and was introduced to them through a presentation to their wider Association. The centre had both e-portfolios and hard-copy

portfolios at the request of families. Interviews and observations of teachers, parents and children revealed more information about the engagement of 
children with their learning. Informed consent was received from half of the 64 families in the centre. The online survey was sent to all teaching staff and families during the data collection site visit; seven of the eleven staff completed the teacher survey and the family survey was completed by eighteen parents.

\subsubsection{Initial introduction of e-portfolios to children and families}

After learning about e-portfolios Grendale EC decided to trial the programme in their setting, involving one family from each of the three rooms and uploading regular stories and snapshots over a few weeks. They received positive feedback and engagement from the families involved and after sending an email to gain permission from all families they began to use e-portfolios centre-wide. The teachers' interest in the online programme spread and soon all families were connected. The centre had a large Asian community and e-portfolios allowed greater interaction and involvement from extended family around the globe. Feedback from families as well as observations showed the value that the children placed on their hard-copy portfolio and therefore teaching staff decided to have both e-portfolios as well as hard-copies for children to engage with. A year on from the introduction of e-portfolios the centre began a self-review looking at how e-portfolios were working within their centre environment and they sent out a survey to families to gather their perspective. Twenty-five families responded to the survey, with $84 \%$ of respondents sharing that they showed their child their e-portfolio at home. Comparatively $84 \%$ also said that they took their child's hardcopy portfolio home regularly, as well as view the online version.

\subsubsection{Children's engagement with their e-portfolios}

The children of Grendale EC had easy access to their hard-copy portfolio whilst in the centre and had a strong sense of ownership over their portfolio. Children of different ages were eager to share their hard-copy portfolio during my visit, and spoke confidently of the different events, interactions and friendships in their stories. Teachers commented in the interviews that they liked to share home stories from the e-portfolios on the television screen at mat time and they encouraged children to share stories with their peers. The baby room used the laptop to share online stories with the younger children. Teachers in the kindergarten room commented that it was difficult to get children to view their e-portfolio on the iPad as they wanted to play games instead; because of this the iPad was primarily used for music. This evidence 
was supported in the online survey with all seven teacher respondents indicating that children engaged with their learning through their hard-copy portfolio, indicating that any online engagement was teacher-initiated and led.

The children of Grendale were familiar with the learning stories in their hard-copy portfolio; they spoke with confidence about their friends, their development and about stories they enjoyed. One example was of a child whose favourite story was about growing carrots and he shared with me "to pick carrots they are a bit dirty under the ground. We have to pull the green bit and cut it off when it's out. Then wash it and water it and leave it wet then eat. It tasted like carrot and cucumber." Other children spoke confidently about their learning journey pointing out development such as "this is me - I didn't smile. I was shy. I was new. Look at my pants", and "these are my handprints but look at my hands now. Big. I grew." The children read their hard-copies regularly, particularly during rest time. Of the 18 children I asked, only two children knew what their e-portfolio was and these two could make links between their hardcopy portfolio and e-portfolio. After reading their hard-copy one of these two children asked me if we could go and print more stories off the computer to add and the other said "I look at home at pictures on the computer, these pictures."

The online survey asked teachers the extent they felt e-portfolios had assisted children to engage more with their learning. Four of the seven said they had noticed a little influence on children's engagement, explaining that the children were too young to engage with their e-portfolio and much preferred their hard-copy portfolio. Three teachers had observed quite a lot of influence commenting that children enjoyed sharing their e-portfolio and the babies loved watching videos of themselves, an element, they felt, that could not be included in traditional documentation. Parents were asked the same question and seven respondents felt that e-portfolios had assisted their child quite a lot with four giving examples saying e- portfolios enabled children to revisit and remember their learning easily, develop self-confidence and helped teachers and parents understand children's lives outside of their care. Six respondents felt that e-portfolios had helped their child a little in engaging with their learning, however none gave an example. Three parents indicated that there was no change for their child with one parent saying that even 
though their child was young they were old enough to engage however very few stories were uploaded by the centre. Two of the eighteen parents felt e-portfolios had assisted their child a great deal in engaging with their learning with one sharing the following:

I think it allows them to engage more about their learning with parents when the stories are viewed, like a reflection and it can take their interest in their learning activity further because discussion or repetition of activity occurs outside the learning centre. Children also witness other's interest in their learning activities which is powerful for encouraging them to further engage.

The online survey asked teachers and parents whether they had observed connections being made in children's play that linked back to their e-portfolio engagement. Four out of the seven teachers observed occasional connections; sharing that they had seen progress with children's learning through viewing videos and stories alongside them. Two teachers selected that no observed connections had been made and commented that children were too young. One teacher commented that they had not noticed any connections but did not give a reason. Two of the 15 parents who answered this question felt that their child frequently made connections but did not give examples. Four parents felt their child made connections occasionally; one parent said that their child talked about the learning and activities when they revisited their e-portfolio. Nine parents selected we have not noticed this with one parent indicating that eportfolios were of little interest to their child.

\subsubsection{Teacher practice around children's engagement}

The teaching team enjoyed implementing e-portfolios in their centre and updated them as often as they could. Data from the online survey showed that of the seven teacher respondents, five had been using e-portfolios between one to two years and two for less than one year. The teachers used e-portfolios to upload individual children's learning stories and larger group learning stories as well as videos, daily snapshots or notices. Each child had their own online page, as well as having access to their room online page; this allowed teachers to collaborate with and inform families about that day's learning activities, children's learning, important notices and planning. Teachers indicated they valued the e-portfolios in making connections and assisting parents in understanding some of their key foci such as Enviroschools or assisting in shifts such as transition to school. Teachers found these pages 
developed relationships with families and external parties, such as primary school teachers, in an effective way that made relevant connections for children. They had found an increased expectation from parents to be uploading stories weekly, however this was not possible based on the ratios in each room. The online survey showed five teachers engaged with e-portfolios at least once a week with the remaining two indicating at least once a fortnight. Parent conversations revealed that parents found it hard to find the time to share the e-portfolio with their child at home and therefore were pleased that the hard-copies remained for the children in the centre. In order to maintain these teachers printed off stories from the e-portfolios and added them to the hard-copies for the children. Teachers commented that not all stories were printed off for children; most of the printed stories were individual rather than group. One teacher commented that the number of stories printed for a child's hard-copy portfolio was determined by the level of parental engagement with their e-portfolio; that is, the more parents engaged online the fewer stories were printed off. Teachers ensured that the comments were also printed off so that these could be viewed with the whole document in the hard-copy portfolio.

The online survey asked teachers how they were helping children engage with their e-portfolio. Five of the seven respondents said they had conversations with children regarding their learning and four teachers noted revisiting children's e-portfolios at quieter times of the day. One teacher indicated she wrote as many learning stories as possible in collaboration with the children and another selected Other; explaining she shared moments with children at mat times or read their hard-copy portfolio. A further question asked teachers the extent that e-portfolios had helped them support children's learning and decision-making. Two teachers said they felt a great deal of support; they indicated improved communication and greater collaboration with parents as a result. Two teachers indicated quite a lot and explained that they understood children's interests better and shared learning more widely with children. Two teachers selected a little; one commented that she had greater collaboration with parents but only a little with children, and another said children engaged more with their hard-copy portfolios. One teacher selected 'not at all' and commented that the young age of the babies hindered engagement due to language abilities. 
Whilst the teaching team faced challenges in the implementation of e-portfolios, their self-review processes assisted them in working through these. One of the biggest difficulties they faced in the early days was challenging the notion of photos and stories being 'cute'. Teachers found that parents did not always write comments on the learning stories and when they did they were often commenting that images and stories were cute. The management team decided this needed to be addressed when a teacher also commented that a parent story was cute. They decided that as a teaching team they needed to define and model what they expected of online comments. As a team they changed their approach to encourage and model to parents their focus on the learning aspects of the story and emphasised how they wanted comments that made connections and shared more about children's interests at home. They have since found that comments were more focused on the learning and greater learning connections were being made by parents, teachers and wider family members as a result.

\subsubsection{Connections between home and the centre}

The online survey sought to gather data around how e-portfolios were being utilised by children within their home environment. Of the 18 parents who responded 13 of these had been using e-portfolios between one to two years and five for less than one year. Nine of these families said they engaged with their child's e-portfolio once a week, four indicated at least once a fortnight and five families selected at least once a month. The online survey asked parents how their child engaged with their e- portfolio at home and what access was provided. 15 parents indicated that their children engaged with their e-portfolio at home with a parent; with the most common mediums being the home computer $(\mathrm{N}=9)$, iPad or electronic device $(\mathrm{N}=7)$ or mobile phone $(\mathrm{N}=4)$. One parent said that their child did not have access but as parents they looked at the stories. In the online survey 13 parents indicated that they viewed their child's eportfolio when new stories were uploaded, with seven parents noting they talked about the stories with their child without showing them. Parents were also asked how their child contributed to their e-portfolio at home. Five families indicated that their child contributed through uploading images or new stories; and one parent shared that their child did not engage at all. Five parents selected Other. Of these five respondents, three said that their child did not 
contribute, and two noted that their children shared their e-portfolio when engaged with other adults.

Of the 10 children whom I spoke with, over half indicated that they looked at their eportfolio at home with their family; however six of these children said they did not look or did not know what I was talking about. Two children said that they helped their parents to choose photos or write stories online, with one child very involved in contributing from home, even asking to go on the computer if the teacher had told her that there was a new story uploaded. Data from the online survey showed that five teachers felt families were engaging quite a lot with one teacher observing a great deal and another teacher a little. In the interviews one parent mentioned that after speaking with her child about her day, her child would sometimes ask how she knew what had happened. A number of other parents indicated that their child did not interact at home and instead regularly took home their hard-copy portfolio to look at with family. The online survey asked whether parents had found e-portfolios had assisted them in supporting their child's learning. Six respondents felt that e- portfolios had helped them quite a lot; one parent indicated that parents can really talk to their child about their day. Four parents felt e-portfolios had helped them a great deal as they felt equipped to ask more relevant questions of teachers and their children, kept up with activities and were able to share their child's learning with their wider family. A further four respondents felt that e-portfolios had helped them a little with one parent commenting that they already checked their child's hard-copy portfolio regularly. One other respondent selected not at all and commented that very little was posted by the centre to view.

All eight families spoken to during the site visit commented on how they valued their child's hard-copy portfolio; this was echoed in the online survey where parents indicated that they valued e-portfolios but preferred the hard-copy portfolio at home. Data from the centre's self-review parent survey showed that nine of the 21 families in the kindergarten room preferred hard-copy portfolios compared with twelve who preferred e-portfolios. Interview and survey data from this study showed that parents felt e-portfolios were fantastic for parent communication and easing apprehension; however they would not want this to be the sole method of documentation as they placed great importance on children independently revisiting their learning through 
hard-copies. This sentiment was echoed by the teachers as they too believed that without the hard-copy portfolio children would be quite removed from their learning. Three parents commented that they believed online and hard-copy served different purposes: online for parent engagement and communication and hard-copy portfolio for children to revisit and share. One parent explained that hard-copy portfolios were perfect for adding artwork and photos, whereas e-portfolios helped to track children's interests and achievements. The online survey data showed that parents felt the accessibility of hard-copy portfolios superseded that of online, as this method required adult instruction: "Access is not as easy online; they can physically pick up their profile book at [centre] and flick through the pages at their leisure. With having it online they are limited to when and how they can access, which is usually when I am accessing it and showing them." Two respondents shared about the varying benefits of both hard-copy portfolio and e-portfolios with one parent giving the following explanation;

When the hard-copy comes home my children like to read through it right from the beginning with a parent or sometimes with a sibling. They like to have control of turning through the pages of the hard-copy. Once shared my children like to take their hard-copy away and independently flick through it on their own. The current hard-copy coming home sometimes encourages them to get out past hard-copy portfolios. With the online version they like to go through the current story and discuss what was happening and then randomly pick and choose ones to look at and go through.

One respondent shared that their child showed little interest in either portfolio medium but would sit on occasion and view their e-portfolio with a parent. Four parents commented that since the introduction of e-portfolios there had been fewer stories added to either of their child's portfolios however they did treasure the ones that were uploaded.

One parent spoke about how she disliked e-portfolios. She did not believe that everything should be electronic, as she felt there was so much value and ownership in traditional methods of documentation. This parent spent a lot of time, alongside her child, adding to their hard-copy portfolio, and these contributions were valued by the teaching staff and shared at mat times with the child's peers. These stories were not added to the child's e-portfolio but every story added by teachers was printed off and added by the child's parents to their hard-copy portfolio. This family believed 
that sharing the child's learning with their wider family was not the teacher's job and instead preferred more hard-copy stories being read and written in the classroom alongside the children. This family did view their child's e-portfolio and commented where necessary, however found that the online medium removed children from contributing to and reflecting upon their learning. This view was made clear to the teaching team and they had been working on adapting their practice to support the different views of parents within the centre.

\subsubsection{Conclusion}

Grendale EC centre had been using e-portfolios for almost 18 months at the time of the case study visit. Due to feedback from their families they maintained both e- portfolios for parents and teachers and hard-copies for children's engagement. The children did not have access to their e-portfolio whilst in the centre, unless shared on a big screen or laptop, and instead engaged with their hard-copy portfolio whilst in the classroom setting. The families of Grendale value e-portfolios for parent engagement however feel hard-copies are important for their children to collaborate and engage with. Children have strong ownership over their learning with their hard- copy portfolio and engage on a daily basis. The teaching team is continuing to push for intentional teacher practice around e-portfolio use, such as modelling comment etiquette and encouraging parents to be actively involved in their child's learning.

\subsection{Chapter Conclusion}

These two case study centres, Dibley Kindergarten and Grendale EC centre, provided valuable data through surveys, interviews and observations that helped to illustrate some of the national survey findings on children's engagement with their learning through e-portfolios. Both EC centres had been using e-portfolios for at least a year and were working on extending their own teaching practice and encouraging greater engagement from parents and children to improve learning outcomes and support children's learning. These centres both identified the need for greater support and training in implementing e-portfolios and indicated ways in which they wanted to extend and challenge their practice. The next chapter will discuss the findings from the two results chapters alongside relevant literature. 


\section{Chapter Six: Discussion}

The final chapter discusses the key findings from the two results chapters to provide a greater understanding of children's engagement with their learning using e- portfolios. These key findings will be discussed in relation to the research question as well as connected to relevant research. The variance in responses and observed data in this study indicates a greater need for more support and professional attention to ensure that centres are harnessing the potential for e-portfolios in the ECE field. The chapter is structured into five themes which address both children's engagement and contribution to their learning as well as teacher practice to support increased engagement by children. The chapter concludes with a discussion of implications for teacher practice, potential future research, and the limitations of the study.

\subsection{Children's engagement with e-portfolios}

As acknowledged in the introduction, engagement is complex to define and occurs on multiple different levels (Abbott 2014). With e-portfolios a deep and thoughtful level of engagement is desired of children to empower them in collaborating and extending their learning. The responses from both the case studies and the online surveys indicated a varied level of engagement by children with their e-portfolios. Thirty-three percent of centres indicated that children were engaging with their eportfolio at least once or twice a week, $32 \%$ of centres said children engaged less than once a fortnight and 19\% of centres indicated that children never engaged. Similar variances were also evident in the case studies; in one setting children revisited their e-portfolio daily using tablets, whereas another centre had no access for children and they instead viewed their hard-copy portfolio. These varied figures indicate the significantly different ways that e-portfolios are being utilised within ECE settings, and highlight areas for further support and research to ensure that e- portfolios can be effectively understood and subsequently used to benefit teachers, families, and most importantly, children.

Online survey comments showed that children preferred to revisit their e-portfolio alongside a teacher, parent or their peers, rather than independently. Observational and interview data revealed episodes of greater interest and engagement by children with their e-portfolio as a result of joint-attention by a teacher, parent or peer. Carr's (2011) research on children's engagement with their learning with hard-copy 
portfolios showed that involvement from teachers and peers resulted in greater engagement and ownership of learning for children. Similarly, in this study, greater levels of engagement and contribution were observed in settings where e-portfolios were a focus for teachers, their enjoyment of technology was evident in their practice and, as a result, there was greater extended engagement by children, increased numbers of stories uploaded and more conversations and connections made. This data supports findings from Hollingworth et al., (2009) whose study revealed that greater levels of engagement occurred with e-portfolios when individuals understood their role in facilitating and contributing to them. Whilst this study (Hollingworth et al., 2009) was set in the adult sector the message is transferrable and relevant to ECE as teachers and parents have a pivotal role in facilitating e-portfolios in the ECE environment to encourage and empower children to engage with their learning. Whilst this role is also important in hard copy documentation, the nature of e- portfolios means that greater support is needed by teachers and parents to connect children to their learning. The value and benefit of e-portfolios may be more apparent with additional support available for teachers to help implement e-portfolios to their greatest potential, and include children confidently into documentation practices. These findings highlight the need for more information and support for teachers to not only develop their own practice, but also assist children in families in deeper engagement as well.

\subsubsection{Children's home engagement with e-portfolios.}

This study sought to investigate children's e-portfolio engagement in both the centre and their home environment. Findings revealed that for many children their home eportfolio engagement was the only access they had to their online learning, as there were no opportunities provided in the centre. Case study data showed that most parents who participated in the survey regularly revisited their child's e-portfolio at home; however teaching staff indicated that they were not aware of how many parents engaged at home as at times there was no evidence. Case study interviews showed a

diverse range of home engagement: some parents actively reading and contributing to the e-portfolio with their children, others using e-portfolios to inform themselves about children's learning without their child, and others not viewing the e-portfolio at all. Parent comments in the survey indicated that time was a significant influence that hindered their involvement with their child and their e-portfolio. The 
national survey showed that in some settings teachers believed it was the role of the parents to engage their child with their e-portfolio and therefore did not provide access, whilst others said they knew children were not engaging at home and therefore made sure that e-portfolios were a valuable part of their teaching practice in the centre. Meade (2012) advocates for the critical role of parents in participating and collaborating with their children's learning at home in order to develop more learnercentred outcomes for their child. The role of parents in supporting and being engaged in their child's learning is a pivotal part of not only the ECE curriculum, Te Whāriki, but also central to children's learning and development (Meade, 2012; Ministry of Education, 1996). This means that teachers have an important role in supporting and encouraging parents to connect to their children's learning, either through leaving comments, uploading stories or making verbal connections to what they have read, so as to encourage their active contribution to centre planning and practices (Goodman, 2013).

\subsection{Children documenting their learning}

When children actively contribute to their own learning, they develop valuable selfassessment and reflective skills (Te One, 2002). Garthwait \& Verrill (2003) argue that collaborating with children in documentation empowers them to be proud of their learning and achievements whilst actively extending themselves. National survey data regarding children's contribution to both general documentation practices and their own e-portfolio, showed that children most commonly took photos for stories, contributed to wall displays and dictated learning stories and project documentation. Children were less likely to write stories online alongside teachers, add stories from home, and add art work. Furthermore a small number of centres indicated that children did not actively contribute to documentation practices within their centre. One example was observed during data collection of a child contributing to their e-portfolio stories alongside a teacher; however observations reveal most documentation preparation was undertaken independently by teachers in the office during non-contact or lunch times. Data indicated that children were more involved in contributing to their hard-copy portfolio as online survey respondents said these were more accessible and encouraged greater participation by children. The differences in children's contribution reveal a discrepancy between hard-copy and online documentation; however one of the benefits of e-portfolios is that they allow 
teachers and children the flexibility to write stories and upload images easily and remotely. These findings suggest missed opportunities for teachers to be utilising technology and including children collaboratively in their documentation practices in the centre at the time of the learning, rather than writing stories independently after the episode. The metaphor of each child weaving their own learning journey is a foundation to the ECE curriculum (Ministry of Education, 1996) and e-portfolios allow teachers to support this through greater flexibility with e-portfolios in encouraging children to contribute to their learning.

Carr's (2011) study noted the importance of teachers co-authoring documentation with children, particularly as teachers have a significant amount of power over what is shared about children. Carr (2011) argues that partnering with children ensures that adult agendas do not dominate and allows children to stay at the centre of their learning. As noted by Phelan and Kinsella, (2013) consulting children in the documentation process allows them a greater say on what they are comfortable sharing with their wider support network, as well as the opportunity to add their own voice. Many of the teacher responses in both the surveys and case studies indicated that collaboration with children was something they wanted to work on within their teaching settings and indicated that their participation in this study had challenged them to reflect on their practice. Jones (2006) and Porter (2008) identified that when teachers step back from their perceived teacher role and build reciprocal relationships with children and families, greater partnerships develop that transform the quality of the learning and assessment developed.

\subsection{Children's engagement with their learning through e-portfolios}

Engagement on a deeper level occurred when children made connections between their interests, experiences and achievements to the learning and stories in their e- portfolio. Survey results of children's engagement with their learning were again quite diverse: some children engaged frequently and competently whereas other centres indicated that children made little connection to their learning at all. National survey data showed that around $40 \%$ of respondents reported that e-portfolios had resulted in children engaging quite a lot to a great deal with their learning indicating that children had a greater contribution and interest in their learning, increased discussion and sharing of their own voice and more excitement and enjoyment with learning. Sixty percent of respondents however felt there had been a little to no 
change regarding children's engagement with their learning commenting that eportfolios were still new to their centre, or that children did not have access to their e-portfolio. Children in one case study were competent in using tablets to access their portfolio at any time of the day and were engaging with their learning independently and alongside their peers or teachers. Instances of this were observed with over half of the children interviewed returning to an activity or skill that they had just been revisiting in their e-portfolio. These children spoke confidently about the stories and what was happening, extended upon their learning by continuing activities they read about, or tested themselves on tasks to develop mastery. Children also took their own photos and videos to add to learning stories, actively engaged with teachers in dictating their voice and had a role in contributing stories from home and sharing these in the centre. Examples such as these show children's strong engagement with their learning, developing their skills to self-assess and reflect on development and achievements. Comparatively, some centres, without access for children to their eportfolio, indicated in the national survey that children had little understanding of where their learning stories came from or how they could actively revisit or contribute to their learning. Survey responses from teachers, in both the national and case study surveys, acknowledged the influence they felt e-portfolios have had on children's engagement with their learning but indicated that teachers needed to be supported for the potential for greater children's engagement to be harnessed in many centres.

Teachers in the case studies raised concerns around children's focus on themselves when revisiting their e-portfolio rather than identifying and discussing the learning, activity or friendships. Whilst this interest in images of oneself was also evident with hard-copy portfolios, teachers in both case studies felt that the self-involved nature of social media could be negatively impinging on children's ability to look further than pictures of themselves to reflect upon learning or activity in a story. Woodward and Nanlohy (2004) argue a similar point, questioning whether it is the technological appeal of e-portfolios that is influencing their desirability or whether their usability will cement their relevance to assessment in the long run. The teachers in one case study setting were working to transform their documentation practices by developing learning stories that focused more on learning and achievements, showing more photos of learning as well as group photos, rather than purely images of the children. 
Barrett (2008) and Meyer and Latham (2008) believe that documentation is about the child's journey and argue that this emphasis must not shift with the introduction of eportfolios, instead they argue it is the role of the teacher to adapt teacher practice to introduce online documentation with their staff, families and children.

\subsection{Accessibility and ownership of e-portfolios}

Carr's study (2011) indicated that accessibility and ownership are two of three important aspects of empowering children to engage with their learning. Having portfolios accessible for children encourages them to not only read them, but also reflect upon and contribute in meaningful ways; this in turn develops ownership over their learning. Traditionally, hard-copies are accessible to children to revisit independently or with adults or peers. With the introduction of e-portfolios some centres have chosen to maintain both hard-copy portfolio and e-portfolios whilst others have removed hard-copies placing all documentation online. National survey data revealed children have varied access to their e-portfolio: $43 \%$ of participating centres did not provide children with access to their e-portfolio; with a further $26 \%$ indicating they only had e-portfolios. An additional $22 \%$ indicated that children had access to their e-portfolio when with an adult but no free access, commenting that sharing eportfolios with children required too much teacher direction, and time to undertake. National survey data showed a variety of ways that teachers and parents were providing children access to their e-portfolio; the most common being computers and $\mathrm{iPad} /$ tablets, both at home and in the centre. One case study setting had tablets available for children to access freely throughout the day. Children were considerate and just used these devices for viewing their e-portfolio. The other case study setting commented that children associated tablets and computers with game play and therefore did not have them available unless a teacher was present to direct the activity. Te One (2000) argues that accessibility is not just about physical accessibility but also intellectual, meaning that learning stories and comments are relatable to children and encourage engagement and reflection. Sixty-four percent of centres reported in the national survey that they had both online and hard-copy versions of children's portfolios in their centre as the families and children in their centres valued both mediums. In one case study setting, e-portfolios were seen as being informative for parents and the hard copies were for children to engage with and share. Whilst this suggests that centres are adapting to the needs of their 
community, the target audience of e-portfolios could be defined before implementing e-portfolios, so that practices can be adapted to include both children and families in documentation.

Steele's (2007) study found that children develop a great sense of ownership with their learning as a result of hard-copy portfolios and attributed this ownership to children being able to share and actively contribute to their portfolio. Carr's findings in 2011 support this as her study found that ownership of one's learning is dependent upon involvement and contribution to the documentation process; that is children understand what is being shared about them and feel that their learning is valued. Such ownership is competently supported through traditional methods of formative assessment and our national curriculum, Te Whäriki, and it is important to consider how these values are transferred into e-portfolios to allow children to have the same level of ownership and access. Findings from this study suggest greater support by teachers to help parents include children in online documentation, and encourage active participation in dictating, writing and sharing learning stories. In one case study centre, children were extremely confident in explaining their learning and what they were capable of. They had an awareness of new learning stories and would ask teachers about particular comments on their stories and how they could reply. Comparatively in the other case study setting, children had little ownership over their e-portfolio with over half of the children involved in the study not knowing what their e-portfolio was or where their learning stories came from. This data shows that ownership can be developed with both hard-copy portfolio and e-portfolios, however it is the support and encouragement from teaching staff that determines whether children engage with the learning documented in their e-portfolio.

\subsection{Teacher practice around e-portfolios}

\subsubsection{Teacher engagement with e-portfolios.}

Findings around teacher engagement echoed those of Goodman's (2013) earlier study, investigating parent and teacher engagement with e-portfolios, where data revealed that parents and teachers were more engaged with children's learning as a result of using e-portfolios. Teachers in this study shared similar increased engagement levels to those in the one previous, as teachers in both studies shared an enjoyment for e-portfolios, particularly as they had observed improved relationships 
and communication with parents and whānau. National survey data showed that teachers felt more connected to children's learning through e-portfolios and as a result were developing confidence in their own documentation practices to support improved learning outcomes for children. Teachers also commented that they felt eportfolios assisted them to collaborate more with children, helped set goals, revisit learning effectively and support children's greater learning interests. Case study survey teacher responses showed the importance they placed on external support and training to effectively use e-portfolios in their setting. The role of teachers and family members is pivotal to the success of e-portfolios in an education setting (Barrett, 2008; Becta, 2007; Garthwait \& Verrill, 2003) in order to facilitate children's engagement with their own learning through this medium.

National online survey data revealed teachers felt a greater expectation from parents and whanau to upload learning stories frequently. Responses from case study families showed regular engagement with their child's portfolio; with some checking daily. National survey findings indicated that $35 \%$ of settings were uploading stories once a week or more to children's e-portfolios with $59 \%$ between once a fortnight to once a month. Teachers in one case study felt pressure from parents to upload more stories, and commented that online learning stories still took the same time to develop and write as hard-copy ones and their teacher ratios and non-contact hours did not allow them time to upload more. Mason, Pegler and Weller (2004) found that completing more stories with greater numbers of students resulted in quantity yet decreased quality of stories for each individual. Instead they promote the importance of developing genuine connections with children and families which in turn result in stories that have greater meaning and relevance for children (Mason et al., 2004). The instantaneous nature of today's society means that information is readily shared and easily accessed, and whilst e-portfolios support this, teachers felt parents needed a greater understanding of the work involved in completing learning stories. For teachers this may mean careful induction of parents and whānau when introducing eportfolios, sharing the process of developing a learning story and being transparent about the work involved in uploading these. Greater awareness of ways to use eportfolios by both parents and teachers will result in stronger connections and reciprocal learning stories that are of relevance to children's learning. 


\subsubsection{Support for teacher practice}

Data responses from both the national survey and case studies highlighted the idiosyncratic approaches taken by management and teachers to decision-making around e-portfolios in the ECE sector. Findings revealed that e-portfolios were implemented in some centres where teachers were not well supported in implementation and therefore decisions were made around printing, accessibility and online feedback without wider discussion of relevant issues. Centres who maintained both hard-copy portfolios and e-portfolios would print off online learning stories and add them to the child's hard-copy portfolio. One case study centre did have both types of portfolios but commented that they were selective about which stories were printed for children's hard-copy portfolios. This selection was based on the level of engagement by a child's parents with their e-portfolio, and the type of story; that is, most learning stories were printed but not most group stories. Whilst the outlay of money and time are significant factors in maintaining both types of portfolio, the purpose of doing so is to enable children's access and therefore children should not be disadvantaged by what teachers choose to print and include in their hard-copy portfolio. Whilst there have been concerns about educational institutions relying so heavily upon technology for all documentation (Lorenzo \& Ittelson, 2005), the value of having both an online and hard-copy portfolio is negated if only some of the information is passed on to children. This concern is evident in the literature with researchers commenting that young children can be easily, and often unintentionally, removed from the information about them that goes online (Becta, 2007; Lorenzo \& Ittelson, 2005). It is important that considerations are addressed around these issues, such as printing and maintaining of both online and hard-copy portfolios, before the implementation of e-portfolios in an ECE setting.

Teachers in both case studies raised concerns around a lack of professional practice when using e-portfolios. Teachers indicated that parents appeared to use e-portfolios similarly to social networking sites, commenting that stories were 'cute' or placing more emphasis on a child's appearance rather than the learning. Both case study centres were concerned about children's lack of interest in their learning as well as the inherent messages given to children through superficial comments. As teachers they were pushing for intentional practice when using e-portfolios firstly within their teaching team, modelling comment etiquette to parents and then encouraging parents 
to provide feedback that acknowledged the learning and made connections to extend children further. As a result of their modelling, teaching staff found parents to be more forthcoming with comments that celebrated their child's learning. This in turn provided opportunities for children to respond to their parent's comments. These findings resonate with Barrett's (2008) study which found that the role of the teacher was critical in successful e-portfolio implementation as their support and modelling is pivotal in empowering parents, whānau and children to effectively engage with learning. Much of the national survey and case study data from this study identified areas where teachers and parents acknowledged how little support they have received, or how they would like to see more support in using the e-portfolios more effectively. Both case study centres had some form of professional development when e-portfolios were introduced but teachers indicated that this was not enough. They reported regular and sustained support was required to help facilitate effective e-portfolio engagement.

\subsection{Harnessing the potential for e-portfolios}

The variance in responses, to both the online survey and observed case study data, indicate the variety of ways that early childhood settings are utilising e-portfolios with children. The data reveals that many settings are not yet harnessing the potential for e-portfolios and young children's engagement with their learning. This indicates a need for greater support, increased training and professional awareness in the implementation of these programmes into ECE settings. The next section highlights some implications for teachers in implementing e-portfolios into their ECE environment.

\subsection{Implications}

\subsubsection{Implications for practice}

E-portfolios are a relatively new approach to assessment and documentation in ECE and their place is still being trialled and tested. Research such as this study can assist in building an understanding of how e-portfolios are being used by EC teachers, parents and children and ways that they can be utilised better to contribute to different aspects of ECE education today. In particular, e-portfolios in an EC environment provide teachers and children with new ways to document and communicate extending learning outcomes for children and developing greater connections (Goodman, 2013). Whilst this research may help shape our 
understanding of the place of e-portfolios in ECE, it does not necessarily provide definitive answers or tangible ideas to support implementation. This study has highlighted the complex nature of e-portfolios and the multi-faceted approach taken by teachers when integrating them into their setting, and identifies the following implications for practice.

Overall the findings in this study highlight how important it is for centres to focus on adapting teacher practice when implementing e-portfolios into an ECE environment. Te Whäriki views children as active contributors to their own learning (Ministry of Education, 1996) and it is sobering to see that in many centres e-portfolios have been implemented in such a way that this focus on child-centred curriculum has been shifted, thus removing children from revisiting their learning. Research has shown that children are competent with technology (Khoo et al., 2013) and when given the right expectations and teacher support use it respectfully to undertake particular tasks, such as documentation or taking photos. A number of settings have found ways to have technology accessible for children whilst in the centre, either with teachers or independently, through providing iPads, centre computers or projectors. These centres commented on the benefits observed in children's learning as a result of supporting active engagement with e-portfolios as part of daily centre practice. The challenge for teachers is to be introducing technology into the curriculum in a genuine way that aligns with their centre philosophy and empowers children to be active contributors to their own learning.

One further aspect identified in this study is support and training for effective eportfolio use. Studies have shown that it is important to be ensuring appropriate provisions are available to support children and their families to effectively engage with e-portfolios before introducing them (Barrett, 2008; Hollingworth et al., 2009; Strudler \& Wetzel, 2008). Considerations around security, suitability for the centre community, practicality and accessibility of training material are all important decisions to make before implementing e-portfolios into a centre (Ministry of Education, 2011). As e-portfolios are used differently in each setting it is important that teacher practice and communication appropriately reflect centre philosophies and values. Findings suggest the provision of professional development for teachers to support them to develop their e-portfolio confidence and practice. Increased 
support and training helps maintain quality practice around documentation and supports greater involvement of children and teachers with children's learning.

Meyer and Latham sum up e-portfolios effectively in that they are a "tool" (2008, p. 40) and it is up to management and teachers to transform their practice to maximise the full potential of e-portfolios. The key purpose of e-portfolios has been overlooked if children are removed from contributing to and revisiting their learning, going against the values of Te Whäriki. Teachers advocate for children to grow up as learners who are confident and active in constructing their own learning journey alongside teachers and whānau and this means being able to revisit their learning, self-assess, reflect and actively plan their next steps. This study raises findings which challenge the sector, encouraging teachers to reflect on their practice and look at alternative ways to effectively include children in planning and documentation.

\subsection{Areas of future research}

Reardon and Hartley (2007) question whether the introduction of e-portfolios into educational settings is of benefit to students' learning outcomes, suggesting there is very little evidence to back up e-portfolios. There is a need for research that examines the impact of e-portfolios on children's learning and achievement over a longer period of time, which provides evidence around self-assessment and evaluation as a result. Suggestions for future research include further empirical studies that focus on children's engagement with e-portfolios, particularly for children of different ethnicities or those with high needs or developmental delays. Interviews in this study offered examples were e-portfolios were used to collaborate with families, educators, and special intervention team members working with children with high needs and developmental delays. This area needs future research to highlight how eportfolios are currently supporting these children and ways they could do so in the future.

The New Zealand Ministry of Education (2011) questioned whether it is necessary for documentation to become digital just to keep up with the changing face of society, thus suggesting the need for further research to be undertaken into this phenomenon to support teachers more effectively. Future longitudinal studies that look at how e-portfolios affect long term education and development would make a useful contribution to this understanding. Since they are a new phenomenon there is 
little evidence that shows their impact over a long period and their effect on overall engagement for children and students in areas such as self-assessment, reflection and contribution to learning.

\subsection{Limitations}

It should be noted that the centres involved in the national online survey and the two case studies are likely to be centres that are typical of the wider New Zealand ECE community. Whilst this study was small scale in terms of the research design and the findings cannot be generalised to all NZ ECE services, it is likely that their opinions and experiences are relatively representative of the successes and challenges faced by other centres using e-portfolios within the wider sector and therefore can offer insights into practice for teachers to consider.

There are a few limitations to this study which are addressed below.

- The national online survey was emailed to 2,315 education and care and kindergarten settings around New Zealand. It was emailed to this large number of centres as there was no way of determining which centres used e- portfolios around the country and therefore a blanket email would elicit the greatest number of responses. This email was distributed using the Qualtrics programme and all centres were emailed at once. The programme allows tracking to see how many emails are opened and how many surveys are started. Of the 2,315 centres emailed only 876 (37\%) opened the email. It was only after consultation with other ECE teachers that I understood that in some centres, emails may have been sent to their spam folder and not seen. Therefore the low number of emails that were opened could be influenced by either lack of eligibility or because the email was redirected to their spam folder.

- Whilst geographic locations of possible participating centres were listed within question one of the national survey the Southland region was unintentionally omitted from the possible choices. One respondent alerted me to this omission and as a result their responses were collated with respondents from the Otago region.

- Case Study centre selection: Twelve early childhood settings indicated their interest in being part of the case study component of this study however not all of these centres used a main e-portfolio provider. Some centres used 
centre management software that had a small e-portfolio component but was not designed for specific e-portfolio use, such as documenting children's learning. Whilst the responses from these centres were included in the data collection they were not considered for inclusion as case studies as they would not be able to provide as useful data for this phase.

\subsection{Conclusion}

The impetus for this research came from my earlier study of parent and teacher engagement with e-portfolios (Goodman, 2013). Whilst that study showed positive findings around adult engagement with online documentation it also produced concerns around children's engagement. If documentation about learning is only available online, how are young children able to revisit, reflect and self-assess their learning? These skills are vital components to learning and development, particularly in the early years. This concern was at the forefront of this study and the findings revealed a significant variance in responses indicating the diverse ways that e- portfolios are being utilised in New Zealand ECE settings, with many participating centres not harnessing their potential for young children. Findings from this study indicate the important role of teachers in facilitating children's e-portfolio engagement; as well as in supporting families to encourage children's engagement at home.

Children are at the forefront of teacher practice each day and it is concerning to see how easily e-portfolios could distance children from their learning. Survey responses revealed differences between children's contribution and engagement with their hardcopy portfolios compared with their e-portfolios; showing that children are less involved in e-portfolio documentation. Findings from this study suggest that eportfolios are implemented more effectively when they are supported by adequate professional development for teachers and alongside thoughtful decision-making for practice. These practices ensure e-portfolios meet the needs of the centre community as well as support and extend young children's learning. The study highlights the need for greater research on e-portfolios in ECE, to discover further evidence around support for teachers and families when introducing e-portfolios to young children. With supported teacher practice, principled decision-making and collaboration with children, e-portfolios can be successfully implemented in ECE to benefit teachers, 
parents and children. Considering they are still a relatively new phenomenon now is the time to gather research and develop practices that partner with children to extend and support learning in a completely new way. 


\section{References}

Abbott, S. (2014, August 26). Student Engagement. Retrieved from The Glossary of Education Reform: http:// edglossary.org/student-engagement/

Barrett, H. C. (2008, March). The Reflect Initiative Research Project. Paper presented to the American Educational Research Association, America. Paper retrieved from http://electronicportfolios.com/portfolios/JAALREFLECT3.pdf

Barrett, H., \& Garrett, N. (2009). Online personal learning environments: Structuring electronic portfolios for lifelong and life-wide learning. On The Horizon, 17 (2), 142-152. doi: 10.1108/10748120910965511

Becta. (2007). The impact of e-portfolios on learning. Coventry: Becta.

Bolstad, R., New Zealand Council for Educational Research, \& Ministry of Education. (2004). The role and potential of ICT in early childhood education: A review of New Zealand international literature (pp.25-34). Wellington: Ministry of Education.

Buzzetto-More, N. A., \& Alade, J. A. (2006). Best practices in e-assessment. Journal of Information Technology Education , 5, 251-269. Retrieved from http://jite.org/documents/Vol5/v5p251-269Buzzetto152.pdf.

Carr, M. (2001). Assessment in early childhood settings: Learning stories. London: Paul Chapman Publishing.

Carr, M. (2011). Young children reflecting on their learning: Teachers' conversation strategies. Early Years: An International Journal of Research and Development, 31 (3), 257-270. doi:10.1080/09575146.2011.613805

Child Rights Information Network. (2014). Text of the Convention [Electronic Version]. Children's Rights Information Network, 1-22. Retrieved August 25, 2014, from http://www.crin.org/en/home/rights/convention

Cohen, L., Manion, L., \& Morrison, K. (2000). Research methods in education. London: RoutledgeFalmer. 
Creswell, J. W. (2008). Educational research: planning, conducting, and evaluating quantitative and qualitative research (3rd ed.). Upper Saddle River, N.J: Pearson/Merrill Prentice Hall.

Davis, K. (2006). 'It's much more muddled-up than that': A study of assessment in an early childhood centre. Unpublished Master's thesis. University of Canterbury, Christchurch.

Emmett, D. (2011). Student engagement with an ePortfolio: A case study of pre-service education students. Unpublished Doctorate Thesis, Queensland University of Technology.

Engaging. (2015). In Merriam-Webster Dictionary (11 ${ }^{\text {th }}$ ed.). Retrieved from http://www.merriam-webster.com/dictionary/engaging

Fagan, T., \& Coutts, T. (2012). To iPad or not to iPad? Retrieved August 15, 2014, from CORE Education: http://www.core-ed.org/thoughtleadership/research/ipad-or-not-ipad

Fendler, L. (2001). Educating flexible souls: The construction of subjectivity through developmentality and interaction. In K. Hultqvist \& G. Dahlberg, (Eds.), Governing the child in the new millennium (pp. 119-142). New York: RoutledgeFalmer.

Garthwait, A., \& Verrill, J. (2003). E-portfolios: Documenting student progress. Science and Children, 40(8), 22-27.

Goldsmith, D. J. (2007). Enhancing learning and assessment through e-portfolios: A collaborative effort in Connecticut. New Directions for Student Services, 119, 31-42. doi:10.1002/ss.247

Goodman, N. (2013). Final report: Parent and teacher engagement using the Educa online portfolio system. Unpublished Report, Victoria University Faculty of Education Summer Scholar Programme.

Guest, G., MacQueen, K. M., \& Namey, E. E. (2012). Applied Thematic Analysis. London: Sage. 
Harris Helm, J., Beneke, S., \& Steinheimer, K. (1998). Windows on learning: Documenting young children's work. New York: Teachers College Press.

Hewett, S. M. (2004). Electronic portfolios: Improving instructional practices. Tech Trends, 48 (5), 24-28.

Hollingworth, S., Allen, K., Kuyok, K., Mansaray, A., \& Rose, A. (2009). An exploration of parents' engagement with their children's learning involving technologies and the impact of this in their family learning experiences. Coventry: Becta.

Howitt, D., \& Cramer, D. (2007). Introduction to research methods in psychology. Upper Saddle River, N.J: Prentice Hall.

Johnson, B., \& Christensen, L. (2012). Educational research: Quantitative, qualitative, and mixed approaches. Thousand Oak, California: Sage Publications.

Jones, C. (2006). Continuity of learning: Adding funds of knowledge from the home environment. Early Childhood Folio 10, 27-31.

Jones, N. (2014, January 18). Tots get thumbs up for touch screens. New Zealand Herald, p. A3.

Joniak, L. (2002). The qualitative paradigm: An overview of some basic concepts, assumptions, and theories of qualitative research. Faculty Fellow Seminar. slis.indiana.edu. [online]. University of Indiana. Indiana.

Joyes, G., Gray, L., \& Hartnell-Young, E. (2009). Effective practice with e- portfolios: How can the UK experience inform practice? Same places, different spaces. Proceedings Ascilite Auckland, (pp. 486-495). Auckland.

Kankaanranta, M. (2001). Constructing digital portfolios: Teachers evolving capabilities in the use of information and communications technology. Teacher Development, 5 (2), 259-276. doi:10.1080/13664530100200139 
Khoo. E., Merry. R., Nguyen, N.H., Bennett. T., \& MacMillan. N. (2013). Early childhood education teachers' iPad supported practices in young children's learning and exploration. Computers in New Zealand Schools: Learning, teaching, technology, 25(1-3), 3-20.

Killman, F. (2013). Child's play. Venture Magazine (1), 6-7.

Lewis, A. (2010). Silence in the context of 'child voice'. Children and Society, 24, 14-23.

Lorenzo, G., \& Ittelson, J. (2005). An overview of e-portfolios. Unknown: Educause.

Loveridge, J. (2004). Young children's learning in early education settings and at home: Mothers' understandings. Early Childhood Folio, 8, 2-8.

Loveridge, J. (Ed). (2010). Involving children and young people in research in educational settings: Report to the Ministry of Education. Wellington: New Zealand Ministry of Education.

Mason, R., Pegler, C., \& Weller, M. (2004). E-portfolios: An assessment tool for online courses. British Journal of Educational Technology , 35 (6), 717-727. doi:10.1111/j.1467-8535.2004.00429.x

Meade, A. (2012). Centre-parent communication about children's learning. Early Childhood Folio, 16(2), 38-43.

Meyer, B., \& Latham, N. (2008). Implementing electronic portfolios: Benefits, challenges and suggestions. Educause Quarterly, 34-41.

Ministry of Education (N.Z.). (1996). Te Whāriki: He Whāriki matauranga mo nga mokopuna of Aotearoa: Early Childhood Curriculum. Wellington: Learning Media.

Ministry of Education (N.Z.). (2009). Kei Tua O te Pae. Retrieved January 2013, from NZ Ministry of Education: http://www.educate.ece.govt.nz/learning/curriculumAndLearning/Assessmen tforlearning/KeiTuaotePae.aspx 
Ministry of Education (N.Z.). (2011). Digital Portfolios: Guidelines for Beginners. Wellington: Ministry of Education.

Mitchell, L. (2003). Children, staff and parents: Building respectful relationships in Australian and New Zealand early childhood education contexts. Making change for children now: Shaping early childhood today (pp. 159-171). Palmerston North: New Zealand Council for Educational Research.

Newby, P. (2010). Research methods for education. Essex: Pearson Education.

Nichols, M., \& McLachlan, C. (2006). E-learning and early childhood teacher education: what does the future hold? Не Кири, 1(1), 17-28. Retrieved from http://www.hekupu.ac.nz/

Papp, R. (2014). Assessment and assurance of learning using e-portfolios. Journal of Case Studies in Accreditation and Assessment, 3, 1-6.

Phelan, S. K., \& Kinsella, E. A. (2013). Picture this . . Safety, dignity, and voice Ethical research with children: Practical considerations for the reflexive researcher. Qualitative Inquiry , 19 (2), 81-90. doi:10.1177/1077800412462987

Plowman, L., McPake, J., \& Stephen, C. (2010). The technologisation of childhood? Young children and technology in the home. Children \& Society, 24, 63-74. doi:10.1111/j.1099-0860.2008.00180.x

Podmore, V.N. (2006). Observation: Origins and approaches to early childhood research and practice. Wellington: NZCER Press.

Porter, L. (2008). Foundations of collaboration. In L. Porter, (Ed.). Teacher-parent collaboration: Early childhood to adolescence (pp. 1-22). Victoria: Acer Press.

Rameka, L. (2007). Māori approaches to assessment. Canadian Journal of Native Education , 30 (1), 126-191. 
Rameka, L. K. (2011). Being Māori: Culturally relevant assessment in early childhood education. Early Years , 30 (3), 245-256.

doi:10.1080/09575146.2011.614222

Reardon, R. C., \& Hartley, S. L. (2007). Program evaluation of e-portfolios. Wiley InterScience (119), 83-97. doi:10.1002/ss.251

Ritchie, J.R., \& Buzzelli, C.A. (2012). The early childhood curriculum of Aotearoa New Zealand. In N. File, J.J. Mueller, \& D.B. Wisneski (Eds.) Curriculum in early childhood education: Re-examined, rediscovered, renewed (pp.146159). New York: Routledge.

Steele, L. (2007). Accessible portfolios: Making it happen in my centre: An Action Research Study. (Unpublished master's thesis). Victoria University of Wellington, Wellington.

Strudler, N., \& Wetzel, K. (2008). Costs and benefits of electronic portfolios in teacher education: Faculty perspectives. Journal of Computing in Teacher Education, 24 (4), 135-142. doi:10.1080/10402454.2008.10784599

Sundin, D., \& Fahy, K. (2008). Critical, post-structural, interpretive interactionism: An update on Denzin's methodology. Nurse Researcher , 16 (1), 7-23.

Te One, S.J. (2000). Voices for the record: Three teachers' experiences of compiling and using individual child portfolios. Unpublished masters thesis: Victoria University of Wellington.

Te One, S. (2002). Portfolios as an alternative assessment tool: Occasional Paper No. 12. Wellington: Victoria University of Wellington and Institute for Early Childhood Studies.

Wade, A., Abrami, P. C., \& Sclater, J. (2005). An electronic portfolio to support learning. Canadian Journal of Learning and Technology/La Revue Canadienne de L'apprentissage et de la Technologie, 31 (3).

Walsham, G. (2006). Doing interpretive research. European Journal of Information Systems, 15(3). doi:10.1057/palgrave.ejis.3000589 
Whalley, M. (2000). Parents' involvement in their children's learning. Early Childhood Practice , 2 (1), 36-57.

Whalley, M., \& Chandler, T. (2007). Parents and staff as co-educators - 'Parents' means fathers too. In M. Whalley \& the Pen Green Centre team (Eds.). Involving parents in their children's learning. (2nd ed.) (pp.66-85). London: Paul Chapman Publishing.

Whalley, M., \& Dennison, M. (2008). Dialogue and documentation: Sharing information and developing a rich curriculum. In M. Whalley (Ed.). Involving Parents in their Children's Learning (pp. 135-155). London: Paul Chapman Publishing.

Wiersma, W. (2000). Research methods in education: An introduction (7th ed.). Boston, MA: Allyn and Bacon.

Wiersma, W., \& Jurs, S. G. (2009). Research methods in education: An introduction (9th ed.). Boston: Pearson Education.

Woodward, H., \& Nanlohy, P. (2004). Digital portfolios: Fact or fashion? Assessment and Evaluation in Higher Education, 29 (2), 227-238.

Yin, R. K. (2009). Case study research: Design and methods (4th ed.). Thousand Oaks: Sage Publications. 


\title{
Appendix A: Participant Information Sheet for National Online Survey
}

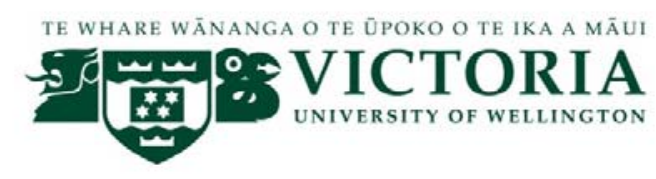

\author{
Participant Information for National Online Survey \\ Research Project: Young children's engagement with online portfolios \\ Researcher: Nicola Goodman \\ Faculty of Education, Victoria University of Wellington
}

My name is Nicola Goodman and I am a Master's student at Victoria University of Wellington. As part of this degree, under the supervision of Dr Sue Cherrington, I am undertaking a research project leading to a thesis. I would like to invite you to take part in this research study investigating young children's engagement with online portfolios, with a particular focus on how children are involved in and reflecting upon their learning using this online medium. This information letter outlines the project as well as elaborates on your involvement if you choose to participate.

\section{Outline of the study}

This research aims to gain a deeper understanding of young children's engagement with online portfolios. The study will firstly draw on the perspectives of teachers in early childhood education settings around New Zealand through a nationwide online survey to education and care and kindergarten settings. Following on from this, case studies will be undertaken in two centres where more focused data can be gathered through a) an initial survey of all parents and staff, b) interviews with children, parents and staff members and c) observations of online portfolios being used in the centre and at home. Data from the online surveys will be used to inform the case study questions and focus areas and so your involvement in the survey is really valuable. The topic of online portfolios in early childhood has a very limited research base and so this study hopes to contribute valuable information to the early childhood field on their impact in young children's environments.

\section{The research question}

The question for this study is:

In what ways are children engaging with their learning through their online portfolio?

In order to answer this question, several sub-questions have been identified: 
- What access is provided for children to view their online portfolio?

- In what ways are children involved in the documentation process?

- $\quad$ How are children encouraged to contribute to their online portfolio?

- What connections are being made by children between the home and their centre through using their online portfolio?

- In what ways are parents revisiting the child's portfolio with their child at home?

In this study the words e-portfolio and online portfolio will be used interchangeably however do refer to the same online portfolio body of work.

\section{Your involvement}

The first part of the data collection is the online survey and this is where you are invited to take part. The online survey asks for just one response per early childhood setting, is made up of multi-choice and written answer questions, and takes around 10-15 minutes to complete. You are able to collaborate your answers as a teaching team or have one person answer the questions based on the experiences and perspectives in your centre. This survey is confidential and your centre will not be identified from the responses you provide. In order to complete the online survey your early childhood setting must currently be using an online portfolio programme to develop e-portfolios for the children. If you do not use online portfolios you are ineligible to complete this survey but I appreciate your interest in the project.

The link to the online survey is attached. This will take you to the informed consent page. It is important that you read this first page as once you begin the survey you are deemed to have given consent and your responses will immediately be recorded.

\section{Participation}

You are under no obligation to take part in this project; however your participation will be valuable in helping to develop an understanding around children's engagement with online portfolios. If you are interested in participating in phase two of the project (case study component), you will be asked to provide a contact email address at the end of the survey. This will not be used to link you to your responses in this survey. (Further information about the next stage of the data collection is outlined further in this letter). 


\section{Right of withdrawal}

You have the right to withdraw at any time throughout the survey, however all responses you have given to the questions prior to withdrawing will still be recorded.

\section{Ethics}

The research study has been approved by the Victoria University of Wellington Human Ethics Committee (Application \#21198, 26/08/2014). If you have any ethical concerns about this project, please contact the Chair of Victoria University of

Wellington Human Ethics Committee, Dr Allison Kirkman

\section{Confidentiality}

Your responses to the online survey will remain confidential to me and my supervisor, Dr Sue Cherrington. The data gathered throughout the project will be kept on a password protected computer and all information will be kept in locked storage for five years before being securely destroyed.

\section{Reporting/Dissemination}

Results from this project will form the basis of this Master's thesis and will be reported anonymously. Online survey responses will be grouped and presented in tables with some respondents' comments selected to reflect the views of the written answer questions. You will not be identified. Once completed the final thesis will be submitted for examination and deposited in the Victoria University of Wellington Library. The intention is for one or more articles on this topic to be submitted for publication in scholarly journals as well as results being presented at conferences.

\section{Further involvement - Case study component}

As part of second phase to this research study I am interested in visiting case study centres in order to see how children are engaging with online portfolios and to speak directly with staff, parents and children to gain a deeper understanding. If your centre is interested in being a case study centre I invite you to share this interest by providing your email address in the final question of the survey. In order to register your interest your centre must meet the following criteria:

- Your centre is using an online portfolio programme

- Your centre has been using this online portfolio programme for at least one year

- Your centre has a number of children aged three to four years of age who would be able to talk about their involvement with their online portfolio

- You have not been involved in another research study in the last two years.

If you fit these criteria and are interested in being part of a week-long case study visit as part of this research I would really appreciate you indicating your interest. Your 
participation would consist of your teaching staff being willing and able to speak with me regarding children's use of online portfolios as well as allowing me to be present in your centre to undertake observations and documentation analysis of children's portfolios. I am also interested in speaking with parents and children to understand their perspective and experiences regarding this online medium.

There will be two randomly selected case study centres chosen from the interested group. Case studies will take place between October-November 2014. If you indicate your interest in participating in this phase of the research, I will be in contact to let you know whether or not you will be a case study setting for this study. I appreciate your consideration in contributing to my research project.

\section{Further questions}

If you have any further questions or would like to receive further information about the online survey or case study component, please contact me, Nicola, or my supervisor, Dr Sue Cherrington

Thank you again for taking the time to consider this request. Your involvement and time in contributing to this research is much appreciated,

Nicola Goodman 


\section{Appendix B: National Online Survey Consent Page (On Qualtrics survey)}

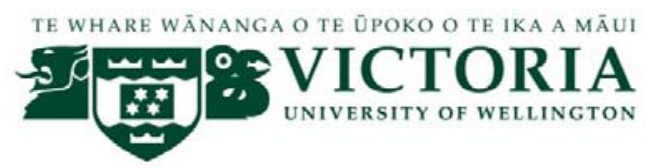

\section{Research Project: Young children's engagement with online portfolios \\ Researcher: Nicola Goodman \\ Faculty of Education, Victoria University of Wellington}

Thank you for taking the time to complete the following survey. As outlined in the emailed participant information sheet this research is being conducted for a Master's thesis at Victoria University of Wellington.

By continuing with this survey, you are deemed to have given your consent to be involved in this project. Please answer every question as incomplete surveys cannot be included in the data results; however if the question is not relevant to you please answer 'not applicable'. You have the right of withdrawal from this survey at any time up until you complete the survey; however your response prior to withdrawing will still be recorded.

To begin the survey, please click on the right arrow bottom at the bottom of the page. This will take you to the first section of the questionnaire. You will use this button to proceed to each new section of the questionnaire once you have answered the questions and every time you push this button your results will be recorded. You are unable to return to previous answered questions so please check your responses before moving to the next section. Please do not use the forward and back buttons on your web browser as these will take you out of the survey.

In the final section of this survey you are asked to provide an email address if your early childhood setting is interested in being a potential case study centre for phase 2 of this research project. Please ensure that you meet the four listed criteria on the final page before providing your email address as these ensure your eligibility for involvement. Please note that your email address will not be used to link you to your answers but will only be used to contact you regarding whether or not you will be a case study setting.

I do appreciate your participation in this survey.

Kind regards,

Nicola Goodman

Masters of Education Student

Faculty of Education

Victoria University of Wellington 


\title{
Appendix C: Participant Information Sheet for Case Study Centre Online Survey - Teaching staff
}

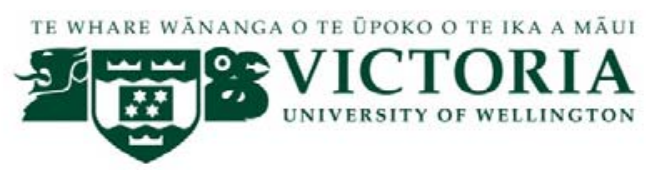

\section{Participant Information Sheet for Case Study Centre Online Survey - Teaching Staff}

\author{
Research Project: Young children's engagement with online portfolios \\ Researcher: Nicola Goodman \\ Faculty of Education, Victoria University of Wellington
}

My name is Nicola Goodman and I am a Master's student at Victoria University of Wellington. As part of this degree, under the supervision of Dr Sue Cherrington, I am undertaking a research project leading to a thesis. I would like to invite you to take part in this research study investigating young children's engagement with online portfolios, with a particular focus on how children are involved in and reflecting upon their learning using this online medium. This information letter outlines the project as well as elaborates on your involvement if you choose to participate.

\section{Outline of the study}

This research aims to gain a deeper understanding of young children's engagement with online portfolios. The study has drawn on the perspectives of teachers in early childhood education settings around New Zealand through a nationwide online survey to education and care and kindergarten settings. Following on from this is the case study component, undertaken in two centres, which comprises of three stages:

- Stage one is an online survey which will be emailed to all users of the online portfolio programme within each case study setting. Responses from this survey will include the perspectives of teaching staff, parents, grandparents and wider family members. This online survey will be completed before face- toface data collection begins within the centre setting.

Stage two and three occur within the centre setting:

- Stage two involves gaining consent from parents for me to observe their child whilst in the centre. Giving consent for this stage allows me to observe and informally speak with children regarding situations or interactions that relate to their online portfolio. Dependant on the consent parents give I will 
be able to also view the child's portfolio and take notes based on what I observe.

- Stage three comprises of more in-depth informal interviews to occur between myself and teaching staff, parents and children. This will bring more depth to the observed data and enable me to ask specific questions based on the general online survey results. Consent also allows me to take observations of interactions related to children's online portfolios and view children's portfolios. Informal interviews with teachers and parents will take around 15-20 minutes and can be undertaken in the participants' home or in the centre setting.

There is very limited research on online portfolios in early childhood and so this study hopes to contribute valuable information to the early childhood field on their impact in young children's environments.

\section{The research question}

The question for this study is:

\section{In what ways are children engaging with their learning through their online portfolio?}

In order to answer this question, several sub-questions have been identified:
- What access is provided for children to view their online portfolio?
- In what ways are children involved in the documentation process?
- How are children encouraged to contribute to their e- portfolio?
- What connections are being made by children between the home and their centre through using their e-portfolio?
- In what ways are parents revisiting the child's portfolio with their child at home?

\section{Your involvement - This information is for stage one.}

The first part of the data collection has been undertaken in the form of a national online survey which was sent to early childhood education and care and kindergarten settings around New Zealand. This survey asked for just one response per setting and invited interested centres to identify themselves as being a case study setting for more in-depth data collection. Your early childhood service, [insert name], indicated 
interest in being a case study centre for this research and were randomly selected from eligible services. The online survey attached precedes my centre visit in order to gather data that I can use to inform my observations and interviews within the centre.

The online survey asks for you to complete a confidential 10-15 minute online survey, consisting of multi-choice and written answer questions, sharing your perspective on children's engagement with online portfolios in the centre environment. You will not be identified from your responses to the online survey in the data analysis, the thesis or any further publications. The link to the online survey is attached. This will take you to the informed consent page. It is important that you read this first page as once you begin the survey you are deemed to have given consent and your responses will immediately be recorded.

\section{Participation}

You are under no obligation to take part in this project; however your participation will be valuable in helping to develop an understanding around children's engagement with online portfolios. I will not be able to identify who has or has not completed the survey - unless you identify yourself in the final section of the survey regarding more in-depth case study involvement. In this situation I will not link you to your responses (full explanation of greater involvement further in the letter).

\section{Right of withdrawal}

You have the right to withdraw at any time throughout the survey, however all responses you have given to the questions prior to withdrawing will still be recorded.

\section{Ethics}

The research study has been approved by the Victoria University of Wellington Human Ethics Committee (Application \#21198, dd/mm/yyyy). If you have any ethical concerns about this project, please contact the Chair of Victoria University of Wellington Human Ethics Committee, Dr Allison Kirkman

\section{Confidentiality}

Your responses to the online survey will remain confidential to me and my supervisor, Dr Sue Cherrington. The data gathered throughout the project will be kept on a password protected computer and all information will be kept in locked storage for five years before being securely destroyed.

\section{Reporting/Dissemination}

Results from this project will form the basis of this Master's thesis and will be reported anonymously. Online survey responses will be grouped and presented in tables with some respondents' comments selected to reflect the views of the written 
answer questions. You will not be identified. Once completed the final thesis will be submitted for examination and deposited in the Victoria University of Wellington Library. The intention is for one or more articles on this topic to be submitted for publication in scholarly journals as well as results being presented at conferences.

\section{Further involvement - Interviews and observation - Stage two/three}

As part of the case study research phase I am interested in observing and speaking with teaching staff in order to gather a deeper understanding of how children are engaging with this method of documentation. I would like to invite your participation in talking with me more about children's contribution and involvement with online portfolios in the centre. Your participation would involve:

- An informal interview with me talking about children's experiences with online portfolios. This will conducted at a time that suits you within your teaching schedule.

- Allowing me to undertake observations of you with other staff, parents, or children relating to online portfolios (with their consent).

Your involvement will not be time consuming and I can arrange for discussions to be held at a time and place that suits you over the case study week. Your involvement will allow me to see further how children are engaging with online portfolios and what is being shared between parents, family members and children. Your involvement would be extremely valuable to me.

If you are interested in being part of this next stage of study please indicate so at the end of the online survey, where prompted, and I will be in touch once I begin the case studies. I really look forward to meeting you.

\section{Further questions}

If you have any further questions or would like to receive further information about the online survey or case study component, please contact me, Nicola,

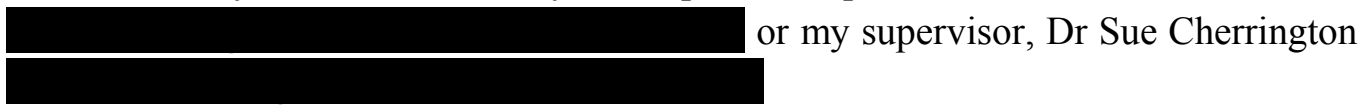

Thank you again for taking the time to consider this request. Your involvement and time in contributing to this research is much appreciated,

Nicola Goodman 
Appendix D: Information sheet for Case Study Centre Online Survey - Families

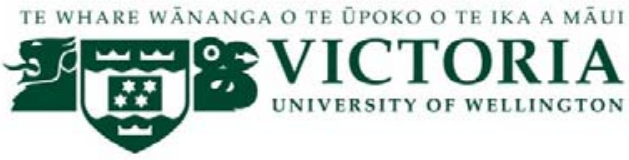

\section{Participant Information Sheet for Case Study Centre Online Survey \\ Research Project: Young children's engagement with online portfolios \\ Researcher: Nicola Goodman \\ Faculty of Education, Victoria University of Wellington}

My name is Nicola Goodman and I am a Master's student at Victoria University of Wellington. As part of this degree, under the supervision of Dr Sue Cherrington, I am undertaking a research project leading to a thesis. I would like to invite you to take part in this research study investigating young children's engagement with online portfolios, with a particular focus on how children are involved in and reflecting upon their learning using this online medium. This information letter outlines the project as well as elaborates on your involvement if you choose to participate.

\section{Outline of the study}

This research aims to gain a deeper understanding of young children's engagement with online portfolios. The study has drawn on the perspectives of teachers in early childhood education settings around New Zealand through a nationwide online survey to education and care and kindergarten settings. Following on from this is the case study component, undertaken in two centres, which comprises of three stages:

- Stage one is an online survey which will be emailed to all users of the online portfolio programme within each case study setting. Responses from this survey will include the perspectives of teaching staff, parents, grandparents and wider family members. This online survey will be completed before face- to-face data collection begins within the centre setting.

Stage two and three occur within the centre setting:

- Stage two involves gaining consent from parents for me to observe their child whilst in the centre. Giving consent for this stage allows me to observe and informally speak with children regarding situations or interactions that relate to their online portfolio. Dependant on the consent parents give I will be able to also view the child's portfolio and take notes based on what I observe. 
- Stage three comprises of more in-depth informal interviews to occur between myself and teaching staff, parents and children. This will bring more depth to the observed data and enable me to ask specific questions based on the general online survey results. Consent also allows me to take observations of interactions related to children's online portfolios and view children's portfolios. Informal interviews with teachers and parents will take around 15-20 minutes and can be undertaken in the participants' home or in the centre setting.

There is very limited research on online portfolios in early childhood and so this study hopes to contribute valuable information to the early childhood field on their impact in young children's environments.

\section{The research question}

The question for this study is:

\section{In what ways are children engaging with their learning through their online portfolio?}

In order to answer this question, several sub-questions have been identified:

- What access is provided for children to view their online portfolio?

- In what ways are children involved in the documentation process?

- How are children encouraged to contribute to their eportfolio?

- What connections are being made by children between the home and their centre through using their e-portfolio?

- In what ways are parents revisiting the child's portfolio with their child at home?

\section{Your involvement - This information is for stage one.}

The first part of the data collection has been undertaken in the form of a national online survey which was sent to early childhood education and care and kindergarten settings around New Zealand. This survey asked for just one response per setting and invited interested centres to identify themselves as being a case study setting for more in-depth data collection. Your child/grandchild's early childhood service, [insert name], indicated their interest in being a case study centre for this research and were randomly selected from eligible services. The online survey attached 
precedes my centre visit in order to gather data that I can use to inform my observations and interviews within the centre.

The online survey asks for you to complete a confidential 10-15 minute online survey, consisting of multi-choice and written answer questions, sharing your perspective and child's experiences with online portfolios in the centre and home environment. You and/or your child will not be identified from your responses to the online survey in the data analysis, the thesis or any further publications. The link to the online survey is attached. This will take you to the informed consent page. It is important that you read this first page as once you begin the survey you are deemed to have given consent and your responses will immediately be recorded.

\section{Participation}

You are under no obligation to take part in this project, however your participation will be valuable in helping to develop an understanding around children's engagement with online portfolios. I will not be able to identify who has or has not completed the survey - unless you identify yourself in the final section of the survey regarding more in-depth case study involvement. In this situation I will not link you to your responses (full explanation of greater involvement further in the letter).

\section{Right of withdrawal}

You have the right to withdraw at any time throughout the survey, however all responses you have given to the questions prior to withdrawing will still be recorded.

\section{Ethics}

The research study has been approved by the Victoria University of Wellington Human Ethics Committee (Application \#21198, 26/08/2014). If you have any ethical concerns about this project, please contact the Chair of Victoria University of Wellington Human Ethics Committee, Dr Allison Kirkman

\section{Confidentiality}

Your responses to the online survey will remain confidential to me and my supervisor, Dr Sue Cherrington. The data gathered throughout the project will be kept on a password protected computer and all information will be kept in locked storage for five years before being securely destroyed.

\section{Reporting/Dissemination}

Results from this project will form the basis of this Master's thesis and will be reported anonymously. Online survey responses will be grouped and presented in tables with some respondents' comments selected to reflect the views of the written answer questions. You will not be identified. Once completed the final thesis will be submitted for examination and deposited in the Victoria University of Wellington 
Library. The intention is for one or more articles on this topic to be submitted for publication in scholarly journals as well as results being presented at conferences.

\section{Further involvement}

\section{General Consent - Stage two}

This stage of the research focuses on the general data collection whilst I am in the centre settings. I am interested in seeing how children are engaging with their online portfolios and their learning. In order to do this I will be conducting observations and having informal conversations whilst in the centre related to online portfolio engagement. Observations and informal conversations will not identify children in any way; however will help to paint a picture of children's engagement with their online portfolios. I invite you to consider your child's role in this study and if you are comfortable with their involvement to sign the consent form. Further information on this stage is provided in a second information sheet which will be given to you.

\section{In-depth informal interviews and observations - Stage three}

As part of the case study research phase I am interested in observing and speaking with parents and children who are using online portfolios in order to gather a deeper understanding of how children are engaging with this method of documentation. I would like to invite your participation in talking with me more about your child's experiences at home and in the centre with online portfolios. Your participation would involve:

- An informal interview with me talking about your child's experiences with online portfolios. This can be conducted either in your home environment or in the centre setting.

- Giving permission for me to observe and speak with your child about their online portfolio either at the centre or at home. Individual consent will be gained from your child at the time of their interview/observation before data is collected.

- Allowing me to take observations of you with teachers, or your child relating to online portfolios.

- Giving permission for me to look through your child's portfolio and make notes so as to see how they are engaging.

Your involvement will not be time consuming and I can arrange for discussions to be held at a time and place that suits you over the case study week. Your involvement will allow me to see further into how children are engaging with online portfolios outside of the centre setting and what is being shared between parents, family 
members and children. Your involvement would be extremely valuable to me. Further information for this stage will be provided in a second information sheet.

If you are interested in yourself and/or your child being part of the interview and observation stage of the research please indicate this interest by providing your email address at the end of the online survey, where prompted, and I will be in touch once I begin the case studies. I really look forward to meeting you.

\section{Further questions}

If you have any further questions or would like to receive further information about the online survey or case study component, please contact me, Nicola, or my supervisor, Dr Sue Cherrington

Thank you again for taking the time to consider this request. Your involvement and time in contributing to this research is much appreciated,

Nicola Goodman 


\section{Appendix E: Case Study Centre Online Survey Consent Page (On Qualtrics survey) - Teachers/Families}

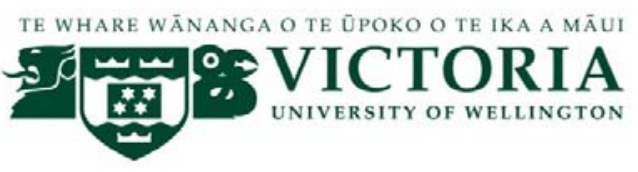

\section{Research Project: Young children's engagement with online portfolios \\ Researcher: Nicola Goodman Faculty of Education, Victoria University of Wellington}

Thank you for taking the time to complete the following survey. As outlined in the emailed participant information sheet this research is being conducted for a Master's thesis at Victoria University of Wellington.

By continuing with this survey, you are deemed to have given your consent to be involved in this project. Please answer every question as incomplete responses cannot be included in the data results; however if the question is not relevant to you please answer 'not applicable'. You have the right of withdrawal from this survey at any time up until you complete the survey; however your response prior to withdrawing will still be recorded.

To begin the survey, please click on the right arrow bottom at the bottom of the page. This will take you to the first section of the questionnaire. You will use this button to proceed to each new section of the questionnaire once you have answered the questions and every time you push this button your results will be recorded. You are unable to return to previous answered questions so please check your responses before moving to the next section. Please do not use the forward and back buttons on your web browser as these will take you out of the survey.

In the final section of this survey you are asked to provide an email address if you are interested in yourself, (and/or your child - if you are a parent) being involved in the interview and observation aspect of the case study settings. Please note that your email address will not be used to link you to your responses but will only be used to contact you regarding your further involvement in the study.

I do appreciate your participation in this survey.

Kind regards,

Nicola Goodman

Masters of Education Student

Faculty of Education

Victoria University of Wellington 


\section{Appendix F: Information sheet for Case Study Involvement - Teaching staff (Stage Two/Three)}

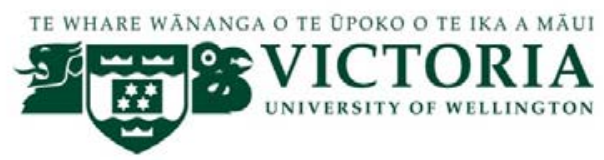

\section{Participant Information Sheet for Case Study Involvement - Teaching Staff (Stage Two/Three) \\ Research Project: Young children's engagement with online portfolios \\ Researcher: Nicola Goodman Faculty of Education, Victoria University of Wellington}

Thank you for showing an interest participating in this stage of my research study on children's engagement with online portfolios. I really appreciate your time and interest in this project. This letter outlines the next aspect of the research study; whilst some of the information is the same as in the online survey letter please take the time to read it as there is additional important information.

My name is Nicola Goodman and I am a Master's student at Victoria University of Wellington. As part of this degree, under the supervision of Dr Sue Cherrington, I am undertaking a research project leading to a thesis. I would like to invite you to take part in this research study investigating young children's engagement with online portfolios, with a particular focus on how children are involved in and reflecting upon their learning using this online medium.

\section{Outline of the study}

This research aims to gain a deeper understanding of young children's engagement with online portfolios. The study has drawn on the perspectives of teachers in early childhood education settings around New Zealand through a nationwide online survey to education and care and kindergarten settings. Following on from this is the case study component, undertaken in two centres, which comprises of three stages:

- Stage one was an online survey emailed to all users of the online portfolio programme within [centre name]. This online survey was completed before this stage of data collection.

Stage two and three occur within the centre setting:

- Stage two involves gaining consent from parents for me to observe their child whilst in the centre. Giving consent for this stage allows me to observe and informally speak with children regarding situations or interactions that 
relate to their online portfolio. Dependant on the consent parents give I will be able to also view the child's portfolio and take notes based on what I observe.

- Stage three comprises of more in-depth informal interviews to occur between myself and teaching staff, parents and children. This will bring more depth to the observed data and enable me to ask specific questions based on the general online survey results. Consent also allows me to take observations of interactions related to children's online portfolios and view children's portfolios. Informal interviews with teachers and parents will take around 15-20 minutes and can be undertaken in the participants' home or in the centre setting.

There is very limited research on online portfolios in early childhood and so this study hopes to contribute valuable information to the early childhood field on their impact in young children's environments.

\title{
The research question
}

The question for this study is:

\section{In what ways are children engaging with their learning through their online portfolio?}

In order to answer this question, several sub-questions have been identified:

\author{
- What access is provided for children to view their online \\ portfolio? \\ - In what ways are children involved in the documentation \\ process? \\ - How are children encouraged to contribute to their e- \\ portfolio? \\ - What connections are being made by children between the \\ home and their centre through using their e-portfolio? \\ - In what ways are parents revisiting the child's portfolio with \\ their child at home?
}

\section{Your involvement - Stage two and three}

Your involvement in this next part of the data collection is very valuable to providing detailed examples that can be used to shed light on children's' engagement. After reading this information sheet, I would appreciate you filling in the consent form and ticking the specific aspects for which you give consent. 
1. Informal Interviews: I would like to undertake an informal interview with you which will take about 20-30 minutes. I will arrange this at a time that suits you within your daily teaching schedule.

In order to ensure accuracy of data collection I will use an audio recorder to record our conversations; if this is something you are uncomfortable with you can let me know and I will alternatively take notes whilst speaking with you. Your responses and any observations I take will only be seen by myself, my supervisor and the appointed transcriber, who will sign a confidentiality agreement before seeing any data.

2. Observations: As part of the data collection I would like to undertake observations around the centre during the day and at drop off and pick up time. By consenting to this you are giving permission for me to observe and record any instances with you engaging with children and/or parents (who have given consent) relating to the topic of children's engagement with online portfolios.

All information gathered will be confidential and no identifying factors will be included in data collection. Your responses will be collated with other information gathered in this study and at times particular statements will be used as quotes to encapsulate a particular aspect or perspective - in these instances there will be no identification and pseudonyms will be used.

Please consider your involvement within this study and complete the consent form to indicate whether you give consent and if so, to which aspects of the case study data collection. I look forward to meeting you during my time in the centre.

\section{Participation}

You are under no obligation to take part in this project, however your participation will be valuable in helping to develop an understanding around children's engagement with online portfolios.

\section{Right of withdrawal}

You have the right to withdraw at any time before the end of the data collection week (insert date); any data already collected will either be securely destroyed or given back to you.

Those who partake in interviews and more in-depth observation have the right to withdraw up to a month after data collection (insert date). This will give you time to review the summary of your interview, if requested, and inform me within two weeks of receiving your summary if you no longer wish to be part of the study. Any data collected will either be securely destroyed or given back to you. 


\section{Ethics}

The research study has been approved by the Victoria University of Wellington Human Ethics Committee (Application \#21198, 26/08/2014). If you have any ethical concerns about this project, please contact the Chair of Victoria University of Wellington Human Ethics Committee, Dr Allison Kirkman

\section{Confidentiality}

All data collected in interviews and observations will remain confidential to me and my supervisor. The data gathered throughout the project will be kept on a password protected computer and all information will be kept in locked storage for five years before being securely destroyed.

\section{Reporting/Dissemination}

Results from this project will form the basis of this Master's thesis and will be reported anonymously. Data collected through interviews and observations will be gathered together and written up as a detailed summary of children's engagement with online portfolios within the centre and home settings. Once completed the final thesis will be submitted for examination and deposited in the Victoria University of Wellington Library. The intention is for one or more articles on this topic to be submitted for publication in scholarly journals as well as results being presented at conferences.

\section{Further questions}

If you have any further questions or would like to receive further information about the online survey or case study component, please contact me, Nicola, or my supervisor, Dr Sue Cherrington

Thank you again for taking the time to consider this request. Your involvement and time in contributing to this research is much appreciated,

Nicola Goodman 


\section{Appendix G: Consent form for Case Study Involvement - Teachers}

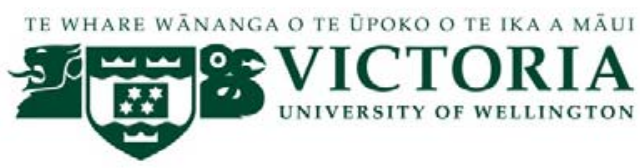

Consent Form for Case Study Involvement - Teachers

\section{Project Title: Young children's engagement with online portfolios}

[Please read the following statements and indicate whether or not you give general consent before proceeding to the more specific aspects further below]

- I have been given an explanation of the nature and purpose of the research project. I have had the opportunity to ask any further questions.

- I understand that the data I give will remain confidential and secure and will only be viewed by the researcher, her supervisor and the appointed transcriber. I understand that all data collected will be securely locked away and destroyed after 5 years.

- I understand that my name will be not be used, along with the names of our ECE centre, staff, parents and children in any of the findings, reports, publications or presentations resulting from this research study. There will be no identifying information revealed; only pseudonyms will be used.

- I understand that this research may be presented in academic or professional journals or at education conferences.

- I understand that I can withdraw at any time without explanation, up until the final day of data collection at the centre (insert date here) or later if I participate in an interview (insert date).

I give my consent to take part in the research after reading the statements above.

I do not give consent to take part in the research after reading the statements above. 
If you have given general consent to participate in the research please tick the specific aspects below that you give consent for yourself to be involved in. A blank box will be considered as not giving consent.

I give permission for the researcher to collect data through observations of interactions between myself with other teachers, children and parents within the centre; informal conversations with teachers, parents and children and through collecting artefacts from children's e-portfolios as examples of children's engagement with online portfolios.

I give permission for the researcher to collect data from interviews with me relating to children's engagement with online portfolios.

I understand that any interviews I partake in will be audio recorded to ensure an accurate recording of my responses.

(Please

\section{turn over)}

I understand that I can receive a summary of my interview if I wish (will be received 2 weeks after the end of data collection). I understand that within two weeks of receiving these summaries I can withdraw my involvement and all data will be either securely destroyed or returned to me.

Name:

ECE Service:

Signature: Date:

I would like to receive a copy of the case study summary

I would like to receive a summary of my interview.

Email Address: 


\section{Appendix H: Participant Information Sheet for Case Study Involvement - Family Members and Children (Stage Two/Three)}

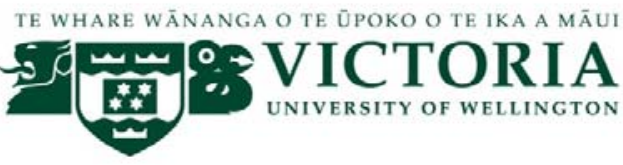

\section{Participant Information Sheet for Case Study Involvement - Family Members and Children (Stage Two/Three)}

\section{Research Project: Young children's engagement with online portfolios \\ Researcher: Nicola Goodman \\ Faculty of Education, Victoria University of Wellington}

Thank you for showing an interest in participating in this stage of my research on children's engagement with online portfolios. I really appreciate your time and interest in this project. This letter outlines the next aspect of the research study; whilst some of the information is the same as in the online survey letter please take the time to read it as there is additional important information.

My name is Nicola Goodman and I am a Master's student at Victoria University of Wellington. As part of this degree, under the supervision of Dr Sue Cherrington, I am undertaking a research project leading to a thesis. I would like to invite you to take part in this research study investigating young children's engagement with online portfolios, with a particular focus on how children are involved in and reflecting upon their learning using this online medium.

\section{Outline of the study}

This research aims to gain a deeper understanding of young children's engagement with online portfolios. The study has drawn on the perspectives of teachers in early childhood education settings around New Zealand through a nationwide online survey to education and care and kindergarten settings. Following on from this is the case study component, undertaken in two centres, which comprises of three stages:

- Stage one was an online survey emailed to all users of the online portfolio programme within [centre name]. This online survey was completed before this stage of data collection.

Stage two and three occur within the centre setting:

- Stage two involves gaining consent from parents for me to observe their child whilst in the centre. Giving consent for this stage allows me to observe and informally speak with children regarding situations or interactions that 
relate to their online portfolio. Dependant on the consent parents give I will be able to also view the child's portfolio and take notes based on what I observe.

- Stage three comprises of more in-depth informal interviews to occur between myself and teaching staff, parents and children. This will bring more depth to the observed data and enable me to ask specific questions based on the general online survey results. Consent also allows me to take observations of interactions related to children's online portfolios and view children's portfolios. Informal interviews with teachers and parents will take around 15-20 minutes and can be undertaken in the participants' home or in the centre setting.

There is very limited research on online portfolios in early childhood and so this study hopes to contribute valuable information to the early childhood field on their impact in young children's environments.

\section{The research question}

The question for this study is:

\section{In what ways are children engaging with their learning through their online portfolio?}

In order to answer this question, several sub-questions have been identified:

- What access is provided for children to view their online portfolio?

- In what ways are children involved in the documentation process?

- How are children encouraged to contribute to their eportfolio?

- What connections are being made by children between the home and their centre through using their e-portfolio?

- $\quad$ In what ways are parents revisiting the child's portfolio with their child at home?

\section{Your involvement - General consent for your child - Stage two}

For this stage of the research I am interested in seeing how children are generally engaging with their online portfolios and their learning. In order to do this I will be part of the centre environment for up to one week. Whilst spending time with the 
children and teachers in their daily routines I will be taking observations and having informal conversations related to children's engagement with online portfolios.

By giving consent for this stage you are allowing me to take observations of your child's engagement with their online portfolio, either independently or with their peers, teachers or you. You are also allowing me to view your child's portfolio and/or have short informal conversations with the children based on what I have observed.

Observations and informal conversations will not identify children in any way and pseudonyms will be used. As well as this no images will be taken of them or from their portfolios. Your child's involvement will help to paint a picture of children's engagement with online portfolios and will be valuable to the data collection. I invite you to consider your child's role in this study and if you are comfortable with their involvement to sign the consent form ticking the aspects you give consent for. I appreciate your support.

\section{Your involvement - Interviews and observation with families and children - Stage three}

Your involvement in this part of the data collection is very valuable to providing detailed examples that can be used to shed light on children's' engagement. After reading this information sheet, I would appreciate you filling in the consent form and ticking the aspects for which you give consent.

1. Informal Interviews (Parents): I would like to undertake an informal interview with you and/or your partner which will take about 15-20 minutes. I will arrange this at a time that suits you, and it can either be done in the centre setting or in your home environment.

In order to ensure accuracy of data collection I will use an audio recorder to record our conversations; if this is something you are uncomfortable with you can let me know and I will alternatively take notes whilst speaking with you. Your responses and any observations I take will only be seen by myself, my supervisor and the appointed transcriber, who will sign a confidentiality agreement before seeing any data.

2. Informal Interviews (Children): I would also like to speak informally with your child and would do so throughout the day, where appropriate, or again in your home environment. The conversations will vary in length dependent upon their responses, however I will ask for their consent before I undertake any data collection with them. In addition, I have a separate consent form where I will get your child to colour in their feeling (happy, neutral or sad) regarding me recording their responses. If they are not happy with my presence, then I will move on and attempt to speak with them at another time. 
3. Observations: As part of the data collection I would like to undertake observations around the centre during the day and at drop off and pick up time. By consenting to yourself and your child being allowed to be observed you are giving permission for any instances I witness with you and your child or teachers relating to this topic to be documented.

4. Document Analysis: In order to develop a better understanding of how children are using online portfolios to reflect on their learning I would like permission to look through your child's portfolio to see how they are engaging and contributing. No images will be taken from these portfolios, only notes taken to explain the engagement and contribution to these portfolios.

All information gathered will be confidential and no identifying factors will be included in data collection. Your responses will be collated with other information gathered in this study and at times particular statements will be used as quotes to encapsulate a particular aspect or perspective - in these instances there will be no identification and pseudonyms will be used.

Please consider the involvement of yourself and your child within this study and complete the consent form to indicate whether you give consent and if so, to which aspects of the case study data collection. I look forward to meeting you during my time in the centre.

\section{Participation}

You and/or your child are under no obligation to take part in this project; however your participation will be valuable in helping to develop an understanding around children's engagement with online portfolios.

\section{Right of withdrawal}

You have the right to withdraw your child's involvement at any time before the end of the data collection week (insert date); any data already collected will either be securely destroyed or given back to you.

For those who partake in interviews and more in-depth observation (parents or children) have the right to withdraw up to a month after data collection (insert date). This will give you time to review the summary of your interview, if requested, and within two weeks of receiving the summary inform me if you no longer wish to be part of the study. Any data collected will either be securely destroyed or given back to you.

\section{Ethics}

The research study has been approved by the Victoria University of Wellington Human Ethics Committee (Application \#21198, 26/08/2014). If you have any ethical concerns about this project, please contact the Chair of Victoria University of 
Wellington Human Ethics Committee, Dr Allison Kirkman

\section{Confidentiality}

All data collected in interviews and observations will remain confidential to me and my supervisor. The data gathered throughout the project will be kept on a password protected computer and all information will be kept in locked storage for five years before being securely destroyed.

\section{Reporting/Dissemination}

Results from this project will form the basis of this Master's thesis and will be reported anonymously. Data collected through interviews and observations will be gathered together and written up as a detailed summary of children's engagement with online portfolios within the centre and home settings. You will not be identified and where applicable pseudonyms will be used. Once completed the final thesis will be submitted for examination and deposited in the Victoria University of Wellington Library. The intention is for one or more articles on this topic to be submitted for publication in scholarly journals as well as results being presented at conferences.

\section{Further questions}

If you have any further questions or would like to receive further information about the online survey or case study component, please contact me, Nicola, or my supervisor, Dr Sue Cherrington

Thank you again for taking the time to consider this request. Your involvement and time in contributing to this research is much appreciated,

Nicola Goodman 
Appendix I: Consent Form for Case Study Involvement - Children and Parents

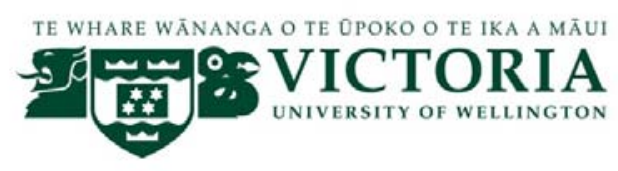

\section{Consent Form for Case Study Involvement - Children and Parents}

\section{Project Title: Young children's engagement with online portfolios}

[Please read the following statements and indicate whether or not you give general consent before proceeding to the more specific aspects further below]

- I/we have been given an explanation of the nature and purpose of the research project. I/we have had the opportunity to ask any further questions.

- I/we understand that the data I/we give will remain confidential and secure and will only be viewed by the researcher, her supervisor and the appointed transcriber. I/we understand that all data collected will be securely locked away and destroyed after 5 years.

- I/we understand that my/our/our child's name will be not be used, along with the names of our ECE centre, staff, parents and children in any of the findings, reports, publications or presentations resulting from this research study. There will be no identifying information revealed; only pseudonyms will be used.

- I/we understand that this research may be presented in academic or professional journals or at education conferences.

- I/we understand that $\mathrm{I} / \mathrm{we}$ can withdraw at any time without explanation, up until the final day of data collection at the centre (insert date here) or later if I/my child participates in an interview (insert date).

I/we give consent for myself/my child to take part in the research after reading the statements above.

I/we do not give consent for myself/my child to take part in the research after reading the statements above. 
If you have given general consent to participate in the research please tick the specific aspects below that you give consent for regarding your child and/or yourself to be involved in. A blank box will be considered as not giving consent.

\section{Consent for Child Involvement}

I/we give permission for observations to be taken of my/our child's interactions with teachers, other children, and myself/us related to their online portfolios

$$
0 \text { in the centre } \quad 0 \quad \text { in our home. }
$$

I/we give permission for the researcher to collect data from informal conversations with my/our child relating to the contents of their e-portfolio as well as their engagement with their e-portfolio

$$
O \text { in the centre } O \text { in our home. }
$$

I/we understand that the researcher will ask my/our child's permission before undertaking any data collection and will not proceed if they do not receive my/our child's approval.

I/We give permission for the researcher to view our child's online portfolio in order to develop an understanding of how children and adults are engaging and contributing to the portfolio.

I/we understand that any interviews my/our child partakes in may be audio recorded to ensure an accurate recording of their responses.

I/we understand that I/we can receive a summary of their interviews if I/we wish (will be provided 2 weeks after the end of data collection). I/we understand that within two weeks of receiving these summaries I/we can withdraw our child's involvement and all data will be either securely destroyed or returned to us.

\section{Consent for Parent Involvement}

I/we give permission for the researcher to collect data from interviews with me/us relating to our child/children's engagement with online portfolios

0 in the centre 0 in our home.

I/we give permission for observations to be taken of myself/us with our child/children or the teachers related to online portfolios and my/our child's engagement

$$
0 \text { in the centre } \quad 0 \quad \text { in our home. }
$$


I/we understand that any interviews I/we participate in may be audio recorded to ensure an accurate recording of my/our responses.

I/we understand that I/we can receive a summary of my/our interview if I/we wish (will be received 2 weeks after the end of data collection). I/we understand that within two weeks of receiving these summaries I/we can withdraw our involvement and all data will be either securely destroyed or returned to us.

\section{Child's Name:}

Parents Name: ECE Service:

Signature: Date:

I We would like to receive a copy of the case study summary I/We would like to receive a summary of my/our interview. I/We would like to receive a summary of my/our child's interviews.

Email Address: 


\section{Appendix J: Child Consent Form}

TE WHARE WÃNANGA O TE ŨPOKO O TE IKA A MÃUI

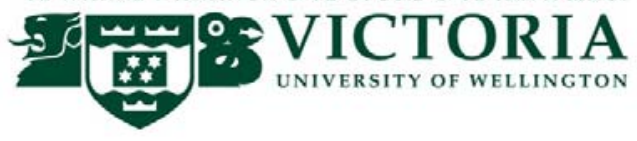

Child's Name:

I am happy for Nicola to write about about what I say or what I show in my online portfolio.

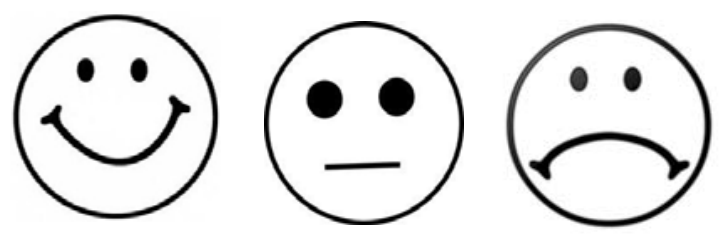




\section{Appendix K: Case Study Data Collection Protocol}

\section{Case Study Data Collection Protocol}

The case study component is the second part of the data collection process. The case study visits to two individual ECE services around New Zealand allows qualitative data to be gathered on how children are engaging with online portfolios in their centre and home environment.

The following data collection processes will take place during the visit:

- Undertaking interviews with teachers and parents to gather their perspectives on how children are engaging with their learning using online portfolios. These interviews will be quite informal and may be undertaken individually or in small groups, at times convenient to the teachers and parents.

- Informal conversations with children will be undertaken during the visit to understand their perspectives regarding their online portfolio as well as if/how they are involved in the documentation process.

- Observational vignettes of interactions between teachers, parents and children that directly or indirectly involve the use of their online portfolio system. A direct example would be an observation of individuals engaged with the online portfolios whereas an indirect example could involve a conversation between teachers and children about their online portfolio.

- Document analysis, where examples of children's engagement can be viewed and linked to their discussions or perspective.

\section{FIELDWORK PROTOCOLS}

\section{General}

In order to gather all the required data each case study visit will be undertaken over the period of a week. The service will have been sent information regarding the case study visit, as well as consent forms and an information sheet for parents and teachers. Prior to the case studies being undertaken an online survey will be sent to the teachers and family members of each service to gather more detailed data before 
interviews and observations take place. Permission will also have been gained from the services' umbrella organisation as well (such as Kindergarten Association or corporate employer) where relevant.

\section{Guidelines for Observations/Vignettes}

Over the course of the week, I will record a range of vignettes.

I will be looking for situations where I can gather descriptive vignettes which will help me to develop a full picture of how children are engaging with their online portfolios, or in what ways they are contributing to or revisiting their learning through this online platform. I will be ensuring that I note down or record conversations with parents, teachers and children that are related to the observations I have taken so I can ensure the correct perspective is recorded for data collection. Particularly with children I will aim to audio record our discussions in order to be able to be fully immersed in the conversation at the time.

\section{I will collect as many vignettes as possible covering:}

- $\quad$ Direct examples of teachers, parents and children engaging with their online portfolios, such as:

- Teachers and/or children uploading stories or announcements to an online portfolio page

- $\quad$ Parents and/or children uploading stories or comments to a child's portfolio

- $\quad$ Children viewing their portfolio, in either an electronic or hard copy version, independently or with peers/teacher/parent.

- $\quad$ Children contributing to their portfolio or engaging in conversation about what they want to contribute.

- Indirect examples of teachers, parents and children engaging with their online portfolios, such as:

Conversations between parents and teachers about a child's engagement with their portfolio 


\section{- Conversations between children and parents or teachers about a child's portfolio \\ - Conversations between children about their learning displayed in their online portfolio.}

\section{Interview: Teachers}

I will carry out semi-structured interviews with the teaching staff (these could be individual or as a group). The interviews are to be audio recorded as well as notes taken on other aspects that may not be picked up by the audio recording. In order to gather the depth of data I will use open prompts to encourage participants to continue sharing without being influenced by myself as the researcher. Prompts such as "that sounds interesting, can you tell me more", "and "can you give me an example ....?" might be useful.

This should take no more than 30 minutes. Some of the questions that will be addressed will be as follows: (Other questions will stem from the responses provided).

1) Please tell me how you introduced the online portfolio programme to the children and parents?

2) How did children adapt to the change in documentation? What were the biggest challenges and greatest successes with children's engagement?

3) I am particularly interested in how children are engaging with their learning through their online portfolio.

a. Could you please give examples of where this has occurred?

b. How do you think using an online portfolio has influenced how they revisit and reflect on their learning?

4) In what ways are children contributing to the documentation practices within the centre through their online portfolio?

5) Has the introduction of online portfolios influenced how you document children's learning? 


\section{Interviews: Parents}

I am aiming to undertake semi-structured interviews with as many parents or other family members as possible. These can be done in small groups or individually, in the centre or the home - dependent upon what parents are most comfortable with. I will identify the number of parents in the notes for each interview. Parents will have indicated their interest to share their perspective in an interview from their online survey so it is important that I thank them for their willingness and explain a little further the purpose of the research. These interviews will be conversational whilst using the questions below as a guide.

The aim of the interview is to gain parents' perspectives of children's engagement with their learning through using their online portfolios: (Questions will be added that stem from their responses).

1) How long have you been part of this centre? How many times a week does your child attend?

2) If your child has had both a hard copy and online portfolio, in what ways does your child engage differently with their learning or experiences through their online portfolio compared with their hardcopy portfolio?

3) Can you give me examples of how you engage with your child and their online portfolio in your home environment?

4) Do other members of your extended family access your child's portfolio online? In what ways does your child engage with them and the learning displayed in their online portfolios?

5) Do you feel your child is more engaged with and aware of their learning as a result of using online portfolios compared with their hard-copy?

I will finish the interview by asking the parent/s if there is anything further they would like to add/say and thank the parent/s for participating. Responses will be audio recorded so as to ensure accurate recording of their contributions. 


\section{Informal Conversations: Children}

I will conduct informal conversations with children to learn more about their perspectives and experiences using online portfolios. Children whose parents have given consent for their involvement will be the only children who will be involved in this aspect of data collection. Children will be asked if they are comfortable for me to take notes/recordings from our conversation before I begin data collection. As well as this children will be asked to colour in their emotion (happy, neutral or sad) on a child consent form as evidence of their permission.

These discussions will be predominately led by the children's comments, however will follow some of the questions below to encourage their discussion:

1. Do you look at your portfolio in the centre? How? Do you look at it at home? How?

2. What are your favourite stories? Do you look at them often?

3. Do you look at your stories with Mum and Dad at home? Do you help them write stories at home?

4. Do you help the teachers write stories or put photos into your portfolio?

5. Do you read the stories with your friends? Do you read their portfolios as well?

6. What do you like best about your online portfolio?

\section{Access to examples from portfolios}

Where teachers, management and/or parents have referred to specific examples from children's portfolios, I will request to see these (where appropriate) and take notes related to the topic of engagement with online portfolios.

When viewing the portfolios, either with children, adults or independently, I will be looking for examples of the following:

- Connections between comments made by children/parents or teachers and evidence in the e-portfolio (stories or snapshots).

- Repeated learning experiences or clear interests through different stories and snapshots in the online portfolio.

- Connections between the centre events or home experiences. 
- Examples of children's contribution to learning stories or experiences within the centre environment. Examples of opportunities for children to contribute.

- Examples of children's contribution of stories and comments alongside parents from their home environment.

- Examples of children sharing and reviewing their portfolios at home or with wider family members. 


\section{Appendix L: National Online Survey Questions}

\section{National Online Survey Questions}

1. Please select the geographic location of your service from the list below:

Northland

Auckland

Waikato

Taranaki

Bay of Plenty Hawkes

Bay

Manawatu/Whanganui

Wairarapa

Wellington

Marlborough/Nelson Tasman

Canterbury

West Coast

Otago

2. How many children is your centre/service licensed for?

Under 30

$30-45$

$45-60$

$60-75$

Above 75

3. Which Online Portfolio Provider does your centre/service use?

Educa

StoryPark

Kinderbooks

Other (please specify)

None 
4. How long has your centre/service been using the Online Portfolio System?

Less than one year

One year - 18 months

18 months - two years

More than two years

5. How many children in your centre/service have an online portfolio?

All of the children

$75 \%-90 \%$

$50 \%-75 \%$

Less than $50 \%$

6. On average, how often are new stories added to children's online portfolios?

At least once a week

Once a week

Once a fortnight

Once a month

Less than once a month

7. What opportunities do you provide for children to access their online

portfolio within the centre/service? (Select as many as are relevant)

Use of centre computer

Use of centre iPad or other electronic device

Use of iPhone or Android phone

Keep a hard-copy as well as an online copy

Children can access with a staff member on the staff computer

No access available

Other (please specify) 
8. On average, how frequently are children revisiting their e-portfolios?

Every day

3 - 4 times a week

1 - 2 times a week

Once a fortnight

Less than once a fortnight

Never

9. How do children prefer to revisit their online portfolio?

Independently

Alongside their peers

Alongside a teacher

Alongside a teacher and their peers

Not applicable

10. If your centre has both online and hard copy portfolios, in what ways do children engage differently with their learning using their online portfolio compared with their hard copy portfolio?

11. What role(s) do children have in the documentation process in your centre?

Taking photos to contribute to stories

Dictating stories or adding their voice

Assisting in writing up their story on the computer/iPad

Reading and/or reflecting on their stories with peers and teachers

Sharing their stories with their peers or putting up stories on the walls

Other (please explain)

12. In what ways are children encouraged to contribute to their online portfolio?

Taking photos to add to stories

Dictating stories or adding their voice

Assisting in writing up their story on the computer/iPad

Contributing comments or responses to those provided on their online

portfolio

Other (please explain) 
13. Have you observed connections being made in children's play and conversation that links back to their engagement with their online portfolio? Please give evidence for your choice.

Yes, frequently

Yes, occasionally

We have not noticed this

14. Are connections being made between home and the centre as a result of children's online portfolios? Please give an example for each where applicable.

by children

by parents

by teachers

15. How are parents revisiting portfolios at home with their children?

Reading the stories aloud with their child at home

Letting the child review their portfolio independently at home

Using the stories online to make connection to learning interests at home

Contributing new stories from home with their child

Sharing the online portfolios with their child and wider family members

Other (please explain)

Not sure how parents revisit the portfolio with their children

16. What challenges have you faced in encouraging children to revisit their online portfolio?

17. To what extent do you think that using an online portfolio system has influenced children to engage more with their own learning than occurred with their hard copy portfolios? (Please give reason for your choice)

A great deal

Quite a lot

A little

Not at all 


\section{Appendix M: Case Study Online Survey Questions (Teaching Staff)}

\section{Case Study Online Survey Questions (Teaching Staff)}

1. How long have you been using the online portfolio system in your centre/service?

Less than one year

One year - 18 months

18 months - two years

More than two years

2. How often do you view or contribute to children's online portfolios?

At least once a week

At least once a fortnight

At least once a month

At least once every six months

Never

3. In what ways have you observed children engaging with their online portfolio within the centre environment?

Viewing their online portfolio independently on the computer or iPad

Viewing their online portfolio with their peers or teachers on the computer or iPad

Showing parents or family members their online portfolio

Looking at a printed copy of their online portfolio independently or with their peers

Re-creating or revisiting learning or interests from reading their online portfolio

Other (please explain)

4. To what extent do children and families appear to be engaging with their online portfolio from their home environment?

A great deal

Quite a lot

A little

Not at all 
5. To what extent do you think that using an online portfolio system has influenced children to engage more with their own learning? (Please give reason for your choice)

A great deal

Quite a lot

A little

Not at all

6. To what extent do you feel that having an online portfolio programme has assisted you in collaborating with children regarding their learning and decisions?

A great deal

Quite a lot

A little

Not at all

7. In what ways do you help children to engage with their online portfolios?

Write as many learning stories as I can in collaboration with the children

Invite children to contribute to some learning or group stories Encourage children to take photos and upload these themselves to their portfolio

Revisit children's portfolios in quieter times of day with them and/or their peers

Have conversations with children regarding their learning presented in their portfolios

Do not help children engage with their online portfolios at all Other (please specify) 
8. Have you observed connections being made in children's play and conversation that links back to their engagement with their online portfolio?

Please give evidence for your choice.

Yes, frequently

Yes, occasionally

I have not noticed this

No 
Appendix N: Case Study Online Survey Questions (Families)

\section{Case Study Online Survey Questions (Families)}

1. Which of the following describes your relationship with the child/children?

Parent or caregiver

Grandparent

Aunty or Uncle

Sibling

Family Friend

Other (please specify)

2. How long have you been using the online portfolio system?

Less than one year

One year - 18 months

18 months - two years

More than two years

\section{Those who identified themselves as anything other than parent/caregiver are asked the following questions.}

3. How often do you view or contribute to the online portfolio?

At least once a week

At least once a fortnight

At least once a month

At least once every six months

Never

4. In what ways do you engage with your child/children in regards to the content in their online portfolio? (Select as many as are relevant)

Talk about on phone or when see them

Write learning stories to respond to or share learning 
Upload images to add to the child's portfolio

View the portfolio with them when you see them

Do not engage at all

Other (please specify)

5. To what extent do you see your child engaging with their learning as a result of revisiting and sharing their online portfolio? (Please give a reason for your choice)

A great deal

Quite a lot

A little

Not at all

\section{Those who identified themselves as parent/caregiver are asked the}

following questions.

3. How often do you view or contribute to the online portfolio?

At least once a week

At least once a fortnight

At least once a month

At least once every six months

Never

4. What opportunities do you provide for your child/children to access their online portfolio at home? (Select as many as are relevant)

Use of home computer

Use of iPad or other electronic device

Use of iPhone or Android phone

Keep a hard-copy at home as well

Children can access with a family member on the home computer

At friends/family house

No access available

Other (please specify) 
5. In what ways do you engage with your child in regards to the content in their online portfolio? (Select as many as are relevant)

View the portfolio with them at the end of the day

View the portfolio with them at the end of the week

View the portfolios with them when new stories are uploaded

Talk about the stories without looking at the portfolios

Write learning stories to respond to or share learning

Upload images to add to the child's portfolio

Do not engage at all

Other (please specify)

6. To what extent do you think that using an online portfolio system has influenced children to engage more with their own learning? (Please give reason for your choice)

A great deal

Quite a lot

A little

Not at all

7. How does your child/children prefer to revisit their online portfolio?

Independently

With a parent

With a sibling or other family member

8. If your child has (or has had) both a hard copy and an online portfolio, in what ways is your child/children engaging differently with their online portfolio compared with their hard copy portfolio?

9. In what ways is your child/children contributing to their online portfolio?

Taking photos to contribute to stories

Dictating stories or adding their voice

Sharing their stories with their peers/family members

Assisting in writing up their story on the computer/iPad

Other (please explain) 
10. Have you observed connections being made in your child's play and conversation that links back to their engagement with their online portfolio? Please give evidence for your choice.

Yes, frequently

Yes, occasionally

We have not noticed this

11. Do you feel that using an online portfolio has assisted you as parents in supporting your child's learning through more connections with teaching staff and more regular information? (Please explain your choice).

A great deal

Quite a lot

A little

Not at all 